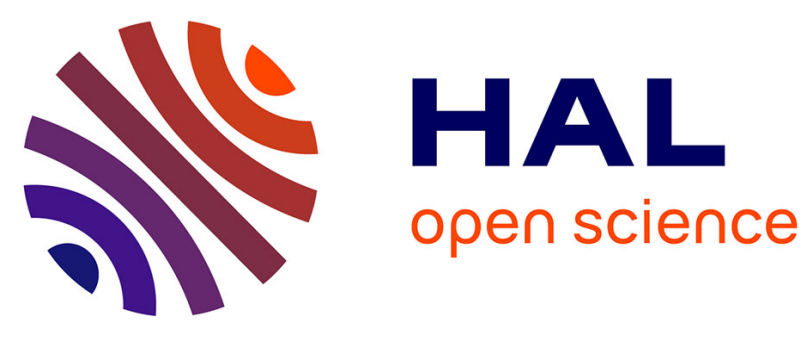

\title{
L'évolution démographique récente de la France. Naissances, décès, unions et migrations : à chacun sa saison
}

Didier Breton, Magali Barbieri, Hippolyte d'Albis, Magali Mazuy

\section{- To cite this version:}

Didier Breton, Magali Barbieri, Hippolyte d'Albis, Magali Mazuy. L'évolution démographique récente de la France. Naissances, décès, unions et migrations: à chacun sa saison. Population (édition française), 2018, 73 (4), pp.623-692. 10.3917/popu.1804.0623 . hal-02137543

\section{HAL Id: hal-02137543 \\ https://hal.science/hal-02137543}

Submitted on 23 May 2019

HAL is a multi-disciplinary open access archive for the deposit and dissemination of scientific research documents, whether they are published or not. The documents may come from teaching and research institutions in France or abroad, or from public or private research centers.
L'archive ouverte pluridisciplinaire HAL, est destinée au dépôt et à la diffusion de documents scientifiques de niveau recherche, publiés ou non, émanant des établissements d'enseignement et de recherche français ou étrangers, des laboratoires publics ou privés. 


\section{Didier BRETON ${ }^{\circ *}$, Magali BARBIERI*, Hippolyte D'ALBIS**, Magali MAZUY*}

\section{L'évolution démographique récente de la France. Naissances, décès, unions et migrations : à chacun sa saison}

\section{I. Évolution générale et structure par âge de la population}

\section{Accroissement et structure de la population}

\section{Un accroissement naturel historiquement bas}

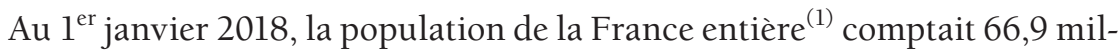
lions d'habitants ${ }^{(2)}$, dont 2,2 millions dans les départements et régions d'outremer (Papon et Beaumel, 2019). Au cours de l'année 2017, la population a augmenté de 221280 personnes, contre +247775 en $2016^{(3)}$. Laccroissement

(1) Les chiffres présentés dans cet article correspondent à la France entière. Par France entière on entend les 101 départements français : 96 départements se situent dans l'espace européen (France métropolitaine) et 5 en dehors (Départements et régions d'outre-mer (Drom anciennement Dom, Guadeloupe, Guyane, La Réunion Martinique et Mayotte). La dénomination « France entière » ne comprend pas les autres territoires de la République française (Nouvelle-Calédonie, Polynésie française, îles Wallis-etFutuna, Terres australes et antarctiques françaises, îles éparses de l'Océan Indien ainsi que la collectivité territoriale à statut particulier de Saint-Pierre-et-Miquelon) qui sont en dehors de la comptabilité nationale et ne font pas partie de l'Union européenne. En annexe figurent les séries longues pour la France métropolitaine. En effet, l'Insee ne fournit les données pour la France entière que depuis 1991.

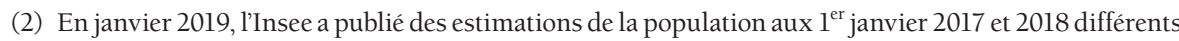
de ceux publiés en janvier 2018 (Papon et Beaumel, 2018, 2019). Ces différences sont une conséquence du remaniement des bulletins du recensement, permettant, entre autres, de mieux repérer les individus ayant plusieurs résidences (Insee, 2019), entraînant alors une diminution de l'effectif total des populations.

(3) Les changements évoqués dans la note 2 ont aussi contraint l'Insee d'ajuster les soldes migratoires estimés des années 2015, 2016 et 2017 de près de 100000 personnes en moins que le solde migratoire évalué (Insee, 2019).

' Université de Strasbourg, Sage (UMR n7363).

* Institut national d'études démographiques (Ined).

** École d'économie de Paris, CNRS.

Correspondance : Didier Breton, Université de Strasbourg, Institut de démographie (IDUS), 22 rue René Descartes - Patio - Bâtiment 5, 67084 Strasbourg Cedex, dbreton@unistra.fr 
de la population française est au plus bas depuis près de 20 ans et s'approche de 3\%o (tableau annexe A.1).

Le solde naturel, moteur historique de l'accroissement de la population française, diminue encore en 2017 avec +164000 personnes, nouveau record historiquement bas, inférieur à celui de l'année 1976 (Breton et al., 2017), alors que la population totale n'a jamais été aussi importante. Le taux d'accroissement naturel est de 2,4\%o (avec un taux brut de natalité de $11,5 \%$ ot un taux brut de mortalité de $9,1 \%$ o) ${ }^{(4)}$. La diminution de l'accroissement naturel tient à la fois à la baisse du nombre de naissances, continuant à creuser la base de la pyramide (figure 1) et à l'augmentation de celui des décès. Celle-ci est due principalement au recul de l'âge au décès et l'arrivée des générations nombreuses, nées entre 1946 et 1974, aux âges de plus forte mortalité. Dans les prochaines années, l'augmentation du nombre de décès devrait s'atténuer du fait de l'arrivée aux grands âges des générations « creuses » nées dans les années 1930 suite à la Grande Dépression (le nombre annuel de naissances en 1939 était de 130000 inférieur à celui de 1930, baisse qui a été régulière sur la période) (Bourgeois-Pichat, 1950; Pailhé, 2010). Quant au nombre de naissances, il devrait de nouveau croître du fait de l'arrivée en âge de procréer des générations plus nombreuses nées après 1998, qui renforcent par ailleurs depuis deux ans les difficultés d'accueil dans les universités françaises.

Durant l'année 2017, le solde migratoire est estimé à + 58000 pour l'ensemble de la France et +66000 pour la seule métropole ${ }^{(3)(5)}$. Notons que la méthode de calcul du solde migratoire entraîne chaque année des corrections pour les années précédentes (Brutel, 2015) ${ }^{(6)}$.

\section{En 2016, l'Allemagne devient le pays de I'UE où le nombre de naissances est le plus élevé, devant la France}

Au $1^{\text {er }}$ janvier 2017, la France reste le deuxième pays le plus peuplé de l'Union européenne (UE) après l'Allemagne, et l'un des 4 pays de l'UE peuplés de plus de 60 millions d'habitants (avec l'Allemagne, l'Italie et le Royaume-Uni). En 2016, il est né plus d'enfants en Allemagne qu'en France, avec un accroissement de $7 \%$ des naissances entre 2015 et 2016 (de 737575 à 792131 naissances). Toutefois, le solde naturel de l'Allemagne demeure négatif (-118000), et si la population allemande augmente, elle le doit à un solde migratoire très important $(+500000)$.

(4) Le taux d'accroissement naturel est la différence entre le taux brut de natalité et le taux brut de mortalité. Il peut se calculer également en faisant le rapport entre le solde naturel et la population moyenne.

(5) Ces soldes migratoires ne tiennent pas compte de l'ajustement. La différence entre les soldes France métropolitaine et France entière s'explique par le solde migratoire négatif des départements d'outre-mer vis-à-vis de la métropole. Les émigrations dépassent en nombre les immigrations, même dans les départements d'outre-mer concernés par de fortes immigrations comme la Guyane ou Mayotte.

(6) La correction est parfois à la hausse et parfois à la baisse. Ainsi, après des prévisions de +47000 , le solde migratoire de 2013 a été en réalité de + 100000 . À l'inverse, le solde migratoire de 2014, estimé à +67000 , a été revu à la baisse (+ 32000) dans le bilan démographique 2017 de l'Insee (Bellamy et Beaumel, 2016, 2017; Papon et Beaumel, 2018). 
Figure 1. Pyramide des âges au $1^{\text {er }}$ janvier 2018
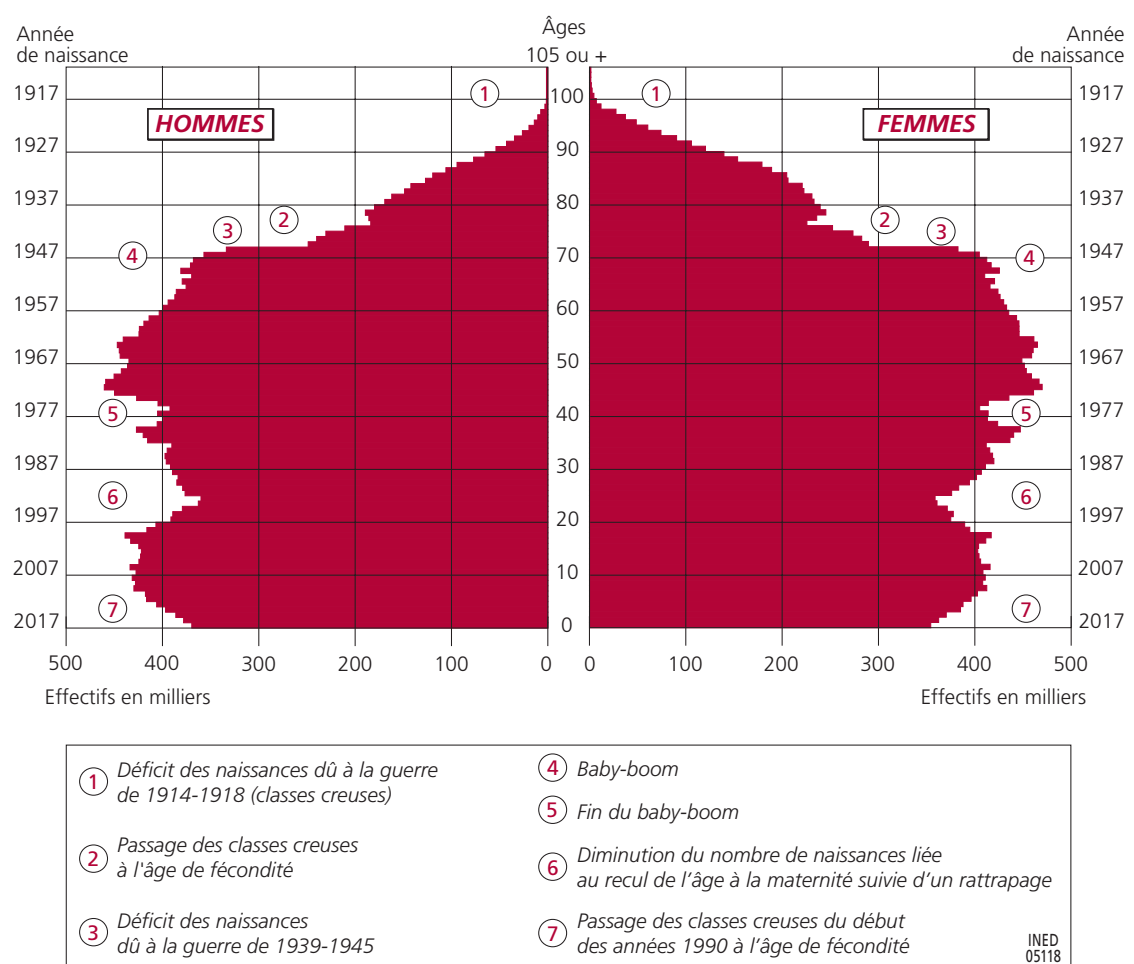

(6) Diminution du nombre de naissances liée

6) au recul de l'âge à la maternité suivie d'un rattrapage

(7) Passage des classes creuses du début
des années 1990 à l'âge de fécondité

Champ : France entière (y compris Mayotte).

Sources: Insee.

Les contributions des soldes naturel et migratoire varient selon les pays et les périodes (tableau 1) et sont affectées à la fois par la crise économique de 2008 et les récents déplacements de population en Europe. La comparaison des périodes 2003-2007 et 2013-2017 montre une diminution de la population de certains pays du fait de soldes naturel et migratoire négatifs sur les deux quinquennats. C'est le cas de pays baltes et d'Europe de l'Est (Bulgarie, Lettonie, Lituanie, Pologne, Roumanie). À l'opposé, certains pays de l'Ouest de l'Europe ont des taux d'accroissement migratoire et naturel relativement stables et positifs sur les deux périodes (Belgique, France, Royaume-Uni). Pour d'autres, la situation s'est inversée entre les deux périodes. Un premier groupe de pays a connu entre 2013 et 2017 une forte baisse de sa composante migratoire, doublée d'une baisse du taux d'accroissement naturel : la Croatie, l'Espagne, la Grèce et le Portugal. À l'opposé, l'Allemagne, l'Autriche, le Danemark, les Pays-Bas et la Suède ont connu un accroissement migratoire fort dans la période la plus récente, allant parfois jusqu'à compenser un accroissement naturel faible, voire négatif, comme en Allemagne ou en Italie. 
Tableau 1. Accroissement total et accroissement migratoire dans les pays de l'Union européenne, périodes 2003-2007 et 2013-2017 (\%)

\begin{tabular}{|c|c|c|c|c|c|c|c|}
\hline \multicolumn{4}{|c|}{$2003-2007$} & \multicolumn{4}{|c|}{$2013-2017$} \\
\hline & \multicolumn{3}{|c|}{ Taux d'accroissement } & & \multicolumn{3}{|c|}{ Taux d'accroissement } \\
\hline & naturel & migratoire & total & & naturel & migratoire & total \\
\hline Irlande & 8,5 & 14,9 & 23,5 & Malte & 2,0 & 21,7 & 23,7 \\
\hline Espagne & 2,0 & 15,6 & 17,6 & Luxembourg & 3,7 & 18,1 & 21,8 \\
\hline Chypre & 4,2 & 12,6 & 16,8 & Suède & 2,5 & 9,0 & 11,5 \\
\hline Luxembourg & 3,6 & 11,7 & 15,3 & Irlande & 7,6 & 2,1 & 9,7 \\
\hline Royaume-Uni & 2,4 & 4,4 & 6,8 & Autriche & 0,4 & 8,2 & 8,6 \\
\hline France & 4,4 & 2,5 & 6,8 & Royaume-Uni & 2,8 & 4,2 & 7,0 \\
\hline Belgique & 1,6 & 4,3 & 5,9 & Danemark & 1,1 & 5,2 & 6,3 \\
\hline Suède & 1,3 & 4,1 & 5,4 & Allemagne & $-2,0$ & 7,7 & 5,7 \\
\hline Italie & $-0,1$ & 5,4 & 5,3 & Belgique & 1,3 & 3,6 & 4,9 \\
\hline Malte & 1,9 & 3,4 & 5,2 & France & 3,2 & 1,0 & 4,2 \\
\hline Autriche & 0,3 & 4,7 & 5,1 & Pays-Bas & 1,6 & 2,4 & 4,0 \\
\hline Finlande & 1,8 & 1,7 & 3,6 & Finlande & 0,4 & 2,8 & 3,1 \\
\hline Danemark & 1,6 & 1,8 & 3,4 & Italie & $-2,2$ & 4,9 & 2,7 \\
\hline Slovénie & $-0,1$ & 3,2 & 3,1 & $\begin{array}{l}\text { République } \\
\text { tchèque }\end{array}$ & 0,2 & 1,6 & 1,8 \\
\hline $\begin{array}{l}\text { République } \\
\text { tchèque }\end{array}$ & $-0,4$ & 3,4 & 3,0 & Slovaquie & 0,6 & 0,5 & 1,2 \\
\hline Grèce & 0,2 & 2,4 & 2,6 & Slovénie & 0,5 & 0,3 & 0,8 \\
\hline Pays-Bas & 3,2 & $-0,7$ & 2,6 & Espagne & 0,2 & $-0,4$ & $-0,3$ \\
\hline Portugal & 0,3 & 1,8 & 2,1 & Chypre & 4,4 & $-4,7$ & $-0,4$ \\
\hline Croatie & $-2,4$ & 2,7 & 0,3 & Estonie & $-1,2$ & 0,8 & $-0,4$ \\
\hline Slovaquie & 0,1 & $-0,1$ & 0,0 & Pologne & $-0,3$ & $-0,2$ & $-0,5$ \\
\hline Pologne & $-0,1$ & $-0,5$ & $-0,5$ & Hongrie & $-3,6$ & 1,0 & $-2,6$ \\
\hline Allemagne & $-1,7$ & 0,9 & $-0,8$ & Portugal & $-2,3$ & $-1,5$ & $-3,8$ \\
\hline Hongrie & $-3,7$ & 1,7 & $-2,0$ & Grèce & $-2,4$ & $-2,5$ & $-4,9$ \\
\hline Estonie & $-2,3$ & $-3,1$ & $-5,4$ & Roumanie & $-3,1$ & $-1,9$ & $-5,0$ \\
\hline Bulgarie & $-5,3$ & $-2,2$ & $-7,5$ & Bulgarie & $-5,9$ & $-0,6$ & $-6,6$ \\
\hline Roumanie & $-2,0$ & $-7,4$ & $-9,4$ & Croatie & $-3,3$ & $-4,2$ & $-7,5$ \\
\hline Lettonie & $-4,7$ & $-4,9$ & $-9,6$ & Lettonie & $-3,6$ & $-5,4$ & $-9,0$ \\
\hline Lituanie & $-4,1$ & $-9,1$ & $-13,2$ & Lituanie & $-3,7$ & $-7,6$ & $-11,3$ \\
\hline $\begin{array}{l}\text { Union } \\
\text { européenne }\end{array}$ & 0,7 & 3,2 & 3,9 & $\begin{array}{l}\text { Union } \\
\text { européenne }\end{array}$ & 0,0 & 2,8 & 2,8 \\
\hline \multicolumn{8}{|c|}{$\begin{array}{l}\text { Note : Les valeurs négatives sont en gras, et celles dont la ligne est grisée représentent les pays dont le rang } \\
\text { européen a le plus changé entre les deux périodes. } \\
\text { Lecture : Les pays sont classés dans l'ordre décroissant du taux d'accroissement total de la période concernée. } \\
\text { Champ : Europe. } \\
\text { Sources : Eurostat, calculs des auteur.e.s. }\end{array}$} \\
\hline
\end{tabular}

\section{Les 20-59 ans représentent moins de la moitié de la population totale}

Au premier janvier 2018, à peine la moitié de la population française est âgée de 20 à 59 ans (49,9 \%) (tableau annexe A.2, figure 1). En 2018 comme en 2017, les moins de 20 ans sont proportionnellement presque aussi nombreux que les 60 ans et plus (autour de 25 \%), ce qui fait de la France une exception 
européenne (figure 2), mais également le pays dont le rapport de dépendance total est le plus élevé en Europe $(0,99)$. Très rares sont les pays dont la proportion des moins de 20 ans est supérieure à celle des 60 ans et plus. Ce sont généralement des pays de petite, voire très petite taille (Irlande et Islande), dont la natalité est restée relativement importante. À l'opposé, les pays dont la fécondité (et la natalité associée) est basse (proche de 1,5 enfant par femme) depuis près de 20 ans, ont des indicateurs de vieillissement très importants : l'Autriche, l'Espagne et la Pologne ou encore l'Allemagne, la Grèce, l'Italie et le Portugal, pays pour lesquels le vieillissement par le bas (diminution des naissances) s'ajoute au vieillissement par le haut (allongement de la durée de vie) de la pyramide.

Figure 2. Rapports de dépendance en Europe au $1^{\text {er }}$ janvier 2017

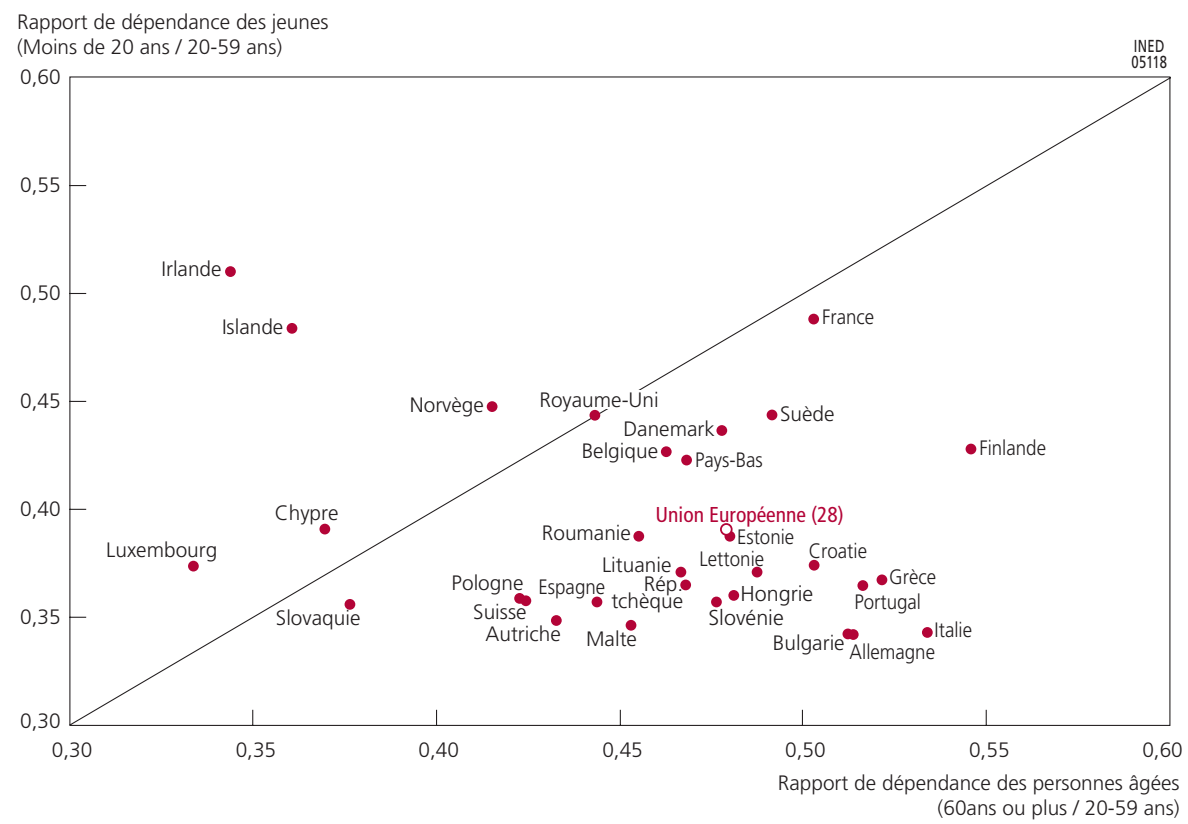

Lecture : En moyenne, au $1^{\text {er }}$ janvier 2017, il y a en France 49 personnes de moins de 20 ans pour 100 personnes de 20-59 ans, et 52 personnes de 60 ans ou plus, pour 100 personnes de 20-59 ans.

Champ : Europe.

Sources : Eurostat, calculs des auteur.e.s.

\section{La population des ménages}

\section{Toujours moins de personnes vivent hors logement ordinaire}

Depuis la mise en place du recensement rénové de la population en 2004, l'Insee publie chaque année des données détaillées de recensement cumulant 5 collectes d'enquêtes annuelles de recensement (EAR). Les données disponibles les plus anciennes datent de 2006 (EAR 2004 à 2008) et les plus récentes de 2015 (EAR 2013 à 2017). Au-delà de l'effectif de la population totale, de sa répartition par sexe et par âge (utilisés comme dénominateurs de nombreux indicateurs dans cet article), il est possible de distinguer les individus selon 
qu'ils vivent en logement ordinaire ou collectif (foyers de travailleurs, maisons de retraite, résidences universitaires, centres de détention, etc.). En 2015, 2,24\% des Français (près de 1,5 million de personnes) vivent en logement collectif avec un premier pic aux âges d'entrée dans la vie adulte (entre $5 \%$ et $10 \%$ autour de 20 ans; figure 3) et une augmentation rapide à partir de 60 ans pour s'approcher ou dépasser 50 \% aux âges les plus avancés (figure 3). La proportion de personnes vivant en logement collectif diminue légèrement entre 2006 et 2015, prolongeant une tendance amorcée depuis 1990 au moins (Pirou et al., 2013) et cela à tous les âges, mais particulièrement au-delà de 60 ans. La diminution progressive de la proportion de personnes vivant en ménage collectif vient d'une part de la diminution des élèves en internat et, d'autre part, du recul de l'âge à l'entrée en institution des personnes âgées (Muller, 2017 ; Pirou et al., 2013).

Figure 3. Évolution de la proportion de personnes vivant en logement collectif en 2006 et 2015, par sexe et âge

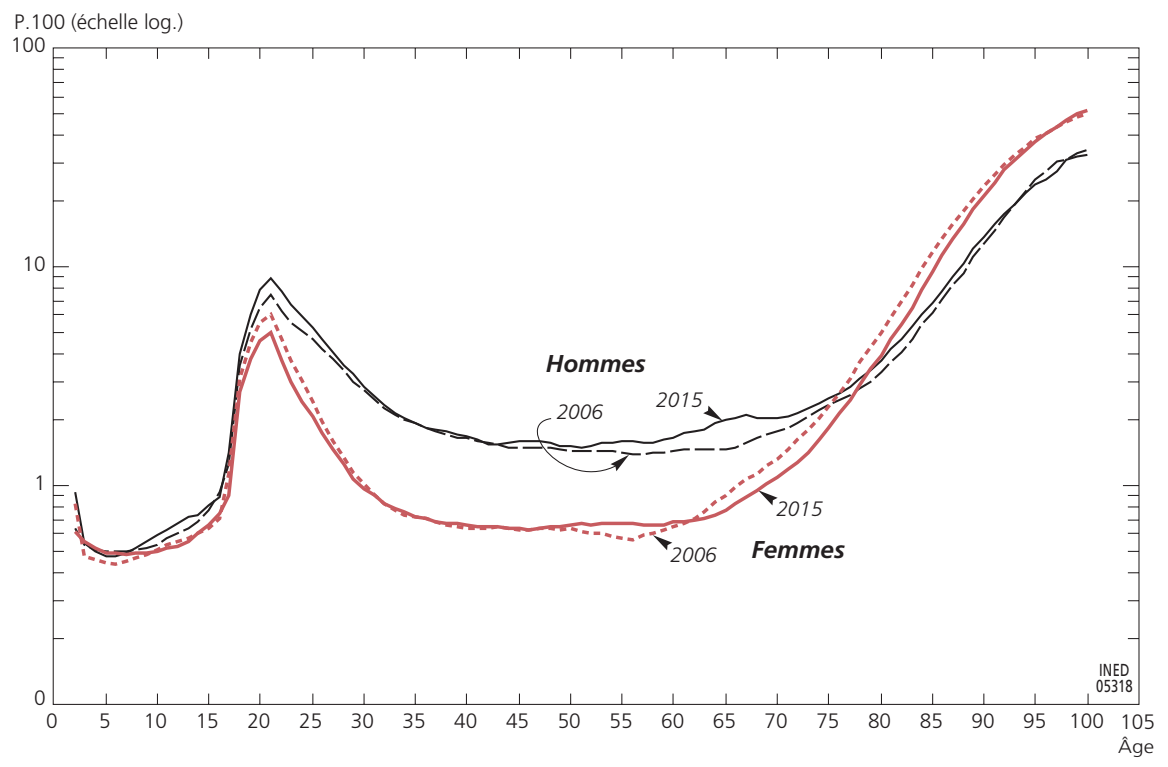

Champ : France entière hors Mayotte, personnes vivant en ménage ordinaire.

Sources: Insee, recensements, calculs des auteur.e.s.

En 2015, la proportion de l'ensemble des hommes vivant en logement collectif est devenue identique ou presque à celle des femmes, après avoir été longtemps légèrement supérieure (2,25\% des hommes et 2,23 \% des femmes en 2015, contre respectivement $2,44 \%$ et $2,20 \%$ en 2006). Si les profils des courbes des taux par âge des hommes et des femmes se ressemblent, les positions relatives des courbes féminines et masculines diffèrent (figure 3). Avant 75 ans, les proportions d'hommes en logement collectif sont plus élevées que celles des femmes, puis le rapport s'inverse du fait de la surmortalité des hommes et des nombreux veuvages qui en découlent. 


\section{La taille des ménages diminue}

En moyenne, en 2015, les ménages comptaient 2,23 personnes contre 2,31 en 2006. Cette diminution prolonge une tendance historique aux origines multiples : la baisse de la fécondité, l'allongement de la vie en bonne santé, l'augmentation des ruptures conjugales, les périodes de vie sans conjoint cohabitant plus fréquentes et plus longues (Daguet, 2017). Le « desserrement » des ménages ${ }^{(7)}$ associé à ces phénomènes entraîne des besoins en logements ${ }^{(8)}$ différents à la fois quantitativement et qualitativement (nombre de pièces, superficie, localisation...). C'est ainsi qu'on observe un accroissement du nombre de logements presque deux fois plus rapide que celui de la population entre 2006 et 2015 ( $+8,6 \%$ contre $+4,9 \%)$.

Le nombre de personnes dans le ménage n'est pas constant au fil de la vie : il varie selon l'âge et le sexe au rythme de la trajectoire familiale (figure 4). Aux plus jeunes âges, les enfants vivent en moyenne dans des ménages de taille relativement importante (plus de 4,0 personnes), c'est également le cas des

Figure 4. Évolution du nombre moyen de personnes par ménage en 2006 et 2015, par sexe et âge

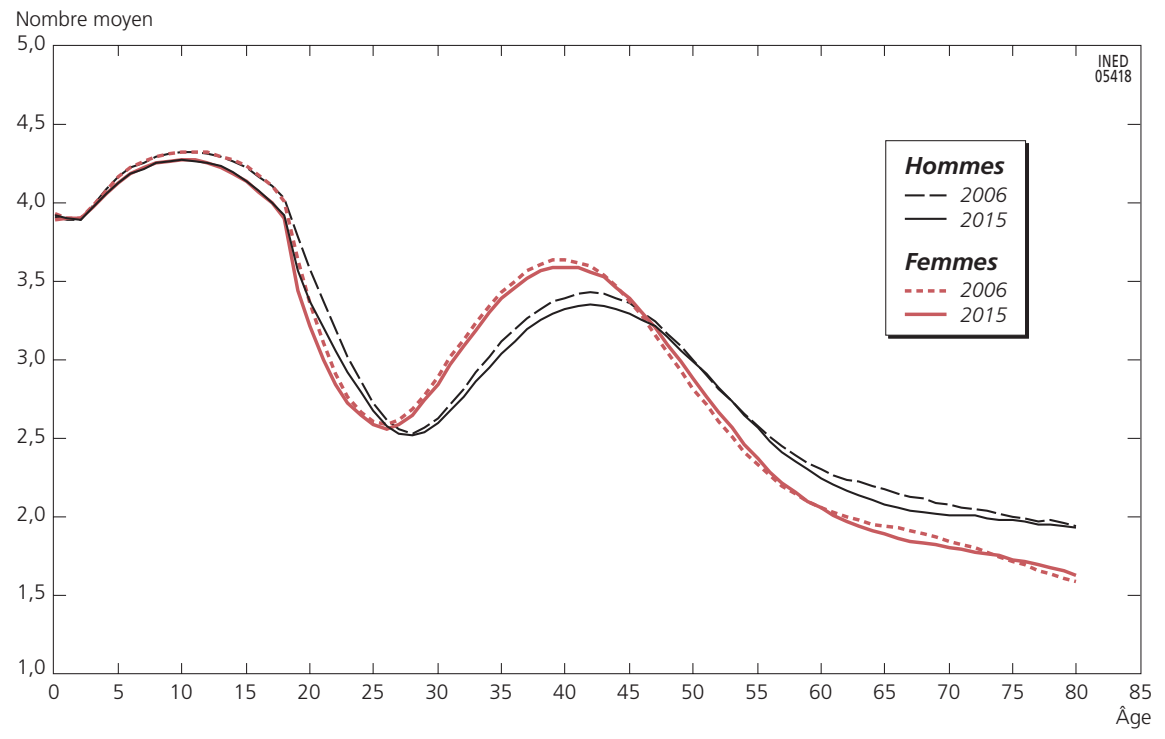

Champ : France entière hors Mayotte, personnes vivant en ménage ordinaire.

Sources : Insee, recensements, calculs des auteur.e.s.

(7) C'est-à-dire de la diminution du nombre moyen de personnes par ménage. Le terme de « desserrement » est régulièrement utilisé dans les travaux d'urbanisme et de projections de population, notamment celles tenant compte des contraintes de logement. Il est défini en 1988 dans le « Dictionnaire de l'urbanisme et de l'aménagement » (Merlin et Choay, 1988) comme le « taux d'occupation du logement ».

(8) Les logements sont ici ceux considérés comme résidence principale. Dans le recensement, la notion de ménage est associée à celle de logement. Un ménage regroupe un ensemble d'individus vivant sous le même toit, au sein d'une résidence dans laquelle ils passent le plus de temps dans l'année. 
adultes aux âges de constitution et d'agrandissement des familles (proche de 3,5 personnes). C'est aux âges de l'entrée dans la vie adulte (de 15 à 25 ans) et de la décohabitation des enfants (après 45 ans) que les personnes vivent dans des ménages plus réduits pour atteindre un minimum aux âges les plus avancés (proche de 1 personne par ménage au-delà de 90 ans). Les formes des courbes des hommes et des femmes sont identiques, mais le niveau diffère entre 25 ans et 45 ans du fait notamment de la monoparentalité davantage féminine, et audelà de 50 ans en raison du moindre risque de veuvage des hommes dû à une espérance de vie plus longue des femmes. La légère diminution de la taille moyenne des ménages entre 2006 et 2015 (-0,08 personne) s'observe à presque tous les âges (à l'exception des 45 et 60 ans) avec un maximum à 19 et 20 ans (-6\% pour les hommes) et entre 65 et 67 ans (- $4 \%$ ). Cette diminution tient donc en partie au vieillissement de la population. Le prolongement de cette tendance semble inéluctable, sauf si, évolution peu probable, les lieux de vie aux âges de la vieillesse se transforment à nouveau avec un retour à des modes de cohabitation intergénérationnelle.

\section{L'immigration en provenance de pays tiers}

Le solde migratoire, qui mesure la différence entre les entrées et les sorties de personnes sur le territoire français au cours d'une année, peut se décomposer entre les entrées et les sorties des ressortissants français ou nés en France, et celles des personnes immigrées qui sont caractérisées par le fait qu'elles sont nées étrangères à l'étranger.

Cette section est consacrée à l'évolution récente des entrées de personnes étrangères en provenance de pays dits tiers, dont les ressortissants majeurs sont soumis à l'obligation de détention d'un titre de séjour. Elle ne concerne pas les ressortissants des pays membres de l'Espace économique européen ${ }^{(9)}$ et de Suisse. Afin de mener des comparaisons temporelles cohérentes, les statistiques sont établies à périmètre géographique constant, ce qui signifie que les flux de ressortissants des pays pour lesquels la détention d'un titre fut obligatoire mais n'est aujourd'hui plus nécessaire, ne sont pas comptabilisés ici ${ }^{(10)}$.

Les flux d'entrées de ressortissants de pays tiers s'établissant légalement en France sont évalués ici à partir des statistiques relatives à la délivrance des titres de séjour et des visas de long séjour valant titres de séjour. Les statistiques sont construites à partir d'extractions de l'Application de gestion des dossiers des ressortissants étrangers en France (AGDREF) du ministère de l'Intérieur

(9) Allemagne, Autriche, Belgique, Bulgarie, Chypre, Croatie, Danemark, Espagne, Estonie, Finlande, France, Grèce, Hongrie, Irlande, Islande, Italie, Lettonie, Liechtenstein, Lituanie, Luxembourg, Malte, Norvège, Pays-Bas, Pologne, Portugal, République tchèque, Roumanie, Royaume-Uni, Slovaquie, Slovénie et Suède.

(10) Du fait de la modification du champ et des méthodes d'estimation retenues, le tableau annexe A.3 fait l'objet d'une refonte depuis 2014. En particulier, l'ensemble des nationalités considérées peut évoluer d'une note de conjoncture à l'autre en fonction de la législation sur le droit au séjour. 
transmises chaque année à l'Ined. La méthodologie suivie pour construire ces flux est décrite en détail dans d'Albis et Boubtane (2015). Le principe de base est le suivant : les personnes sont comptabilisées dans le flux de l'année où elles reçoivent pour la première fois un titre de séjour permettant de résider au moins un an en France. Dans la plupart des cas, cette année est la même que l'année d'entrée, mais elle peut lui être parfois postérieure (notamment parce que la personne a pu détenir auparavant un titre autorisant un séjour plus court). C'est donc davantage l'entrée dans le statut de migrant permanent - autrement dit de résident légal et durable - qui est mesurée, que l'entrée effective sur le territoire.

De façon complémentaire, le ministère de l'Intérieur publie une série statistique de flux migratoires qui repose sur la comptabilisation de tous les premiers titres de séjour délivrés aux personnes majeures. Les champs ne sont donc pas les mêmes. Les flux d'entrées d'étrangers peuvent également être estimés à partir d'autres sources statistiques. L'Insee utilise les recensements de la population, ce qui permet aussi d'évaluer les entrées des ressortissants de l'Espace économique européen et les ressortissants des pays tiers sans titre de séjour. Cependant, pour un même périmètre géographique, les évaluations des flux d'entrées réalisées à partir des recensements sont plus faibles que celles obtenues à partir d'AGDREF (Temporal et Brutel, 2016).

\section{Une poursuite de l'augmentation des flux d'entrées}

Le tableau 2 présente les flux d'entrées pour les années 2011 à 2016. Le flux a représenté 218354 personnes en 2016, soit son plus haut niveau depuis 2000 (tableau annexe A.3). Les flux en 2016 représentent 4 \% d'entrées supplémentaires par rapport à 2015 et $23 \%$ de plus qu'en 2011.

Tableau 2. Flux d'entrées de ressortissants de pays tiers, selon l'année de début de validité et la durée de validité du premier titre de séjour d'un an et plus

\begin{tabular}{|c|c|c|c|c|c|c|}
\hline Durée de validité du titre & 2011 & 2012 & 2013 & 2014 & 2015 & 2016 \\
\hline Titres de moins de 10 ans & 157669 & 159077 & 173058 & 178677 & 187626 & 193163 \\
\hline Titres de 10 ans ou plus & 20002 & 20934 & 19338 & 21210 & 22414 & 25191 \\
\hline Total & 177671 & 180011 & 192396 & 199887 & 210040 & 218354 \\
\hline \multicolumn{7}{|c|}{$\begin{array}{l}\text { Champ : Titres délivrés en France et à l'étranger aux ressortissants des pays étrangers, à l'exception des pays } \\
\text { membres de l'Espace économique européen et de la Suisse (périmètre constant de } 2011 \text { à 2016). Titres délivrés } \\
\text { l'année N et enregistrés dans l'extraction de la base réalisée en juillet de l'année N+2. Les titres de moins de } 10 \\
\text { ans ont une durée de validité comprise entre } 364 \text { et } 3649 \text { jours; les titres de } 10 \text { ans ou plus ont une durée de } \\
\text { validité de plus de } 3649 \text { jours. } \\
\text { Source: Calculs des auteur.e.s à partir des extractions de la base AGDREF transmises à l'Ined. }\end{array}$} \\
\hline
\end{tabular}

Parmi les personnes comptabilisées, la part des bénéficiaires d'un premier titre dont la durée de validité est supérieure ou égale à dix ans reste faible, légèrement inférieure à $12 \%$ en 2016. Le titre de séjour de 10 ans ou plus, typiquement la carte de résident, est généralement obtenu après un ou plusieurs titres de moins de 10 ans. 
Selon Eurostat, qui diffuse des informations transmises par l'Insee, le flux total d'étrangers s'est établi à 240888 personnes en $2016^{(11)}$. Cette évaluation inclut également les ressortissants des pays non soumis à l'obligation de détention d'un titre de séjour (soit ceux des pays de l'Espace économique européen et la Suisse). Toujours selon Eurostat, si l'on retire ces derniers, le flux est alors de 158156 personnes, soit une estimation bien plus faible que l'évaluation réalisée ici à partir des données AGDREF.

\section{La part des femmes diminue mais reste hétérogène selon le continent d'origine}

Les nouveaux immigrés sont jeunes : en 2016, les personnes âgées de 18 à 34 ans représentaient 63,1 \% de l'ensemble du flux (tableau 3) et 70,2 \% des adultes. La part des mineurs est stable à 10,3\% en 2016. Il faut préciser que seuls les mineurs détenteurs d'un titre de séjour ${ }^{(12)}$ sont comptabilisés. La détention d'un titre n'est pas obligatoire pour les étrangers mineurs mais peut être nécessaire, notamment pour se déplacer hors du territoire français. Par ailleurs, les personnes mineures nées en France de parents étrangers ne sont, par définition, pas comptabilisées dans les flux d'entrées. La première ligne du tableau 2 ne recense donc que les personnes mineures nées à l'étranger et titulaire d'un titre de séjour.

Tableau 3. Distribution du flux d'entrées (\%) par groupe d'âges, selon l'année de début de validité du premier titre de séjour d'un an et plus

\begin{tabular}{|l|ccc|c|c|c|}
\hline Groupe d'âges & 2011 & 2012 & 2013 & 2014 & 2015 & 2016 \\
\hline 0-17 ans & 9,9 & 9,7 & 9,5 & 10,3 & 10,2 & 10,3 \\
$18-34$ ans & 64,5 & 64,4 & 62,8 & 62,2 & 62,5 & 63,1 \\
35-64 ans & 24,2 & 24,4 & 26,2 & 25,7 & 25,5 & 24,9 \\
65 ans et plus & 1,4 & 1,5 & 1,5 & 1,7 & 1,7 & 1,8 \\
\hline
\end{tabular}

La figure 5 propose une représentation plus fine de la répartition par âge et sexe du flux de l'année 2016. Le pic à 18-19 ans s'explique par les personnes arrivées mineures qui attendent leur majorité pour demander un titre de séjour et par les étudiants. La figure montre que les femmes sont plus nombreuses que les hommes entre 20 et 31 ans, mais l'âge moyen des femmes était de 29,3 ans tandis que celui des hommes était de 28,9 ans.

Les ressortissants d'Afrique sont très majoritaires au sein du flux d'entrées; leur part a représenté 57,8\% en 2016 (tableau 4). Lannée 2016 est marquée par une augmentation de la part des ressortissants des pays d'Asie et d'une baisse de ceux des pays d'Afrique et d'Amérique.

(11) Les données d'Eurostat sont disponibles en ligne (http://ec.europa.eu/eurostat/en/data/database) et sont reprises par l'OCDE sur son site (http://www.oecd.org/els/mig/keystat.htm).

(12) Ce titre est dénommé « document de circulation pour étranger mineur » et a été créé par décret le 24 décembre 1991. 
Figure 5. Répartition par âge et sexe du flux d'entrées en 2016

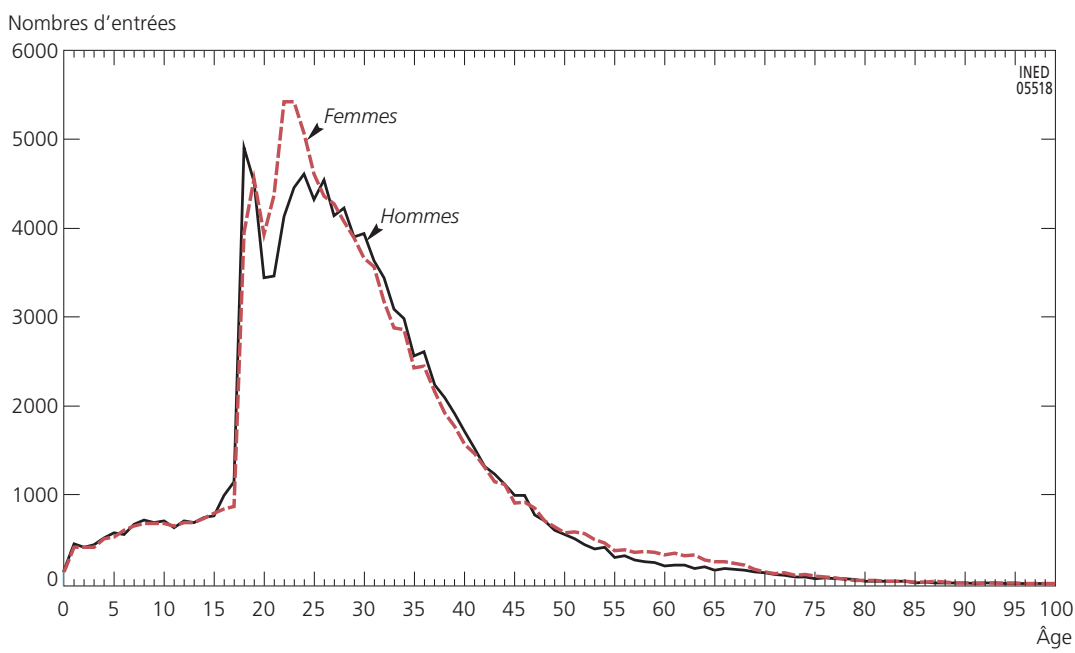

Champ : Titres délivrés aux personnes étrangères. Voir tableau 2.

Source : Calculs des auteur.e.s à partir des extractions de la base AGDREF transmises à I'Ined.

Tableau 4. Distribution du flux d'entrées (\%) par continent d'origine, selon l'année de début de validité du premier titre de séjour d'un an et plus

\begin{tabular}{|l|r|r|r|r|r|r|}
\hline $\begin{array}{c}\text { Continent } \\
\text { d'origine }\end{array}$ & 2011 & 2012 & 2013 & 2014 & 2015 & 2016 \\
\hline Afrique & 56,9 & 57,0 & 57,0 & 58,0 & 58,2 & 57,8 \\
Amérique & 11,9 & 11,5 & 10,8 & 10,5 & 10,4 & 9,4 \\
Asie & 24,3 & 24,5 & 25,3 & 24,5 & 24,4 & 25,6 \\
Europe & 6,3 & 6,3 & 6,2 & 6,3 & 6,3 & 6,7 \\
Océanie & 0,5 & 0,4 & 0,4 & 0,4 & 0,4 & 0,4 \\
\hline
\end{tabular}

Note : La somme n'est pas toujours égale à 100 du fait des arrondis et des valeurs manquantes. Champ : Titres délivrés aux personnes étrangères. Voir tableau 2. La Turquie est classée en Asie. L’Europe comprend tous les pays d'Europe hors EEE et Suisse.

Source : Calculs des auteur.e.s à partir des extractions de la base AGDREF transmises à I'Ined.

Dans le flux d'entrées, les femmes sont très légèrement majoritaires et ont représenté, en 2016, 50,6\% du total (tableau 5). Leur proportion se réduit depuis 2014. En 2016, les femmes étaient moins nombreuses que les hommes parmi les ressortissants d'Afrique tandis qu'elles étaient majoritaires parmi les ressortissants de tous les autres continents. Elles sont en particulier surreprésentées parmi les ressortissants des pays d'Europe.

\section{La part du flux d'entrées pour motif familial diminue depuis 2013}

Le motif familial ${ }^{(13)}$ reste le principal motif d'entrée en France mais il est en forte diminution depuis 2013. Il a représenté 49\% du flux d'entrée en 2016 (tableau 6). En comparaison, les entrées pour motifs d'études (25,9\%),

(13) Les étrangers mineurs détenteurs d'un titre de séjour sont ici inclus dans ce motif. 
Tableau 5. Part des femmes dans le flux d'entrées (\%) par continent d'origine, selon l'année de début de validité du premier titre de séjour d'un an et plus

\begin{tabular}{l|cc|c|c|c|c|}
\hline $\begin{array}{l}\text { Continent } \\
\text { d'origine }\end{array}$ & 2011 & 2012 & 2013 & 2014 & 2015 & 2016 \\
\hline Afrique & 47,5 & 49,0 & 49,2 & 49,9 & 49,3 & 48,3 \\
Amérique & 58,7 & 58,3 & 58,3 & 57,7 & 56,7 & 57,3 \\
Asie & 54,7 & 54,7 & 54,1 & 53,8 & 53,0 & 51,3 \\
Europe & 60,7 & 60,4 & 60,4 & 60,2 & 60,0 & 58,6 \\
Océanie & 54,0 & 52,4 & 55,4 & 50,1 & 52,7 & 53,5 \\
\hline Ensemble & 51,4 & 52,2 & 52,2 & 52,3 & 51,6 & 50,6 \\
\hline Champ : Titres délivrés aux personnes étrangères. Voir tableau 2. La Turquie est classée en Asie. L'Europe \\
comprend tous les pays d'Europe hors EEE et Suisse. \\
Source : Calculs des auteur.e.s à partir des extractions de la base AGDREF transmises à I'Ined. \\
\hline
\end{tabular}

Tableau 6. Distribution du flux d'entrées (\%) par motif de délivrance du premier titre d'un an et plus, selon l'année de début de validité du titre

\begin{tabular}{|l|r|r|r|r|r|c|}
\hline Motif de délivrance & 2011 & 2012 & 2013 & 2014 & 2015 & 2016 \\
\hline Familial & 53,5 & 55,5 & 56,1 & 55,0 & 52,7 & 49,0 \\
Études & 25,2 & 23,8 & 24,0 & 23,8 & 25,3 & 25,9 \\
Humanitaire & 9,5 & 9,7 & 8,9 & 9,9 & 10,2 & 12,7 \\
$\quad$ dont Réfugié & 6,0 & 6,1 & 5,6 & 6,4 & 7,2 & 9,8 \\
Professionnel & 7,6 & 6,6 & 6,7 & 7,2 & 7,7 & 8,1 \\
Divers et non & 4,2 & 4,5 & 4,4 & 4,2 & 4,2 & 4,3 \\
renseigné & Champ : Voir tableau 3. La ligne « Réfugié » regroupe les titres accordés pour les motifs « Réfugié et apatride, \\
asile territorial et protection subsidiaire ». \\
Source : Calculs des auteur.e.s à partir des extractions de la base AGDREF transmises à l'Ined. \\
\hline
\end{tabular}

humanitaires $(12,7 \%)$ et professionnels $(8,1 \%)$ sont faibles mais en augmentation. Le motif humanitaire recoupe deux situations principales : les étrangers malades (6 178 personnes en 2016) et les personnes recevant un titre de séjour parce qu'ils ont obtenu le statut de réfugié ou d'apatride, l'asile territorial ou la protection subsidiaire (21 473 personnes) ${ }^{(14)}$. Les titres délivrés en raison de ce second ensemble de situations ont augmenté de plus de 41\% en 2016. Ils sont la conséquence de la hausse des demandes d'asile enregistrées depuis 2014 (d'Albis et Boubtane, 2018). Le motif professionnel (17 726 personnes en 2016) regroupe des personnes qui à près de 75 \% sont salariées ou actives non salariées. Le reste concerne les travailleurs saisonniers ou temporaires ainsi que les scientifiques ou artistes.

Les femmes sont surreprésentées parmi les bénéficiaires de titres octroyés pour un motif familial et sous-représentées parmi les motifs humanitaires et surtout professionnels (tableau 7). Parmi les étudiants, les femmes sont aussi nombreuses que les hommes.

(14) Il est important de distinguer ces personnes des demandeurs d'asile qui sont considérés comme faisant partie de la migration temporaire. On ne comptabilise dans le motif humanitaire du flux d'entrées que les personnes dont la demande a été instruite et a connu une issue favorable. 
Tableau 7. Part des femmes dans le flux d'entrées (\%) par motif de délivrance du premier titre d'un an et plus, selon l'année de début de validité du titre

\begin{tabular}{|c|c|c|c|c|c|c|}
\hline Motif de délivrance & 2011 & 2012 & 2013 & 2014 & 2015 & 2016 \\
\hline Familial & 57,3 & 57,3 & 57,1 & 58,3 & 58,1 & 58,0 \\
\hline Études & 49,9 & 51,1 & 50,4 & 50,0 & 49,0 & 49,4 \\
\hline Humanitaire & 43,6 & 43,5 & 44,1 & 44,8 & 44,6 & 41,3 \\
\hline Professionnel & 22,2 & 23,5 & 24,9 & 23,1 & 24,8 & 23,6 \\
\hline Ensemble & 51,4 & 52,2 & 52,2 & 52,3 & 51,6 & 50,6 \\
\hline
\end{tabular}

Les motifs d'entrée sont très différemment répartis en fonction du continent d'origine (tableau 8). Le motif familial est surreprésenté parmi les Africains (56,1\% de leurs titres en 2016) et les Européens (52,3\%) et sous-représenté parmi les Asiatiques (33,4\%) et les Américains (45,6\%). Le motif d'études est surreprésenté parmi les Asiatiques (33,4\%) et les Américains $(29,9 \%)$ et sousreprésenté parmi les Européens (11,6\%). Le motif humanitaire est particulièrement présent chez les Européens (25,0\%) et les Asiatiques (20,2\%) et il est

Tableau 8. Distribution du flux d'entrées (\%) par motif de délivrance du premier titre d'un an et plus et continent d'origine, selon l'année de début de validité

\begin{tabular}{|c|c|c|c|c|c|c|}
\hline $\begin{array}{l}\text { Continent d'origine et } \\
\text { motif de délivrance }\end{array}$ & 2011 & 2012 & 2013 & 2014 & 2015 & 2016 \\
\hline \multicolumn{7}{|l|}{ Afrique } \\
\hline Familial & 61,5 & 64,8 & 64,4 & 63,5 & 61,2 & 56,1 \\
\hline Études & 21,2 & 19,3 & 20,1 & 20,2 & 22,8 & 24,8 \\
\hline Humanitaire & 7,8 & 7,8 & 7,4 & 8,0 & 7,5 & 9,7 \\
\hline Professionnel & 6,5 & 4,9 & 5,1 & 5,5 & 5,7 & 6,4 \\
\hline \multicolumn{7}{|l|}{ Amérique } \\
\hline Familial & 51,2 & 48,0 & 49,1 & 49,4 & 45,9 & 45,6 \\
\hline Études & 26,7 & 28,7 & 28,6 & 28,9 & 29,8 & 29,9 \\
\hline Humanitaire & 3,0 & 2,9 & 2,4 & 2,0 & 1,9 & 2,2 \\
\hline Professionnel & 10,4 & 10,6 & 10,3 & 10,5 & 13,4 & 12,3 \\
\hline \multicolumn{7}{|l|}{ Asie } \\
\hline Familial & 37,8 & 39,0 & 40,7 & 37,8 & 35,3 & 33,4 \\
\hline Études & 36,9 & 34,6 & 33,4 & 33,3 & 32,8 & 30,9 \\
\hline Humanitaire & 12,0 & 13,2 & 12,5 & 14,6 & 17,2 & 20,2 \\
\hline Professionnel & 8,6 & 8,2 & 8,5 & 9,5 & 10,2 & 10,8 \\
\hline \multicolumn{7}{|l|}{ Europe } \\
\hline Familial & 47,2 & 50,5 & 55,3 & 53,8 & 53,5 & 52,3 \\
\hline Études & 14,8 & 14,7 & 13,9 & 13,0 & 13,1 & 11,6 \\
\hline Humanitaire & 26,1 & 23,7 & 18,5 & 21,3 & 21,3 & 25,0 \\
\hline Professionnel & 7,5 & 6,7 & 7,2 & 6,4 & 6,5 & 6,1 \\
\hline
\end{tabular}


très faible chez les Américains (2,2\%), qui sont surreprésentés dans le motif professionnel (12,3\%). La migration issue du continent africain se caractérise par une décroissance du motif familial au profit de tous les autres motifs. Les motifs de la migration américaine sont stables depuis 2015. La migration asiatique se caractérise par une forte baisse des migrations familiale et d'études au profit de migrations humanitaire, du fait de la guerre en Syrie, et professionnelle. Enfin, la migration européenne est marquée par une hausse de la migration humanitaire et une baisse des migrations d'études et familiale.

\section{Plus de 35000 demandeurs d'asile ont été admis au séjour en 2016}

Les demandeurs d'asile peuvent être admis au séjour en France de plusieurs façons. Si leur demande est acceptée, ils obtiennent un des titres relevant du motif humanitaire (ils sont ici comptabilisés à la quatrième ligne du tableau 6). Comme le montre d'Albis et Boubtane (2018), une partie des déboutés va néanmoins être admise au séjour en France en obtenant un titre de séjour pour un autre motif, le plus souvent familial. Les taux d'admission au séjour en fonction de la date de dépôt de la demande sont présentés dans d'Albis et Boubtane (2018). La perspective est ici différente. Le tableau 9 porte sur le flux d'entrée annuel de personnes ayant déposé une demande d'asile auprès de l'OFPRA. Elles ont représenté 35262 personnes en 2016, soit 16,1\% du flux d'entrées ${ }^{(15)}$. Conséquences de la guerre en Syrie, le nombre de demandeurs d'asile admis au séjour et sa part dans le flux sont, en 2016, les plus élevés depuis 2011. Dans

Tableau 9. Distribution des flux d'entrées (\%) de personnes ayant déposé une demande d'asile, selon l'année de début de validité

du premier titre d'un an et plus, le continent d'origine et le motif de délivrance

\begin{tabular}{|c|c|c|c|c|c|c|}
\hline & 2011 & 2012 & 2013 & 2014 & 2015 & 2016 \\
\hline Part des femmes & 39,3 & 39,7 & 40,7 & 41,5 & 41,1 & 39,7 \\
\hline \multicolumn{7}{|c|}{ Continent d'origine } \\
\hline Afrique & 42,9 & 41,1 & 37,8 & 37,9 & 35,9 & 36,9 \\
\hline Amérique & 5,9 & 4,9 & 5,2 & 4,7 & 4,1 & 3,0 \\
\hline Asie & 33,7 & 36,6 & 41,6 & 41,4 & 44,0 & 43,9 \\
\hline Europe & 16,3 & 15,7 & 13,8 & 14,5 & 14,9 & 15,3 \\
\hline \multicolumn{7}{|c|}{ Motif de délivrance } \\
\hline Familial & 35,8 & 36,8 & 45,1 & 38,1 & 33,1 & 35,8 \\
\hline Études & 0,4 & 0,5 & 0,5 & 0,6 & 0,5 & 0,4 \\
\hline Humanitaire & 55,5 & 57,3 & 48,4 & 54,4 & 59,5 & 55,5 \\
\hline Professionnel & 7,7 & 4,7 & 5,3 & 6,2 & 6,2 & 7,7 \\
\hline Flux d'entrées & 22236 & 22169 & 25132 & 25703 & 27507 & 35262 \\
\hline \multicolumn{7}{|c|}{$\begin{array}{l}\text { Champ: Titres délivrés en France et à l'étranger aux ressortissants des pays étrangers, à l'exception des pays } \\
\text { membres de l'Espace économique européen et de la Suisse (périmètre constant de } 2011 \text { à 2016) ayant déposé } \\
\text { un demande d'asile entre } 1985 \text { et l'année de validité du premier titre d'un an et plus. Titres délivrés l'année N } \\
\text { et enregistrés dans l'extraction de la base réalisée en juillet de l'année N+2. } \\
\text { Source: Calculs des auteur.e.s à partir des extractions de la base AGDREF transmises à l'Ined. }\end{array}$} \\
\hline
\end{tabular}

(15) Cette proportion est supérieure à la part du flux admis pour motif humanitaire du fait de l'admission pour d'autres motifs. 
le flux d'entrées de personnes ayant demandé l'asile, la part des femmes est plus faible que dans l'ensemble du flux d'entrées : elles représentaient moins de $40 \%$ en 2016, soit une proportion stable depuis 2011. Depuis 2013, les ressortissants d'Asie sont les plus nombreux au sein du flux de personnes ayant déposé une demande d'asile. Ils représentaient en 2016 près de $44 \%$ du total. Les ressortissants d'Afrique ont quant à eux représenté près de $37 \%$ du total. Ces personnes ont été admises au séjour majoritairement pour raisons humanitaires (55,5\% des entrées en 2016) et familiales (35,8\%).

\section{Près de $28 \%$ des entrées ont lieu en août et septembre}

Les premiers titres d'un an ou plus sont particulièrement nombreux entre août et octobre (figure 6). Cette saisonnalité s'explique essentiellement par les étudiants, dont $60 \%$ des entrées ont lieu au cours des mois d'août et de septembre. Dans une moindre mesure, le motif professionnel connaît également une variation saisonnière, les mois de septembre et octobre concentrant à eux seuls 23\% des entrées. En revanche, les motifs familial et humanitaire ne connaissent pas de variation notable au cours de l'année.

Figure 6. Flux d'entrées de ressortissants de pays tiers en 2016 par motif, selon le mois de début de validité et la durée de validité du premier titre de séjour d'un an et plus, par motifs

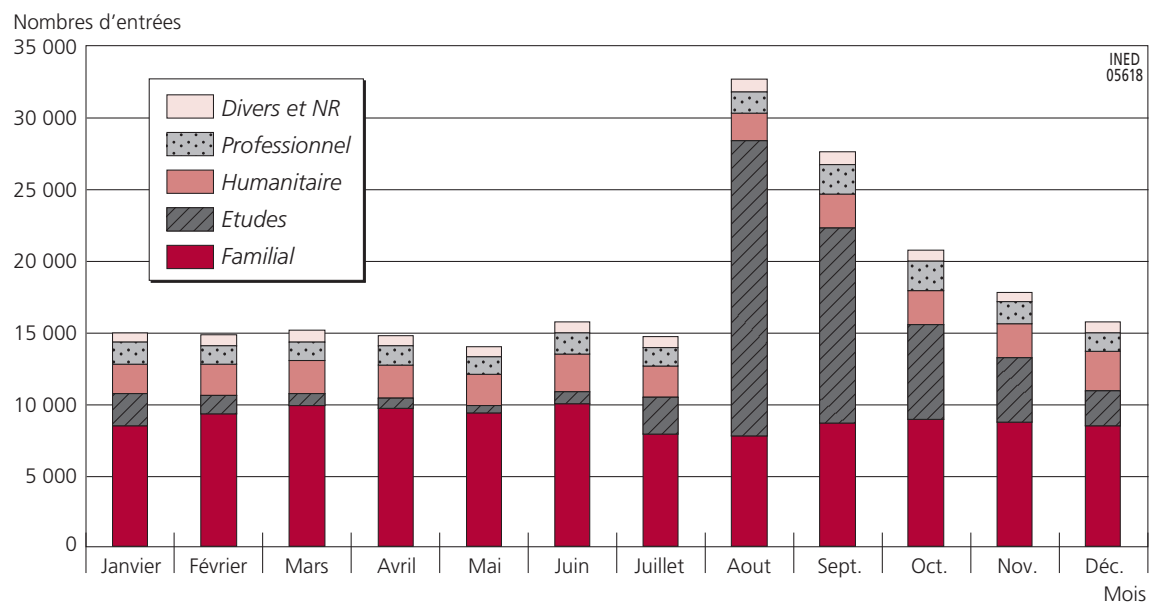

Champ : Voir tableau 2.

Source : Calculs des auteur.e.s à partir des extractions de la base AGDREF transmises à I'Ined.

\section{Naissances et fécondité}

\section{Une baisse de la fécondité des jeunes}

Au cours de l'année 2017, on a enregistré 769500 naissances sur le territoire national (730000 pour les départements métropolitains $)^{(16)}$. Pour la troisième

(16) Voir la note de bas de page $n^{\circ} 2$. 
année consécutive, le nombre de naissances diminue du fait de la baisse conjuguée de la population en âge de procréer et de la fécondité (Papon et Beaumel, 2019). L'indicateur conjoncturel de fécondité est passé de 2,0 enfants par femme au début des années 2010 à 1,9 en 2016 et 2017, rejoignant le niveau observé au début des années 2000. Par rapport à l'année précédente, le nombre annuel de naissances a baissé de 2,4\% en 2015, de 1,9\% en 2016 (année bissextile) et de 1,8\% en 2017. Les estimations du nombre de naissances de l'année 2018 montrent que la baisse se confirme et qu'elle serait de 1,6 \% entre 2017 et 2018 (7580000 naissances; Papon et Beaumel, 2019). La fécondité française reste cependant élevée au regard des pays voisins (tableaux annexes A.6 et A.7).

Lors de ces dernières années de diminution, c'est la fécondité des moins de 25 ans qui a relativement le plus baissé (tableau 10, figure 7). Il s'agit potentiellement d'un effet de calendrier, qui pourrait se traduire à terme, s'il n'y a pas ou peu de rattrapage ultérieur, par une diminution du nombre moyen d'enfants par femme au sein des générations (tableau annexe A.5). Elle sera modérée si une partie des naissances sont décalées dans le temps.

Tableau 10. Évolution de la fécondité par groupe d'âges, de 2012 à 2017

\begin{tabular}{|c|c|c|c|c|c|c|c|c|c|c|c|}
\hline \multirow{2}{*}{$\begin{array}{l}\text { Âge atteint } \\
\text { dans l'année }\end{array}$} & \multicolumn{6}{|c|}{ Somme des taux par âge (p. 1000 femmes) } & \multicolumn{5}{|c|}{ Variation absolue } \\
\hline & 2012 & 2013 & 2014 & 2015 & 2016 & $2017^{(a)}$ & $\begin{array}{l}2012- \\
2013\end{array}$ & $\begin{array}{l}2013- \\
2014\end{array}$ & $\begin{array}{l}2014- \\
2015\end{array}$ & $\begin{array}{l}2015- \\
2016\end{array}$ & $\begin{array}{l}2016- \\
2017\end{array}$ \\
\hline Moins de 20 ans & 40 & 38 & 37 & 35 & 32 & 30 & -2 & -1 & -2 & -3 & -2 \\
\hline $20-24$ ans & 267 & 257 & 252 & 240 & 231 & 222 & -10 & -5 & -12 & -9 & -9 \\
\hline $25-29$ ans & 627 & 618 & 612 & 592 & 574 & 555 & -9 & -5 & -21 & -17 & -20 \\
\hline 30-34 ans & 656 & 650 & 658 & 648 & 643 & 635 & -6 & 8 & -9 & -3 & -11 \\
\hline $35-39$ ans & 333 & 338 & 347 & 347 & 345 & 343 & 5 & 9 & 0 & -2 & -2 \\
\hline 40 ans ou plus & 85 & 88 & 93 & 93 & 95 & 98 & 3 & 5 & 0 & 2 & 3 \\
\hline Total $\left(I C F^{*}\right)$ & 2008 & 1988 & 1999 & 1955 & 1920 & 1883 & -19 & 11 & -44 & -32 & -41 \\
\hline \multicolumn{12}{|c|}{$\begin{array}{l}\text { * ICF : indicateur conjoncturel de fécondité (somme des taux de fécondité par âge) exprimé en nombre moyen } \\
\text { d'enfants pour } 1000 \text { femmes. En raison des arrondis, le total peut différer légèrement de la somme, et les } \\
\text { variations peuvent ne pas correspondre exactement aux différences apparentes. } \\
\text { (a) Données provisoires. } \\
\text { Champ : France entière (y compris Mayotte depuis 2014). } \\
\text { Source: Insee, calculs des auteur.e.s. }\end{array}$} \\
\hline
\end{tabular}

\section{Des enfants autour de 30 ans}

Au cours des 20 dernières années, les courbes de fécondité à chaque âge se sont modifiées. Actuellement, 63 \% des naissances sont concentrées entre 25 et 35 ans (tableau 10), et le recul de l'âge moyen à la maternité se poursuit. En 1994, les femmes de 25-29 ans contribuaient pour près de $40 \%$ à la fécondité totale, en 2017 à moins de 30 \% (figure 8). Depuis le milieu des années 2000, ce sont les naissances de femmes âgées de 30 à 34 ans qui ont le plus de poids dans la fécondité totale (plus d'un tiers en 2017). La fécondité à partir de 30 ans contribue à $57 \%$ du total. Inversement, la fécondité aux jeunes âges participe peu à la fécondité 
Figure 7. Évolution des taux de fécondité par âge (pour 1000 femmes) entre 20 et 39 ans, de 1994 à 2017
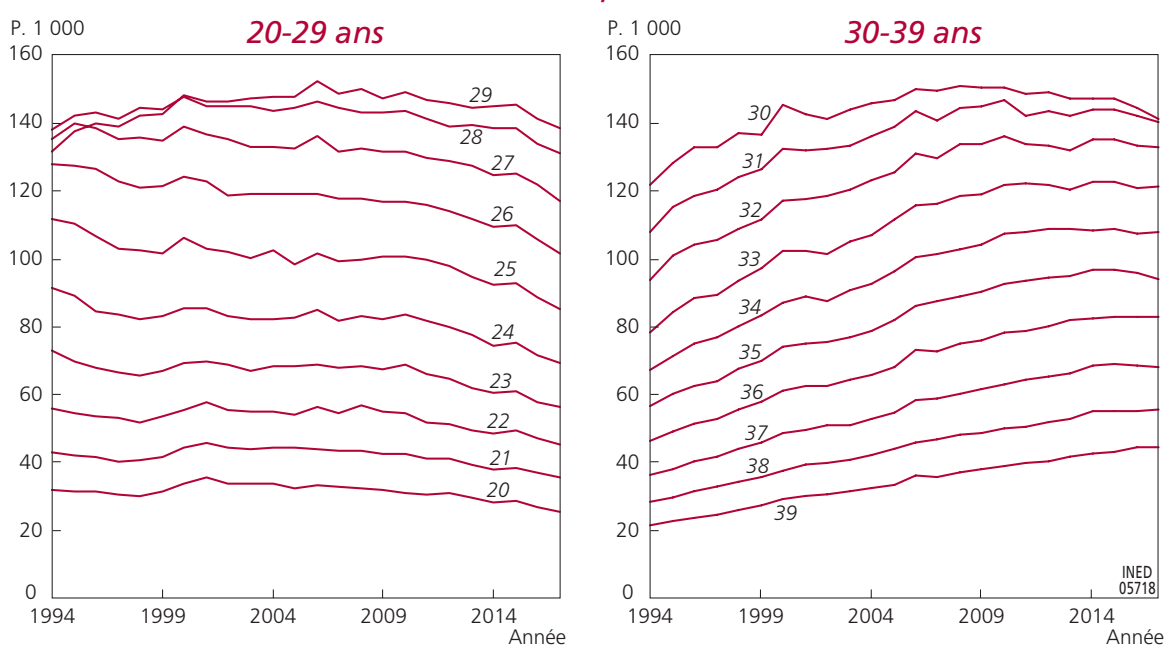

Champ : France entière (y compris Mayotte depuis 2014).

Source: Insee, calculs des auteur.e.s.

Figure 8. Contribution de chaque groupe d'âges

à l'indicateur conjoncturel de fécondité, de 1994 à 2017 (\%)

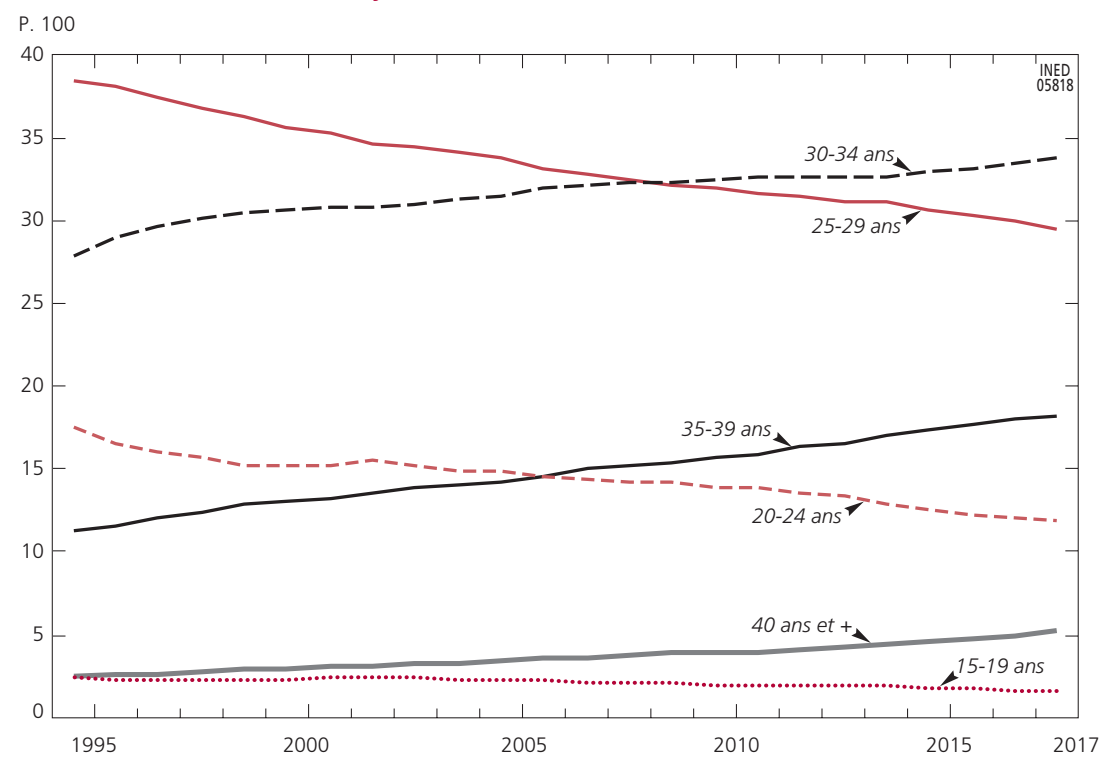

Champ : France entière (y compris Mayotte depuis 2014).

Source: Insee, calculs des auteur.e.s.

totale (12 \% pour les 20-24 ans) et la fécondité des 15-19 ans, qui était déjà relativement faible il y a 20 ans, continue de baisser pour atteindre 1,6\%. Les naissances avant l'âge de 20 ans sont de plus en plus rares, traduisant une bonne couverture 
contraceptive chez les jeunes (Rahib et Lydié, 2016; Rahib et al., 2016) et un recours sans doute fréquent à l'IVG en cas de grossesse non prévue.

Les courbes des taux de fécondité avant 30 ans suivent une tendance régulière à la baisse depuis le début des années 2000, mais leur diminution, plus marquée depuis quelques années, réduit significativement l'indicateur conjoncturel de fécondité. Il s'agit en effet d'âges auxquels la fécondité est élevée (tableau 10, figure 8). Par ailleurs, les taux de fécondité après 30 ans se sont stabilisés récemment ou ont diminué légèrement. Ainsi, l'indicateur conjoncturel baisse (de 2,01 en 2012 à 1,89 en 2017) et l'âge moyen à la maternité continue d'augmenter. En 2017, les femmes ont accouché en moyenne à 30,7 ans, contre 30,1 ans en 2012 (tableau annexe A.4).

\section{Moins de naissances les samedis, dimanches et jours fériés}

Au cours de l'année 2017, on a enregistré mensuellement entre 57900 (en février) et près de 68500 naissances (en juillet). La fin de l'hiver et l'arrivée du printemps sont les périodes au cours desquelles le nombre de naissances est le moins élevé, tandis qu'entre juillet et octobre les naissances sont plus nombreuses. Elles correspondent à des conceptions étalées sur le second semestre de l'année précédente. Les couples souhaitent dans l'idéal programmer une naissance pour le printemps (période préférée pour un accouchement), or le délai moyen de conception s'étend souvent sur plusieurs cycles d'ovulation (Régnier-Loilier, 2010; Régnier-Loilier et Rohrbasser, 2011). L'arrêt de la contraception en juilletaoût n'augure donc pas d'une naissance en mai. Les périodes de naissances sont alors en léger décalage par rapport au calendrier préférentiel des couples.

Le nombre journalier de naissances est d'environ 2000 (figure 9), avec des variations plus ou moins marquées. Le calendrier des accouchements programmés explique les variations les plus fortes, ces accouchements étant planifiés lors des jours ouvrés. Ainsi, les naissances sont plus rares lors des week-ends et des jours fériés. Les naissances du dimanche sont les moins nombreuses, notamment en mars-avril, mois pour lesquels on enregistre de manière générale moins d'accouchements. Sur l'ensemble de l'année 2017, la journée du 25 décembre est celle au cours de laquelle il y a eu le moins d'accouchements. En septembre, le week-end précédant la rentrée scolaire et les jours de rentrée scolaire sont également des périodes où les accouchements sont moins nombreux, sans doute du fait d'une moindre programmation des accouchements ces jours-là (figure 9).

\section{26000 naissances suite à une assistance médicale à la procréation (AMP)}

Sur l'ensemble des naissances, on en compte environ 26000 issues de l'AMP en 2016 (Agence de biomédecine, 2018; La Rochebrochard, 2018), soit un peu plus de $3 \%$ de l'ensemble des naissances. La technique la plus employée est la 
Figure 9. Nombre journalier de naissances en 2017

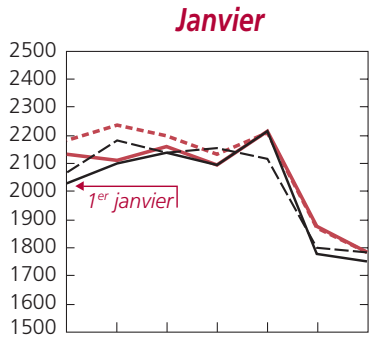

Lundi Mardi Merc. Jeudi Vend. Sam. Dim.

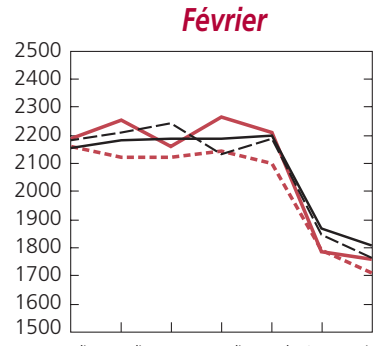

Lundi Mardi Merc. Jeudi Vend. Sam. Dim.

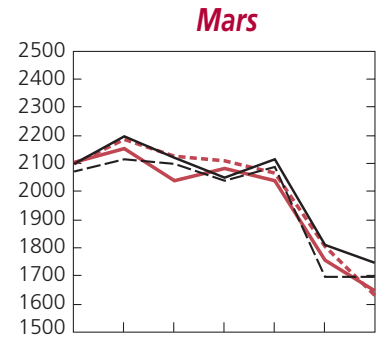

Lundi Mardi Merc. Jeudi Vend. Sam. Dim.
Avril

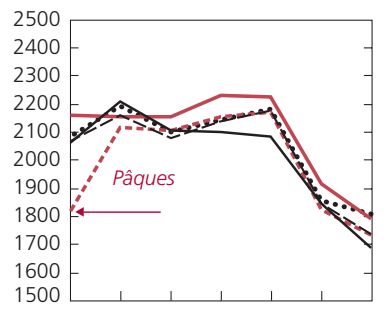

Lundi Mardi Merc. Jeudi Vend. Sam. Dim.

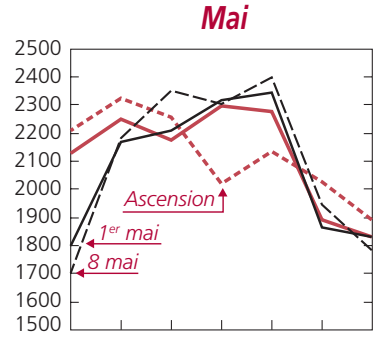

Lundi Mardi Merc. Jeudi Vend. Sam. Dim.

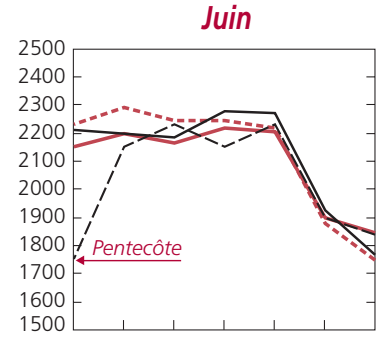

Lundi Mardi Merc. Jeudi Vend. Sam. Dim.
Juillet

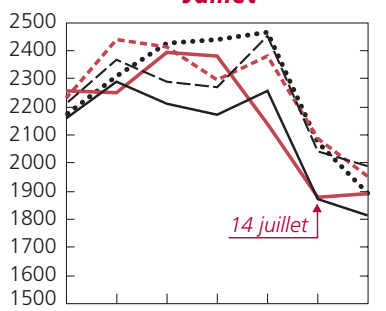

Lundi Mardi Merc. Jeudi Vend. Sam. Dim.

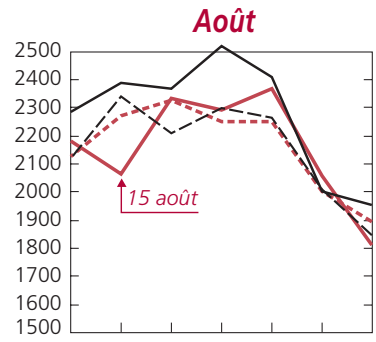

Lundi Mardi Merc. Jeudi Vend. Sam. Dim.

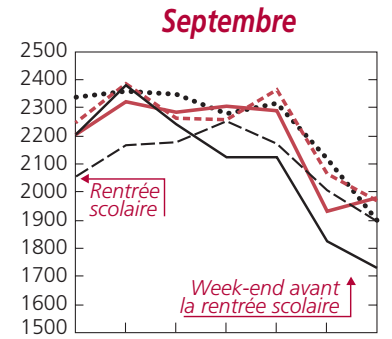

Lundi Mardi Merc. Jeudi Vend. Sam. Dim.
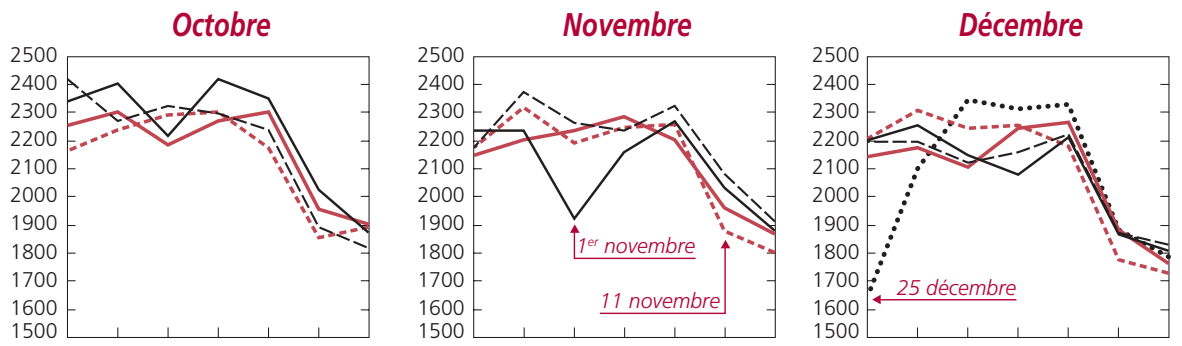

Lundi Mardi Merc. Jeudi Vend. Sam. Dim.

Lundi Mardi Merc. Jeudi Vend. Sam. Dim.

Lundi Mardi Merc. Jeudi Vend. Sam. Dim.

\begin{tabular}{|c|c|c|c|c|c|}
\hline - Semaine 1 & - - Semaine 2 & — Semaine 3 & ---- Semaine 4 & •... Semaine 5 & $\begin{array}{l}\text { INED } \\
05918\end{array}$ \\
\hline
\end{tabular}

Champ : France entière.

Source: Insee, calculs des auteur.e.s. 
fécondation in vitro (FIV, $50 \%)^{(17)}$. L'insémination « artificielle » (IA), moins invasive pour les corps féminins, concerne $25 \%$ des naissances; près d'un autre quart des naissances est issu d'un transfert d'embryons congelés (Agence de biomédecine, 2018, figure AMP10). La grande majorité des FIV et des IA (95\%) sont réalisées avec les gamètes des deux conjoints (AMP intraconjugale). Le recours aux donneurs est relativement réduit, reflet d'une AMP à dominante biologique, conjugale et hétéronormée (Gross et Bureau, 2015), du point de vue législatif et dans les pratiques. Les personnes « exclues » du système d'AMP, insatisfaites des prises en charge ou dans l'attente d'un don qui peut s'avérer être longue, se rendent pour certaines d'entre elles à l'étranger (en particulier en Belgique, en Espagne et en Grèce). Les centres à l'étranger reçoivent de France surtout des femmes en attente de don, des femmes non en couple ou des couples de même sexe (Rozée et La Rochebrochard, 2013). Un faible nombre de couples hétérosexuels ou de même sexe ont également recours à la gestation pour autrui à l'étranger, pratique hautement polémique du fait de positionnements éthiques et moraux clivés, et actuellement interdite en France.

\section{5. $11 \%$ des enfants nés en 2017 portent le double nom de leurs parents}

Depuis l'année 2005, année d'entrée en vigueur de la réforme du nom de famille ${ }^{(18)}$, les parents peuvent transmettre leurs deux noms à leurs enfants, grâce à une procédure d'enregistrement du choix du nom à l'état civil (Mazuy et al., 2015, 2016). En 2017, un peu plus de 11 \% des enfants se sont vu attribuer le double nom. Ce choix, dont se saisissent une minorité de couples, et qui peut paraître égalitaire du fait qu'il met en avant la double filiation, reste toutefois empreint des usages traditionnels : le nom du père se trouve en première position huit fois sur dix (tableau 11). Ces pratiques ont peu évolué depuis le début des années 2010.

\section{Les interruptions volontaires de grossesse (IVG)}

\section{Légère augmentation du taux de recours à I'IVG}

Le nombre d'interruptions volontaires de grossesse (IVG), en baisse depuis 2014, a légèrement augmenté en 2017 (Vilain, 2018). On a enregistré 216700 IVG en 2017 (202919 pour la France métropolitaine), contre 214800 en 2016. Ce chiffre est toutefois plus faible qu'en 2015 (218097), 2014 (227 038) et 2013

(17) On distingue à l'heure actuelle deux techniques : FIV-ICSI ou hors ICSI. Linjection intra-cytoplasmique de spermatozoïde (ICSI) est une technique qui consiste à sélectionner un spermatozoïde qui est directement introduit dans l'ovocyte (La Rochebrochard, 2018). La technique s'est développée depuis le début des années 1990 et est à l'heure actuelle la technique majoritaire : 34 \% de FIV-ICSI et $16 \%$ de FIV hors ICSI dans le total des naissances suite à une technique d'AMP.

(18) Loi du 4 mars 2002, entrée en vigueur le $1^{\text {er }}$ janvier 2005, donnant la possibilité de transmission du nom de la mère. On parle désormais de «nom de famille » et plus de nom patronymique. Toute mention au patronyme est supprimée dans la loi. 
Tableau 11. Répartition des noms de naissance des enfants nés en 2017 (\%)

\begin{tabular}{|l|c|}
\hline \multicolumn{1}{|c|}{ Nom attribué à l'enfant } \\
\hline Nom du père & 82,4 \\
Nom de la mère & 6,2 \\
Nom du père suivi du nom de la mère & 8,7 \\
Nom de la mère suivi du nom du père & 2,5 \\
Autre nom ou non déclaré & 0,2 \\
\hline Total & 100,0 \\
\hline Champ : Naissances vivantes enregistrées en France entière, y compris Mayotte. \\
Source : Insee, statistiques de l'état civil. \\
\hline
\end{tabular}

(229021) ; 202919 IVG concernent des femmes résidant en France métropolitaine (tableau annexe A.8). La baisse du nombre de femmes en âge de procréer ne s'est pas traduite, en 2017, par un moindre recours à l'IVG. Par contre, on note une diminution des IVG avant l'âge de 25 ans (figure 10). Globalement, la courbe du nombre moyen d'IVG suit une tendance similaire à celle de l'indicateur conjoncturel de fécondité, à un niveau quatre fois moindre (Mazuy et al., 2015; Vilain, 2018). L'augmentation des IVG en 2017 s'est produite chez les femmes âgées de 30-34 ans et 35-39 ans tandis que les IVG avant 20 ans continuent à diminuer (figure 10). Le mouvement de rajeunissement de l'âge à l'IVG, observé depuis la fin des années 1990, semble s'interrompre. Les données de

Figure 10. Évolution du nombre d'IVG pour 1000 femmes, par groupe d'âges, de 1990 à 2017

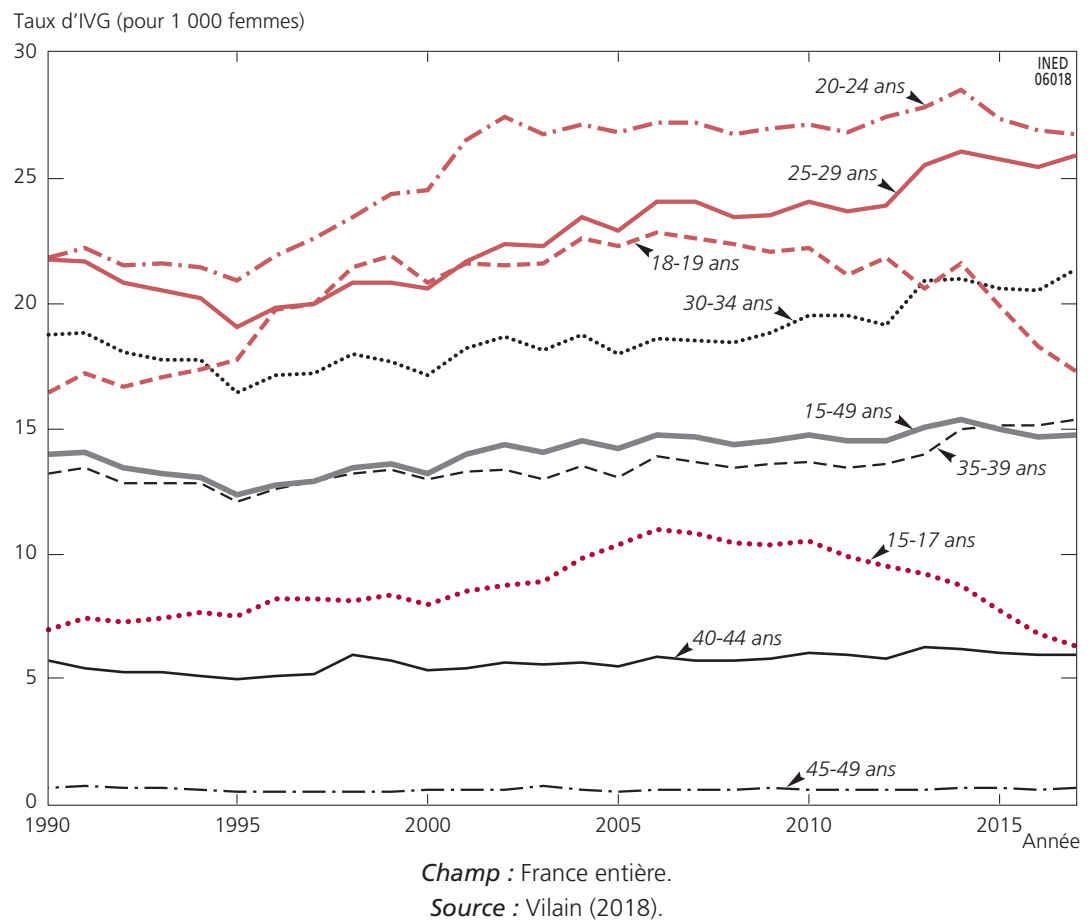


l'année 2018 nous permettront de voir si la baisse du recours à l'IVG chez les jeunes se poursuit. Elle peut correspondre en partie à une baisse des conceptions chez les 20-29 ans, comme en témoigne la baisse de la fécondité à ces âges (voir infra).

\section{La saisonnalité des IVG}

La répartition mensuelle des IVG oscille autour d'une moyenne d'environ $8 \%$ (figure 11). La répartition relative aux IVG pratiquées en établissements hospitaliers est relativement proche de celles réalisées hors établissements hospitaliers ${ }^{(19)}$. Le léger décalage entre les courbes peut s'expliquer par le fait que les IVG hors établissements hospitaliers sont uniquement des IVG médicamenteuses, qui interviennent donc à une durée moyenne de grossesse plus courte.

Figure 11. Répartition mensuelle des IVG selon le type d'établissement en 2017 P. 100

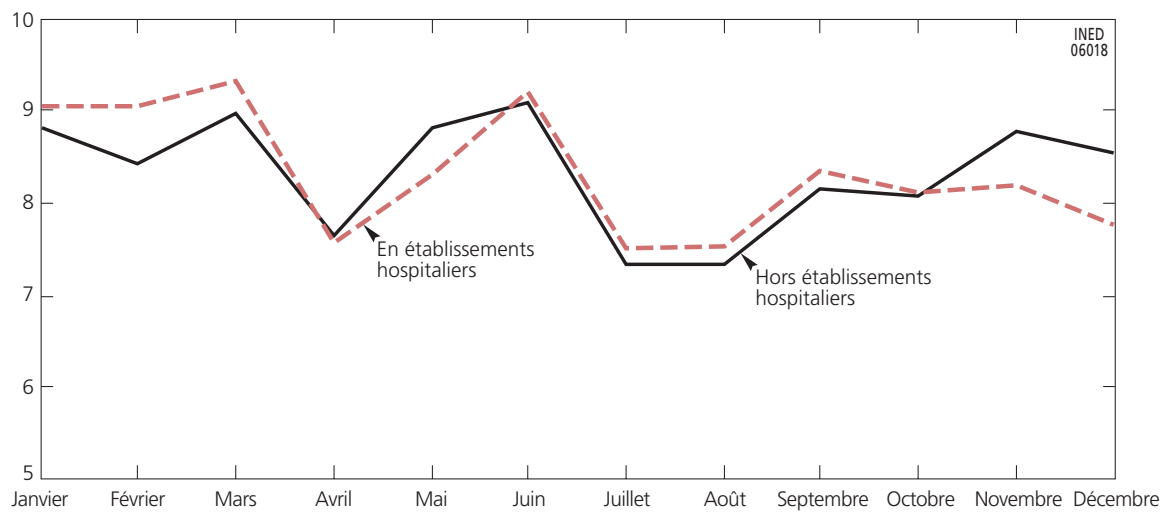

Note : Chaque mois a été ramené à une même base pour neutraliser les variations du nombre de jours dans le mois. Champ : France entière.

Source : Calculs des auteur.e.s à partir des données de la Drees.

Il y a plus d'IVG en début d'année, correspondant à des conceptions de la fin de l'année précédente et au pic de la Saint-Sylvestre (Régnier-Loilier, 2010; Régnier-Loilier et Rohrbasser, 2011). Le mois d'avril, qui est par ailleurs une période de vacances, est marqué par un plus faible recours à l'IVG. La forte remontée du mois de juin peut correspondre à une accélération de la prise en charge avant le début de l'été. L'augmentation observée en septembre peut également être interprétée comme une forme de « rattrapage » qui fait suite aux grossesses des mois de juillet-août non prises en charge du fait de la période

(19) On dispose de deux types de données : d'une part celles collectées via le programme de médicalisation des systèmes d'information (PMSI) pour les IVG réalisées en centres hospitaliers; d'autre part le nombre de remboursements de forfaits (honoraires ou médicaments) pour les IVG médicamenteuses réalisées hors établissement hospitalier, fourni par la Caisse nationale d'assurance maladie des travailleurs salariés (CNAM-TS), à partir des données du régime général depuis 2005, des centres de santé et centres de planification ou d'éducation familiale depuis 2009, par la Mutualité sociale agricole (MSA) et la Sécurité sociale des indépendants depuis 2010 (Vilain, 2018). 
estivale. La difficulté d'accès aux services d'IVG lors de la période estivale fait partie des points soulevés par la commission nationale dans son rapport sur les données relatives à l'IVG (Commission IVG, 2016). La question de l'accès à l'IVG et de la difficulté à trouver des personnels formés et habilités pour assurer un recours dans de bonnes conditions est une problématique récurrente dans la plupart des pays (Guillaume et Rossier, 2018). Cela a été spécifiquement le cas en France, dans le Sud de la Sarthe en 2018, où un centre hospitalier n'a plus été en mesure de pratiquer des IVG pendant 3 trimestres de l'année. Cette situation a mis en évidence les difficultés inhérentes au manque de personnel et le blocage que peut entraîner, au niveau local, la possibilité de faire valoir la clause de conscience des praticiens.

\section{Mariages, pacs, unions libres et divorces}

\section{Les contractualisations d'union}

Une reprise du nombre d'unions contractualisées après la baisse de 2016

En 2017, 427865 unions $^{(20)}$ (193950 pacs ${ }^{(21)}$ et 233915 mariages) ont été enregistrées, soit une augmentation de $3603(+0,8 \%)$, après la diminution de 1001 unités (- 0,24\%) entre 2015 et 2016 (tableau 12, tableau annexe A.9). En 2016, c'était la première fois depuis 2013 , année d'ouverture du mariage aux personnes de même sexe, que le nombre de contractualisations d'unions diminuait.

La tendance à la hausse devrait se poursuivre en 2018 à en croire la dernière estimation du nombre de mariages publiée par l'Insee, soit 229000 entre personnes de sexe différent et 6000 entre personnes de même sexe (Papon et Beaumel, 2019) ${ }^{(22)}$.

Laugmentation du nombre de contractualisations d'unions en 2017 concerne l'ensemble des unions, quelle que soit leur forme et quelle que soit le sexe des conjoints. Ce sont les mariages et les pacs hétérosexuels (+3248) qui augmentent le plus en nombre absolu, mais en termes relatifs, ce sont les unions entre personnes de même sexe $(+2,5 \%)$ (tableau 12). Laugmentation de 2017 contraste avec la baisse « historique » de l'année 2016 caractérisée par la diminution forte des mariages, qu'ils soient hétérosexuels $(-2953 ;-1,3 \%)$ ou entre personnes de même sexe $(-638 ;-8,2 \%)$. Seuls les pacs hétérosexuels et lesbiens

(20) Un certain nombre de mariages sont le fait de personnes déjà pacsées. Le pacs et le mariage se réalisent très rarement la même année, mais ce nombre n'est pas publié. Seule une exploitation spécifique pourrait permettre d'obtenir la part des doubles comptes en ayant la répartition des dissolutions selon le mois et l'année de la signature du pacs.

(21) Pacte civil de solidarité : la loi sur le pacs date du 15 novembre 1999, elle autorise des unions civiles entre personnes de sexe différent ou de même sexe.

(22) Les nombres provisoires de mariages et de pacs ont été publiés par l'Insee pour l'année 2018 mais les fichiers détaillés ne le sont pas encore. La différence entre les estimations et le chiffre définitif est souvent minime, mais en 2017 cet écart a été plus important : 233915 mariages enregistrés contre 228000 estimés (Papon et Beaumel, 2018, 2019). 
Tableau 12. Nombre d'unions officialisées en 2016 et 2017 et évolution entre 2015, 2016 et 2017 selon la nature de l'union et le sexe des conjoint.e.s

\begin{tabular}{|c|c|c|c|c|c|c|c|c|c|}
\hline & \multicolumn{3}{|c|}{ Année 2016} & \multicolumn{6}{|c|}{ Évolution 2015 - 2016} \\
\hline & Mariages & Pacs & Total & Mariages & $\%$ & Pacs & $\%$ & Total & $\%$ \\
\hline $\begin{array}{l}\text { Entre une femme } \\
\text { et un homme }\end{array}$ & 225612 & 184425 & 410037 & -2953 & $-1,3$ & 2495 & 1,4 & -458 & $-0,1$ \\
\hline $\begin{array}{l}\text { Entre personnes } \\
\text { de même sexe }\end{array}$ & 7113 & 7112 & 14225 & -638 & $-8,2$ & 95 & 1,4 & -543 & $-3,7$ \\
\hline Masculin & 3672 & 3862 & 7534 & -413 & $-10,1$ & -70 & $-1,8$ & -483 & $-6,0$ \\
\hline Féminin & 3441 & 3250 & 6691 & -225 & $-6,1$ & 165 & 5,3 & -60 & $-0,9$ \\
\hline \multirow[t]{3}{*}{ Total } & 232725 & 191537 & 424262 & -3591 & $-1,5$ & 2590 & 1,4 & -1001 & $-0,2$ \\
\hline & \multicolumn{3}{|c|}{ Année 2017} & \multicolumn{6}{|c|}{ Évolution 2016 - 2017} \\
\hline & Mariages & Pacs & Total & Mariages & $\%$ & Pacs & $\%$ & Total & $\%$ \\
\hline $\begin{array}{l}\text { Entre une femme } \\
\text { et un homme }\end{array}$ & 226671 & 186614 & 413285 & 1059 & 0,5 & 2189 & 1,2 & 3248 & 0,8 \\
\hline $\begin{array}{l}\text { Entre personnes } \\
\text { de même sexe }\end{array}$ & 7244 & 7336 & 14580 & 131 & 1,8 & 224 & 3,1 & 355 & 2,5 \\
\hline Masculin & $/ /$ & 4084 & $/ /$ & $/ /$ & $/ /$ & 222 & 5,7 & // & // \\
\hline Féminin & $/ /$ & 3252 & $/ /$ & // & $/ /$ & 2 & 0,1 & // & /1 \\
\hline Total & 233915 & 193950 & 427865 & 1190 & 0,5 & 2413 & 1,3 & 3603 & 0,8 \\
\hline \multicolumn{10}{|c|}{$\begin{array}{l}\text { // : données non publiées au moment de l'écriture de l'article. } \\
\text { Champ : France entière. } \\
\text { Sources: Ministère de la Justice, Insee, état civil. }\end{array}$} \\
\hline
\end{tabular}

avaient augmenté entre 2015 et 2016, mais à des rythmes extrêmement bas : + 1,4\% pour les pacs - taux le plus faible depuis l'année 2011, mais très spécifique à cette année-là du fait du changement de fiscalité (Breton et al., 2017).

En 2017 comme en 2016, le nombre de mariages célébrés continue à être légèrement supérieur au nombre de pacs. Pour 2017, les causes de dissolution de pacs ne sont pas encore publiées, contrairement à l'année 2016. Cette annéelà, le nombre de mariages était encore plus important que le nombre de pacs, même une fois déduites les dissolutions de pacs pour mariage (40670, tableau 13).

Tableau 13. Évolution du nombre de dissolutions de pacs selon le motif, 2012-2016

\begin{tabular}{|c|c|c|c|c|c|c|}
\hline \multirow[b]{2}{*}{ Année } & \multirow[b]{2}{*}{$\begin{array}{l}\text { Nombre total } \\
\text { de dissolutions }\end{array}$} & \multicolumn{5}{|c|}{ Motif de dissolution du pacs } \\
\hline & & $\begin{array}{l}\text { Commun accord } \\
\text { des partenaires }\end{array}$ & $\begin{array}{c}\text { Demande } \\
\text { unilatérale de } \\
\text { l'un des partenaires }\end{array}$ & Mariage $^{(a)}$ & Décès & $\begin{array}{l}\text { Autres cas ou } \\
\text { non renseigné }\end{array}$ \\
\hline 2012 & 61507 & 28532 & 1552 & 30660 & 731 & 32 \\
\hline 2013 & 69540 & 32138 & 1733 & 34870 & 766 & 33 \\
\hline 2014 & 76267 & 34927 & 2062 & 38483 & 724 & 71 \\
\hline 2015 & 79386 & 38295 & 2144 & 38139 & 740 & 68 \\
\hline 2016 & 84662 & 40972 & 2220 & 40670 & 730 & 70 \\
\hline
\end{tabular}

(a) Le mariage peut être celui des deux partenaires pacsés ou de l'un des deux. À défaut de statistiques détaillées, on fait l'hypothèse que les dissolutions de pacs pour cause de mariage ne correspondent pas à une rupture d'union mais au mariage des deux partenaires.

Champ : France entière.

Source : Ministère de la Justice. 
En effet, les mariages ne sont alors que la confirmation d'une union préalablement officialisée par un pacs. Mais, très probablement, la hiérarchie s'est inversée (figure 12). La tendance à la hausse du nombre de dissolutions de pacs par mariage montre que des trajectoires d'officialisation d'union se mettent en place petit à petit, initiées de plus en plus souvent par un pacs, et suivies parfois d'un mariage ${ }^{(23)}$.

Figure 12. Évolution du nombre de pacs et de mariages, 2003-2016

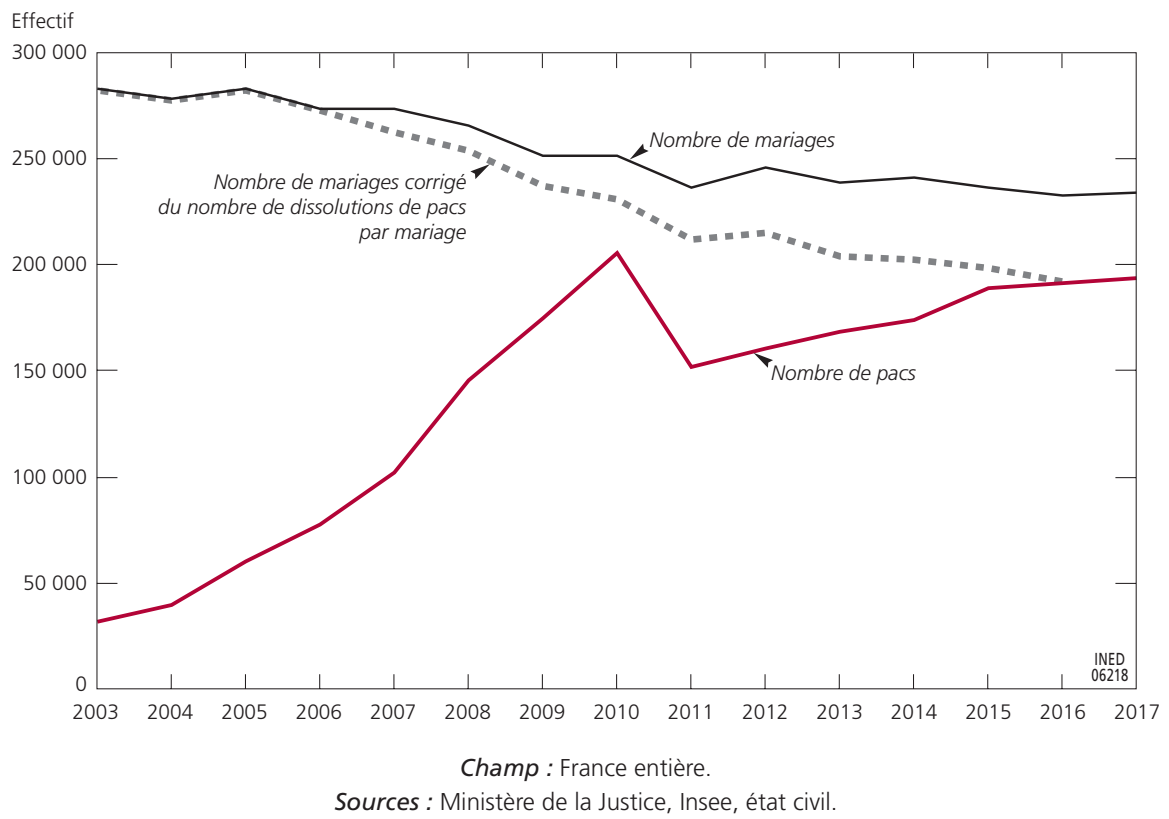

\section{6 et 2017, années avec les plus faibles proportions de contractualisation d'unions entre personnes de même sexe}

Les unions entre personnes de même sexe totalisent un peu plus de $3 \%$ de l'ensemble des contractualisations d'union (3,3\% en 2016 et 3,4\% en 2017); $3,1 \%$ des mariages et 3,8 \% des pacs. La baisse des contractualisations est avant tout liée au nombre de mariages entre partenaires de même sexe qui a très fortement diminué en 2016, et n'a été compensée ni par la faible augmentation des mariages ni celle des pacs entre personnes de même sexe.

Le nombre de pacs entre personnes de même sexe continue à augmenter et dépasse en 2017 celui du nombre de mariages (qu'ils soient ou non précédés d'un pacs) (figure 13). La trajectoire d'union s'ouvrant par un pacs et suivie d'un mariage, semble plus répandue parmi ces couples. En 2016, près d'un tiers des mariages entre personnes de même sexe $(35,5 \%)$ sont le prolongement

(23) Malheureusement le nombre de dissolutions de pacs pour mariage ne sont pas publiées par durée de pacs, information nécessaire pour calculer la proportion de pacs se terminant par un mariage au sein d'une cohorte annuelle de pacs. 
d'un pacs. Cette proportion ne cesse de diminuer depuis 2013 (50,0\%), date de l'ouverture du mariage aux couples de même sexe.

Figure 13. Évolution du nombre de pacs et de mariages entre personnes de même sexe, 2013-2017

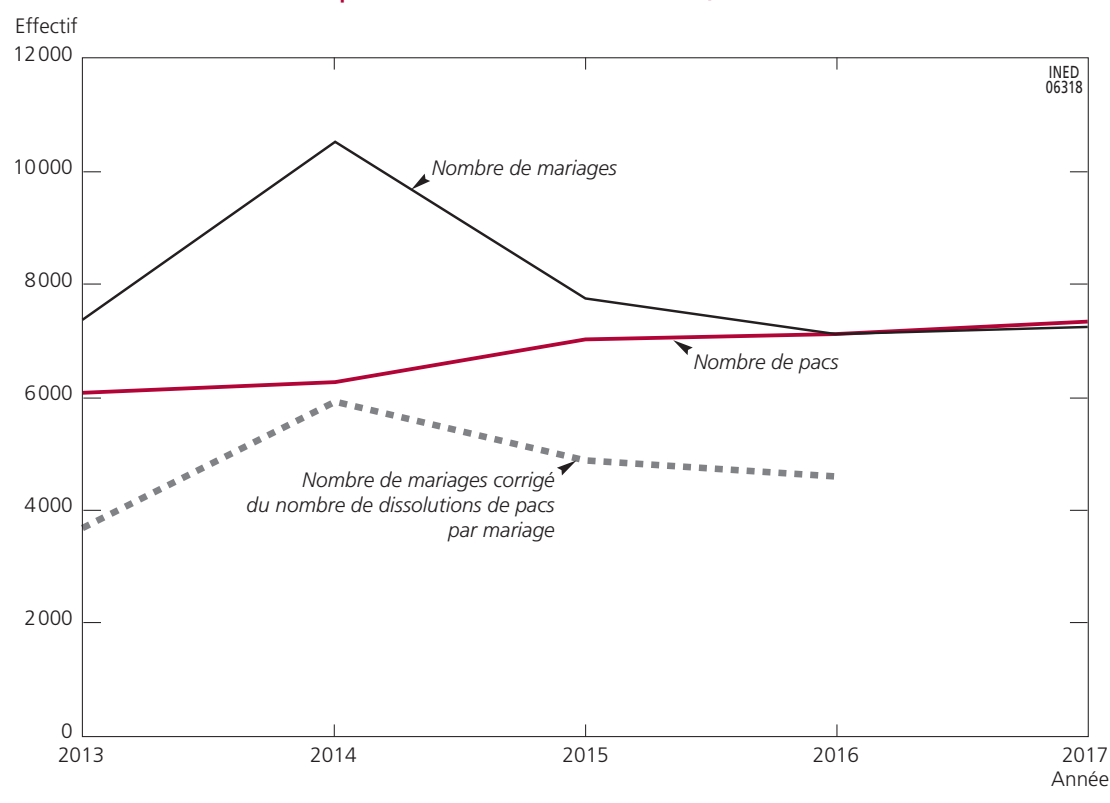

Champ : France entière.

Sources : Ministère de la Justice, Insee, état civil.

Des pacs plus précoces que les mariages, notamment pour les couples de même sexe

Pour les unions célébrées en $2016^{(24)}$, les répartitions par sexe et âge des pacs et des mariages hétérosexuels d'une part, et entre personne de même sexe d'autre part, présentent de fortes similitudes. C'est le cas pour les âges modaux (entre 25 et 29 ans) - bien qu'un peu plus fréquents pour les pacs hétérosexuels - comme pour leur distribution par sexe, bien qu'on observe une dissymétrie au-delà de 45 ans, en particulier pour les unions de sexe différent (figure 14). Dans les deux sous-populations, les pacs sont plus précoces et leur nombre est équivalent ou supérieur à celui des mariages avant 30 ans - même 35 ans dans le cas de pacs entre deux hommes.

Les différences entre types de couples sont plus nettes du point de vue des événements réduits ${ }^{(25)}$ (nombre moyen de mariages et de pacs par individu

(24) Les données des fichiers détaillés du recensement de 2017 ne seront publiées qu'au courant du premier semestre 2019. L'analyse par sexe et par âge porte donc sur l'année 2016.

(25) Pour calculer les événements réduits, le dénominateur est composé de l'ensemble des individus, quel que soit leur statut matrimonial. Les dénominateurs des mariages et des pacs réduits d'un âge donné sont donc identiques. 
Figure 14. Répartition (\%) par sexe et âge des mariages et des pacs des unions hétérosexuelles et de personnes de même sexe, 2016

A. Unions hétérosexuelles

B. Union de personnes de même sexe
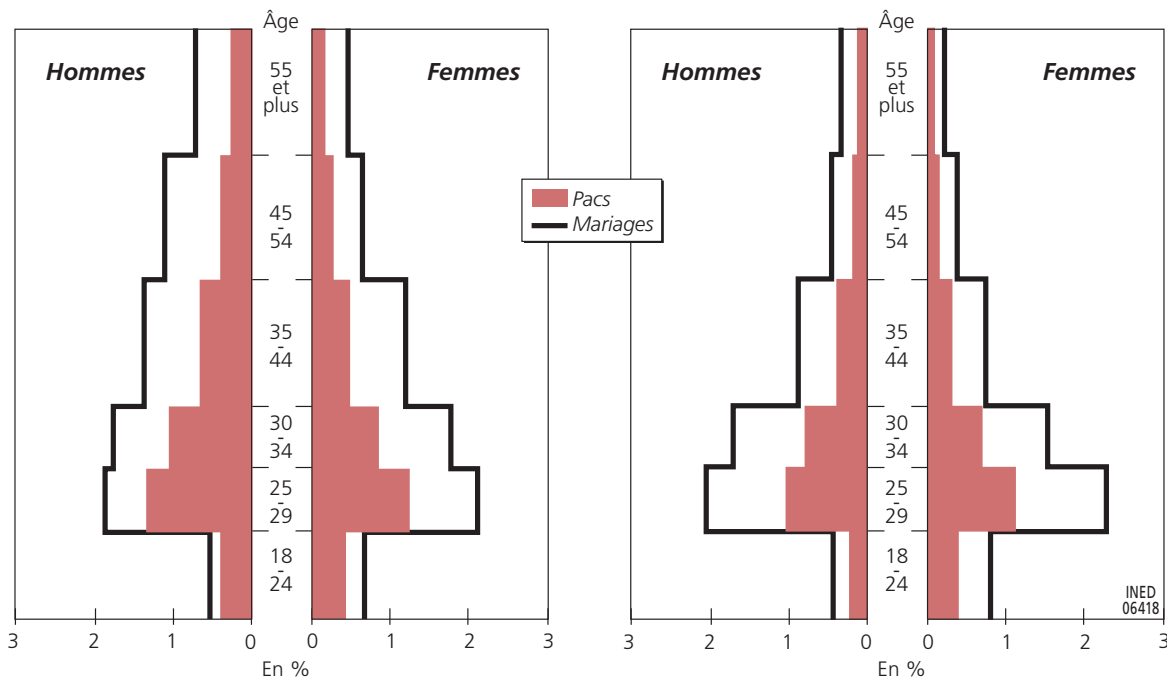

Champ : France entière.

Sources: Ministère de la Justice, Insee, état civil, calculs des auteur.e.s.

d'une classe d'âges donnée) (figure 15). Pour les unions hétérosexuelles, les courbes sont presque confondues, même si le nombre moyen de mariages est plus important au-delà de 30 ans, ce qui correspond en partie à des mariages de personnes préalablement pacsées (figure 15.A). Pour les couples de même sexe, le contraste entre les courbes par âge de pacs et de mariage est plus marqué, les pacs étant plus précoces (figure 15.B). Toutefois, les différences entre

Figure 15. Pacs et mariages réduits par sexe et âge, en 2016

A. Unions hétérosexuelles

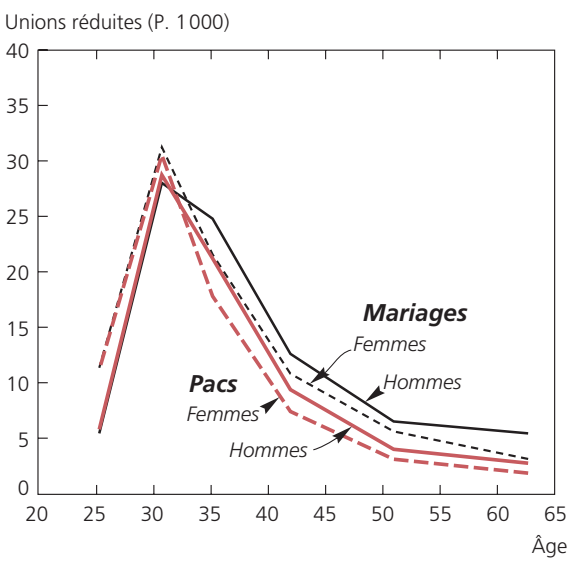

B. Union de personnes de même sexe

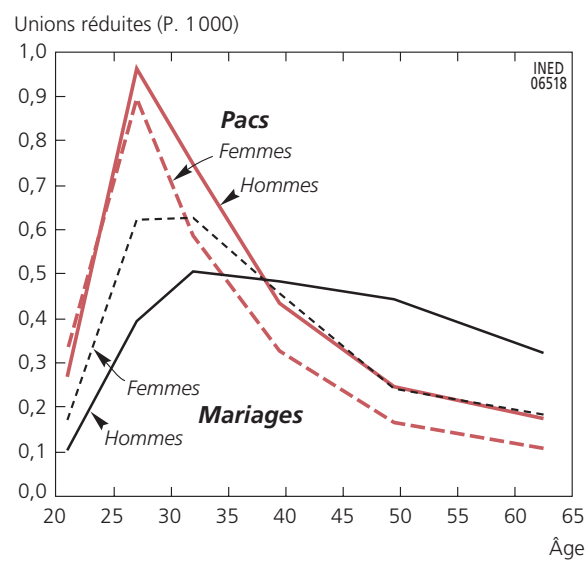

Champ : France entière.

Sources: Ministère de la Justice, Insee, état civil. 
les deux types de couples s'atténuent, notamment à partir de l'année 2013, année d'ouverture du mariage aux couples de même sexe (Mazuy et al., 2016). Les mariages plus tardifs entre personnes de même sexe sont difficiles à expliquer. Elles pourraient être le reflet d'une plus grande difficulté sociale à faire accepter une union, ou bien une pratique différente, prolongeant, par choix, la période d'union libre ou ayant une trajectoire d'union plus spécifique. Une autre explication serait liée à une structure sociale différente des couples de même sexe, avec un poids plus important de personnes diplômées ou urbaines, deux caractéristiques associées à un calendrier de mise en couple plus tardif (Bailly et Rault, 2013; Buisson et Laplinte, 2013).

Entre 2014 et 2016, le nombre d'unions pour 1000 personnes (somme des événements réduits) augmente pour les pacs de même sexe ou de sexe différent, et diminue pour les mariages (à l'exception des hommes qui se marient avec des femmes). Par ailleurs, l'âge à la contractualisation augmente. La seule exception est celle des mariages entre personnes de même sexe dont l'âge moyen des conjoints diminue (de 40,8 ans à 40,1 ans pour les unions masculines, de 36,9 ans à 35,6 ans pour les unions féminines) (tableau 14).

Tableau 14. Nombre d'unions pour 1000 personnes

(somme des évènements réduits) et âge moyen à l'union en 2014 et 2016

\begin{tabular}{|l|c|c|c|c|c|c|c|c|}
\hline \multirow{2}{*}{} & \multicolumn{9}{c|}{ Pacs } & \multicolumn{4}{c|}{ Mariages } \\
\cline { 2 - 9 } & \multicolumn{2}{|c|}{ Homme } & \multicolumn{2}{c|}{ Femme } & \multicolumn{2}{c|}{ Homme } & \multicolumn{2}{c|}{ Femme } \\
\cline { 2 - 9 } & $\begin{array}{l}\text { Avec un } \\
\text { homme }\end{array}$ & $\begin{array}{c}\text { Avec une } \\
\text { femme }\end{array}$ & $\begin{array}{c}\text { Avec une } \\
\text { femme }\end{array}$ & $\begin{array}{c}\text { Avec un } \\
\text { homme }\end{array}$ & $\begin{array}{c}\text { Avec un } \\
\text { homme }\end{array}$ & $\begin{array}{c}\text { Avec une } \\
\text { femme }\end{array}$ & $\begin{array}{c}\text { Avec une } \\
\text { femme }\end{array}$ & $\begin{array}{c}\text { Avec un } \\
\text { homme }\end{array}$ \\
\hline \multicolumn{8}{|c|}{2014} \\
\hline $\begin{array}{l}\text { Somme des } \\
\text { événements réduits } \\
\text { Âge moyen }\end{array}$ & 16 & 398 & 13 & 405 & 23 & 529 & 21 & 545 \\
\hline \hline & 32,9 & 31,3 & 32,0 & 29,8 & 40,8 & 33,5 & 36,9 & 31,8 \\
\hline $\begin{array}{l}\text { Somme des } \\
\text { événements réduits } \\
\text { Âge moyen }\end{array}$ & 19 & 457 & 16 & 450 & 18 & 555 & 16 & 544 \\
\hline
\end{tabular}

Champ : France entière.

Sources : Ministère de la Justice, Insee, état civil, calculs des auteur.e.s.

\section{Les unions libres}

La diminution historique du nombre de mariages depuis le milieu des années 1970 ne reflète pas une diminution de la propension à vivre en couple, mais bien une désinstitutionnalisation des unions. En l'absence d'un enregistrement continu des mises en union (contrairement aux pacs et aux mariages), il est difficile de connaître le nombre d'unions libres débutées chaque année. Une estimation est toutefois possible en exploitant des données spécifiques comme celles de l'échantillon démographique permanent (EDP) : le nombre annuel d'unions libres est bien plus important que le nombre annuel de mariages 
ou de pacs. Ainsi, 546000 nouvelles unions libres se seraient formées annuellement entre 2011 et 2014, soit plus du double du nombre de mariages sur la même période et trois fois plus que le nombre de pacs (Costemalle, 2017).

Lanalyse des données du recensement confirme le maintien de la forte propension à vivre en couple, mais la moindre formalisation des unions : les proportions de femmes et d'hommes vivant en couple au moment du recensement - quel que soit le type d'union -ne baissent quasiment pas entre 2006 et 2015, contrairement à celles des mariés (figure 16). Une partie des personnes vivant en couple sans être mariés sont probablement pacsées. La question relative au pacs n'a en effet été introduite dans les bulletins individuels du recensement qu'en 2015 (Buisson, 2017). Il faudra donc attendre fin 2019 pour disposer des données de 5 vagues d'enquêtes annuelles de recensement et exploiter cette information.

Figure 16. Proportion (\%) de personnes en couple et de personnes mariées au moment du recensement, par sexe et groupe d'âges, en 2006 et 2015

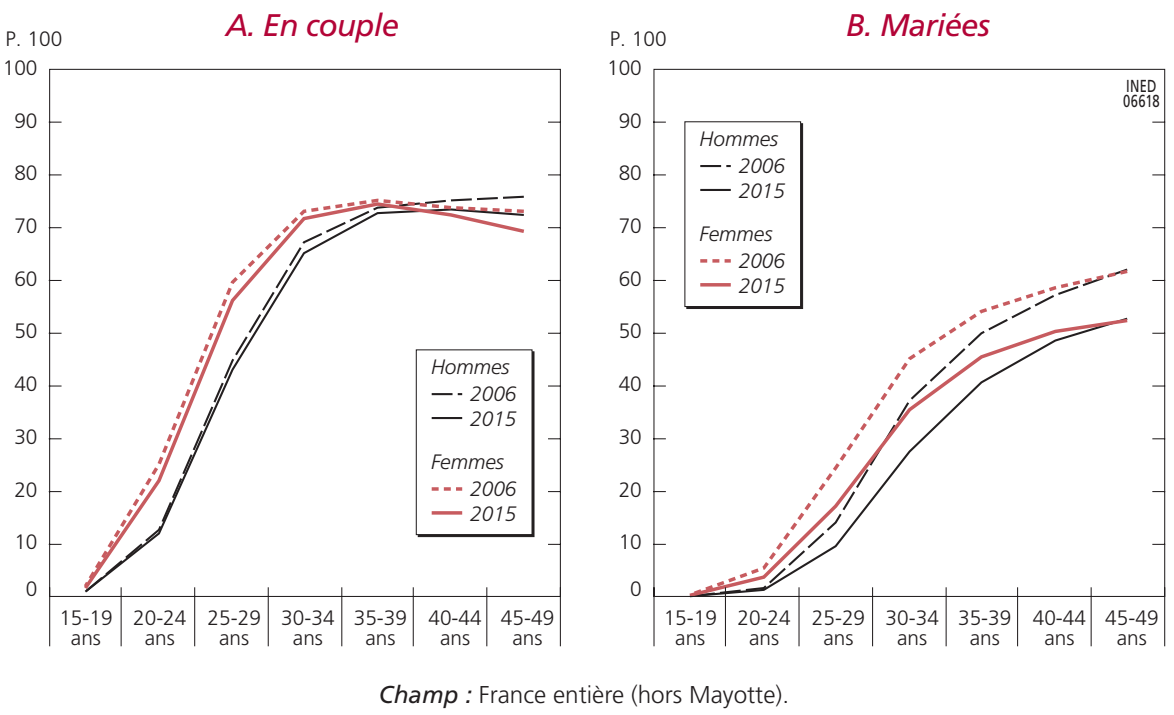

Source : Insee recensements, exploitation principale, calculs des auteur.e.s.

\section{Les premiers mariages:}

\section{une baisse au fur et à mesure des générations}

Les quotients de primo-nuptialité, c'est-à-dire le risque de se marier à un âge donné pour une personne célibataire, sont quasiment inchangés entre 2015 et 2016, et les légers pics observés aux âges de 40 ans et 50 ans se maintiennent (Breton et al., 2017). Une génération qui tout au long de sa vie se comporterait comme les célibataires de l'année 2015 atteindrait un niveau historiquement bas de premiers mariages (tableau annexe A.9).

Lorsqu'on analyse les caractéristiques de la nuptialité par génération, la proportion d'hommes et de femmes s'étant mariés au moins une fois continue 
de baisser, quel que soit l'âge (tableau annexe A.10; Rault et Régnier-Loilier, 2015) et devrait atteindre, à l'issue de leur vie, le seuil de 0,5 mariage par homme pour la génération 1990 et 0,6 mariage par femme des mêmes générations.

\section{Saisonnalité des unions}

\section{Les mariages plus concentrés durant l'été, les pacs en fin d'année}

À l'occasion des 70 ans de la revue Population, deux chercheurs de l'Ined ont repris et actualisé les travaux de Jean Bourgeois-Pichat publiés en 1946 sur la saisonnalité des mariages (Bourgeois-Pichat, 1946; Rault et RégnierLoilier, 2016). Ils rappellent l'intérêt sociologique de l'étude de l'évolution de la saisonnalité des mariages, véritable révélateur de l'importance des valeurs et des contraintes qui régissent les sociétés, mais aussi leur perte d'influence au cours du temps. La religion et les rythmes des récoltes ont longtemps dicté la répartition mensuelle des mariages, alors qu'aujourd'hui ce sont plutôt des préoccupations d'agrément : la réussite d'un mariage sera avant tout mesurée à l'aune du nombre d'invités et de la qualité de la fête, dépendant en partie d'une météo clémente. Les conjoints choisissent la date de cet événement en essayant de le singulariser, par exemple en choisissant une date symbolique, ou en facilitant la venue des invités en choisissant des jours fériés. Pour ce qui est de leur répartition journalière, les mariages sont, à quelques exceptions près, très concentrés le samedi ${ }^{(26)}$.

Pour ces différentes raisons, les mariages sont aujourd'hui principalement concentrés le printemps et l'été (figure 17) et la répartition entre les mois concernés dépend partiellement du nombre de samedis dans chacun de ces mois. C'est le cas des années 2010 et 2011 ( 5 samedis en juillet contre seulement 4 en juin et en août), ou en 2012, 2013 et 2016 (5 samedis en juin et seulement 4 en mai et juillet). En 2012 par exemple, le pic de septembre est probablement lié aux 5 samedis de ce mois faisant suite aux « tristes » mois de juillet et août qui n'en comptaient que 4 cette année-là. L'année 2015 présente une forme un peu particulière, probablement pour au moins deux raisons : le nombre de samedis en mai (5) doublé d'un nombre légèrement plus important de mariages en février (année « exceptionnelle » puisque la Saint-Valentin tombait cette année-là un samedi). En 2014, il y avait également 5 samedis en mai contre 4 en juin, mais, événement relativement rare, la Pentecôte et son long week-end tombait en juin, comme en 2017 d'ailleurs.

La répartition mensuelle des mariages dessine un deuxième pic en décembre, bien moins important que celui du milieu d'année. La raison, qui concerne de façon plus marquée les pacs, tient à la fin de l'exercice fiscal. La suppression

(26) Les exceptions sont celles relatées par Rault et Régnier-Loilier concernant le 12/12/2012, le jour de la Saint-Valentin (Rault et Régnier-Loilier, 2016) ou d'autres raisons culturelles, comme par exemple à La Réunion (Dumas-Champion, 2008) où 50,1 \% des mariages en 2016 ont été célébrés un vendredi, contre $9,4 \%$ à l'échelle nationale. 
Figure 17. Répartition mensuelle des mariages et des pacs de 2010 à 2016

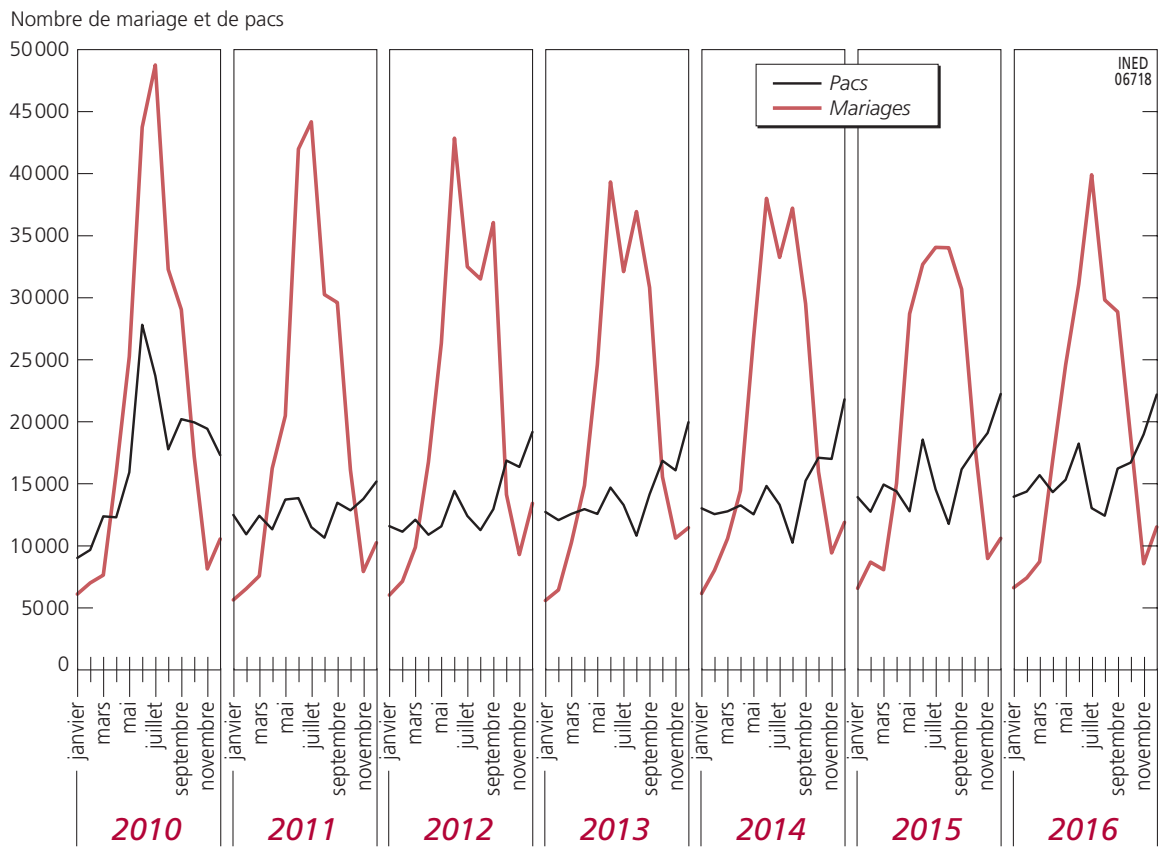

Source : Insee, état civil.

en 2011 de l'avantage fiscal du mariage et du pacs en milieu d'année n'a eu d'effet que sur la répartition mensuelle des pacs, qui ne donnent pas lieu aux mêmes célébrations que les mariages (Mazuy et al., 2016). Le pic des mariages en décembre est certainement dû aussi à la possibilité de fêter cet événement en famille, durant les vacances de fin d'année. Il faut également souligner la particularité des départements d'outre-mer : alors qu'au niveau national en 2016, 4,9 \% des mariages ont eu lieu en décembre, la proportion est de 20,3\% dans ces départements (24,7 \% en Martinique, 22,1 \% en Guadeloupe, 19,8 \% à La Réunion où décembre correspond à l'été, 14,6 \% en Guyane et 14,1 \% à Mayotte). En métropole, la proportion ne dépasse jamais 7,2 \% (à Paris et dans le département de Saint-Saint-Denis).

La saisonnalité des mariages est d'autant plus forte que les époux ont un profil proche de la «norme », au sens statistique, c'est-à-dire le cas le plus souvent observé et que l'on pourrait décrire de la manière suivante : deux conjoints de sexe différent, âgés de 25 à 34 ans (homme plus âgé ou du même âge que la femme), de nationalité française et célibataires l'un et l'autre au moment de se marier. Pour ces couples, près de 60 \% des mariages sont enregistrés entre mai et août (figure 18), soit dix points de plus que pour les couples de même sexe et douze points de plus lorsque les deux partenaires sont divorcés (48,5\%). Les couples dont l'un ou les deux conjoints sont de nationalité étrangère sont ceux pour lesquels la saisonnalité du mariage est la moins marquée. 
Figure 18. Répartition mensuelle des mariages (\%) en France selon différents profils des époux en 2016

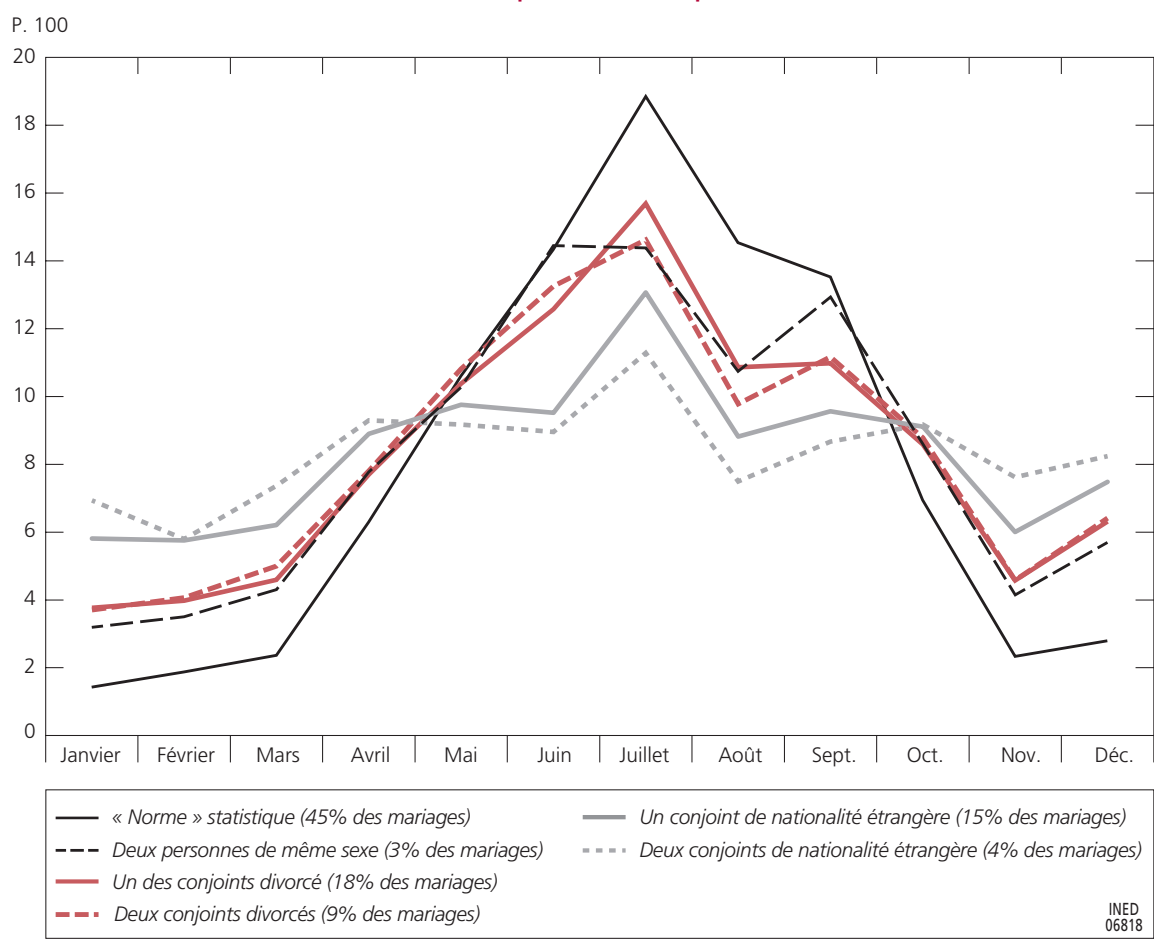

Champ : France métropolitaine.

Sources : Insee, état civil, calculs des auteur.e.s.

Toutefois, dans ce cas, il est possible que les priorités liées au mariage soient spécifiques et associées à des projets de vie différents ou des contraintes administratives.

\section{La cohabitation commence généralement en septembre}

Une période d'union libre, le plus souvent cohabitante, ouvre généralement la trajectoire d'union, éventuellement suivie d'un pacs ou/puis d'un mariage. Comme le confirment les données de l'enquête Étude des parcours individuels et conjugaux (Épic), les mariages directs ont quasiment disparu (Rault et Régnier-Loilier, 2015). La mise en couple cohabitant suit une saisonnalité propre, différente de celles des mariages et des pacs. Le mois de septembre semble celui « préféré » pour débuter une cohabitation, suivi de janvier et juin (figure 19). Cette saisonnalité confirme celle observée à partir de l'enquête Étude de l'histoire familiale de 1999 (EHF) (Breton, 2006). Elle traduit avant tout la dimension pratique des mises en couple cohabitant au moment des rentrées scolaires et universitaires, notamment dans un contexte d'allongement et de massification des études supérieures. 
Figure 19. Évolution (\%) de la répartition mensuelle

des débuts d'unions cohabitantes entre 1984 et 2013

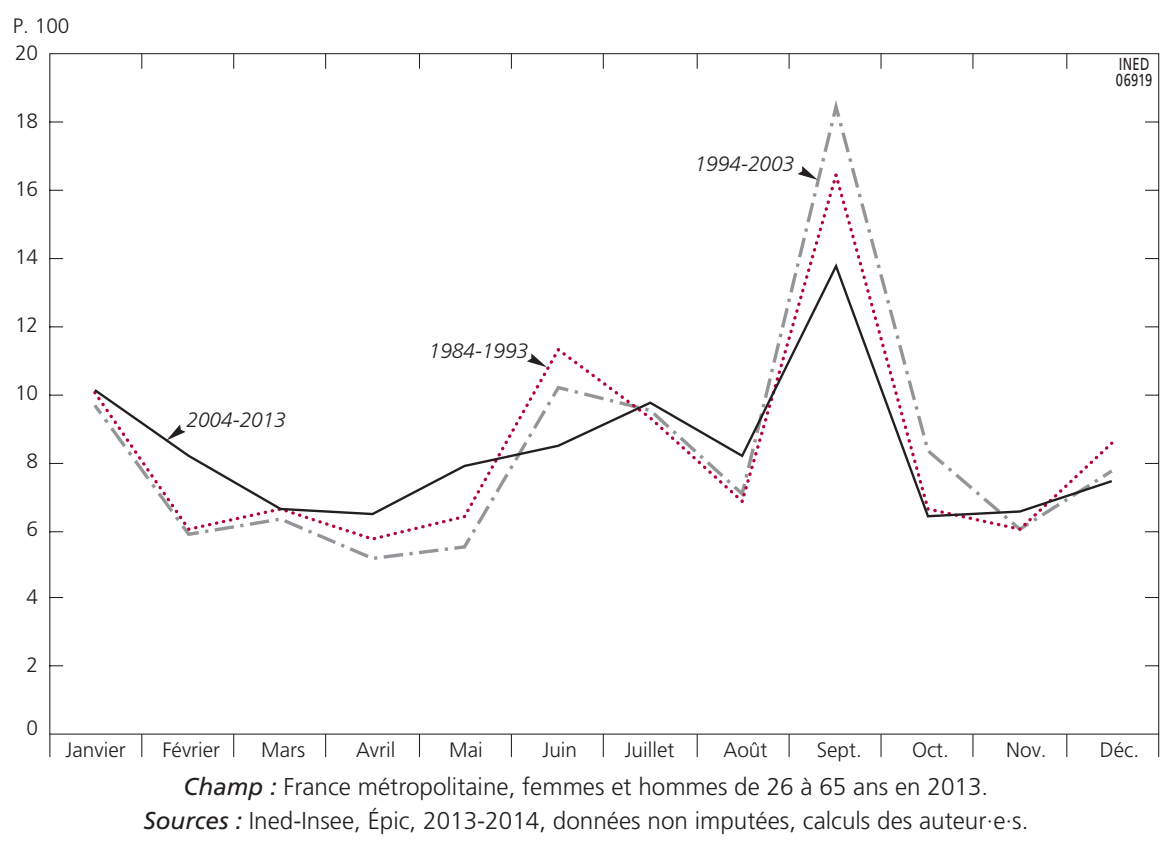

\section{Une nouvelle augmentation de la divortialité}

L'année 2016 est marquée par une augmentation des indicateurs de divortialité, que cela soit en nombre absolu (+ 4375) ou pour les indicateurs synthétiques contrôlant en partie les effets de taille, comme le taux brut de divorces (qui passe de 1,86 divorce pour 1000 habitants à 1,92) ou l'indice conjoncturel de divortialité (+ 4,5\%). Cette augmentation met fin à trois années de baisse consécutive de 2012 à 2014 (tableau annexe A.9). Elle est presque totalement due à l'augmentation du nombre de divorces par consentement mutuel. Comme souvent dans les variations de la divortialité, on peut y voir un lien avec des changements législatifs assouplissant les procédures. En l'occurrence, celui de 2016 donne davantage de pouvoir au juge, qui peut désormais liquider le régime matrimonial des époux en même temps qu'il prononce leur divorce ${ }^{(27)}$ (art. 267 du Code civil - février 2016). L'entrée en vigueur le $1^{\mathrm{er}}$ janvier 2017 d'une nouvelle modalité de divorce (divorce sans juge) produira probablement un effet similaire.

Les risques de divorce sont toujours maximum 5 ans après le mariage en 2016, et augmentent en 2016 quelle que soit la durée de mariage (figure 20).

(27) La liquidation du régime matrimonial est une procédure qui vise à lister et évaluer les biens et les dettes qui reviendront à chacun des époux en cas de divorce. Cette procédure se faisait devant notaire, sauf en cas d'absence de biens immobiliers, et peut désormais avoir lieu devant le juge. 
Figure 20. Quotients de divorces (\%) selon la durée de mariage, de 2013 à 2016

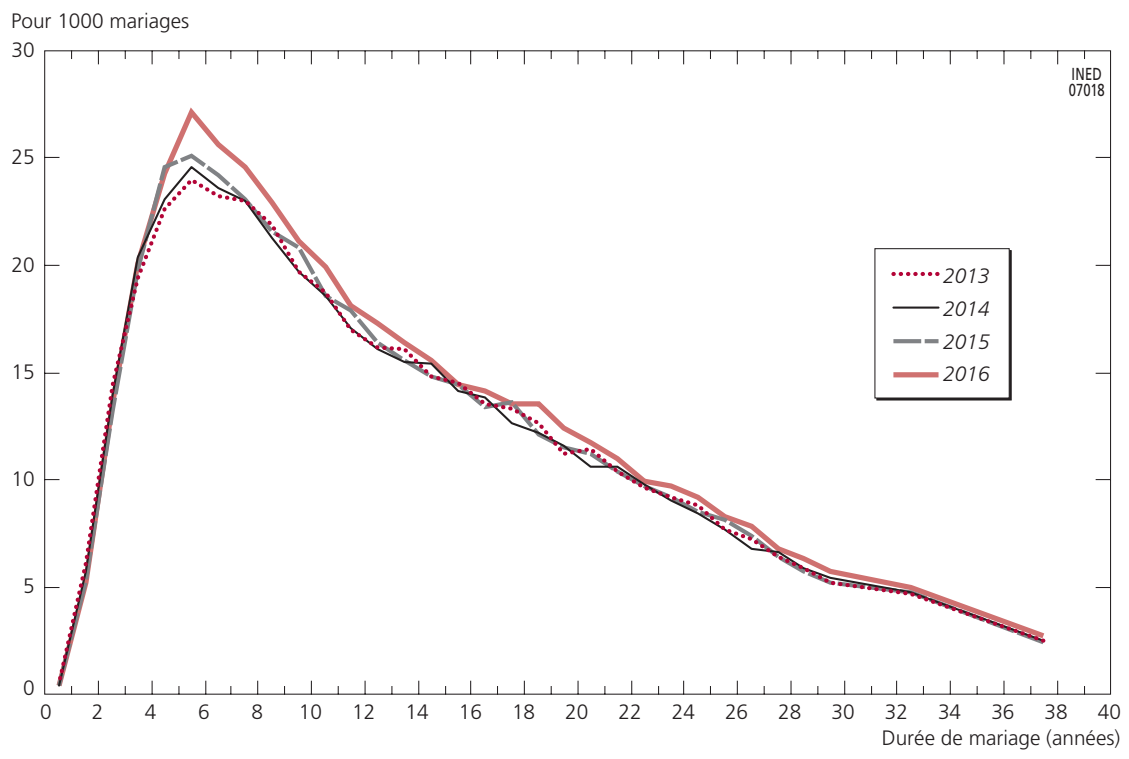

Champ: France entière hors Mayotte.

Source: Insee, calculs des auteur.e.s.

L'augmentation des divorces concerne de plus en plus les couples ayant des enfants mineurs. En 2016, les 128043 divorces ont concerné 169830 enfants dont 115945 mineurs, soit des augmentations respectives de 3,5\%, 3,0 \% et 3,95\% par rapport à l'année 2015 (ministère de la Justice).

\section{La mortalité}

\section{Les caractéristiques de la mortalité}

\section{L'espérance de vie reprend sa progression}

Selon les derniers chiffres (provisoires) de l'Insee, le nombre de décès survenus en France (France métropolitaine et DOM) au cours de l'année 2017 aurait atteint le niveau record de 606000, dont 594000 en métropole et 12000 dans les départements d'outre-mer. Laugmentation du nombre de décès est liée exclusivement au vieillissement démographique, qui se traduit par un accroissement du nombre de personnes âgées et donc soumises à des taux de mortalité élevés au sein de la population générale, ainsi qu'à l'arrivée aux âges de forte mortalité des générations nombreuses de l'après-guerre, et non à une baisse des progrès dans la durée de vie. En effet, après le pic de mortalité de 2015, lorsque l'espérance de vie à la naissance avait régressé du fait des conditions épidémiologiques particulières qui ont prévalu cette année-là (épidémie de grippe intense et inhabituellement concentrée sur les premiers mois de 
l'année plutôt qu'étalée sur tous les mois de l'hiver 2014-2015), les gains en durée de vie ont à nouveau été positifs en 2016. En 2017, l'espérance de vie à la naissance est estimée à 79,4 ans pour les hommes et à 85,2 ans pour les femmes pour l'ensemble du pays (79,4 ans et 85,3 ans en France métropolitaine), correspondant à un taux brut de mortalité de 9,1 pour 1000 habitants (tableaux annexes A.1 et A.11).

\section{La France dans la moyenne des pays européens}

En 2016, année la plus récente pour laquelle nous disposons de données comparatives, la France reste dans la moyenne des pays européens pour l'espérance de vie à la naissance (tableau annexe A.12), sans changement notable par rapport aux années précédentes. La position relativement mauvaise du pays en matière de mortalité infantile (proche de la médiane et derrière seize pays à la mortalité infantile plus faible - tableau annexe A.13) est compensée par un classement très avantageux en ce qui concerne la mortalité à 65 ans et plus.

Le pays continue d'occuper une position globalement très favorable au sommet du classement féminin, malgré une érosion progressive. Alors que les Françaises jouissaient de la plus longue durée de vie au monde dans les années 1990, elles ont lentement perdu cet avantage au profit du Japon d'abord, puis d'autres pays européens. Dans les conditions de mortalité de 2016, les Japonaises peuvent espérer vivre 87,2 ans contre 85,3 ans pour les Françaises, qui sont également devancées pour les Espagnoles (86,3 ans), les Italiennes (85,6 ans), les Suisses (85,6 ans) et les Luxembourgeoises (85,4 ans).

La situation française est depuis longtemps beaucoup moins favorable pour les hommes (79,3 ans d'espérance de vie à la naissance en 2016 pour l'ensemble du pays) dont la durée de vie se situe à un niveau proche de la moyenne européenne. Aux côtés de l'Autriche, la France est devancée par plusieurs pays d'Europe de l'Ouest (Suisse, Islande, Luxembourg, Pays-Bas, Irlande et RoyaumeUni), d'Europe du Nord (Norvège, Suède, Islande) et d'Europe du Sud (Italie et Espagne). En revanche, tous les pays d'Europe de l'Est et quelques pays relativement favorisés sur le plan économique, comme la Belgique ou l'Allemagne, ont des espérances de vie masculines inférieures à celle de la France.

\section{Une évolution de la mortalité variable selon l'âge et le sexe}

La figure $21^{(28)}$ illustre les changements de la mortalité selon le sexe au cours de la vie, en présentant le rapport des quotients de mortalité par âge de 2004-2006 à ceux de 2014-2016. Les progrès ont concerné, tant chez les hommes que chez les femmes, tous les âges sauf les plus élevés. Ils ont toutefois été moindres chez les très jeunes enfants, autour de 65 ans et après 95 ans. À l'inverse, ils ont été particulièrement importants autour de 20 ans, avec un quotient de mortalité à 18 ans en 2014-2016 inférieur de $40 \%$ par rapport à

(28) Comme pour le reste des résultats présentés ensuite, cette figure est produite à partir des données des tables triennales de l'Insee qui se rapportent exclusivement à la France métropolitaine. 
Figure 21. Évolution de la mortalité à chaque âge de 2004-2006 à 2014-2016 (rapport des quotients par âge lissés sur 3 âges, sauf à 0 an)

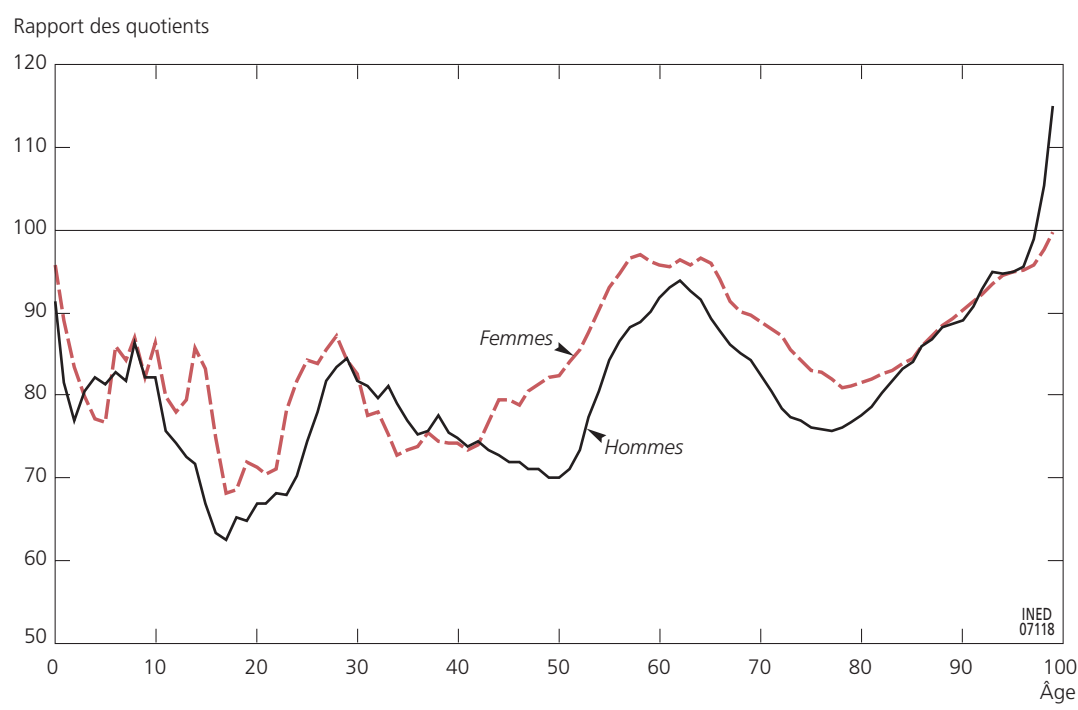

Champ : France métropolitaine.

Source : Insee, tables de mortalité 2004-2006 et 2014-2016.

2004-2006 pour les hommes et de $35 \%$ pour les femmes. Ils ont également été plus marqués autour de 40 ans (baisse d'environ $25 \%$ au cours de cette période) pour les deux sexes. Après cet âge et jusqu'à 50 ans, les progrès ont été plus visibles pour les hommes (baisse de $30 \%$ ). Les progrès ont également été importants à 75-85 ans (quotient inférieur d'environ $25 \%$ pour les hommes et de $20 \%$ pour les femmes en 2014-2016 par comparaison à 2004-2006).

Par ailleurs, les progrès ont été plus avantageux pour les hommes que pour les femmes, d'une manière générale, entre 2004-2006 et 2014-2016. La figure 22 présente les rapports des quotients masculins aux quotients féminins par année d'âge en 2004-2006 et en 2014-2016. Elle indique d'abord que la mortalité masculine reste supérieure à la mortalité féminine à tous les âges. La surmortalité masculine est particulièrement forte chez les jeunes de 20 à 35 ans, avec des risques de mortalité des hommes trois fois supérieurs à ceux des femmes, notamment autour de 25 ans. Elle est également plus importante chez les adultes de 50 à 70 ans, pour lesquels les quotients masculins représentent le double des quotients féminins. Ces deux pics de surmortalité se sont toutefois émoussés au cours de la dernière décennie du fait de la baisse de la mortalité plus faible chez les femmes que chez les hommes, particulièrement à ces âges. Lévolution récente s'inscrit dans une tendance de long terme dans la mesure où l'écart d'espérances de vie entre les sexes, qui avait atteint un maximum de 8,3 ans en 1992, a diminué progressivement pour atteindre 5,9 ans en 2017 selon les chiffres provisoires de l'Insee. 
Figure 22. Surmortalité masculine à chaque âge en 2004-2006 et 2014-2016 (rapport des quotients masculins aux quotients féminins lissés sur 3 âges, sauf à 0 an)

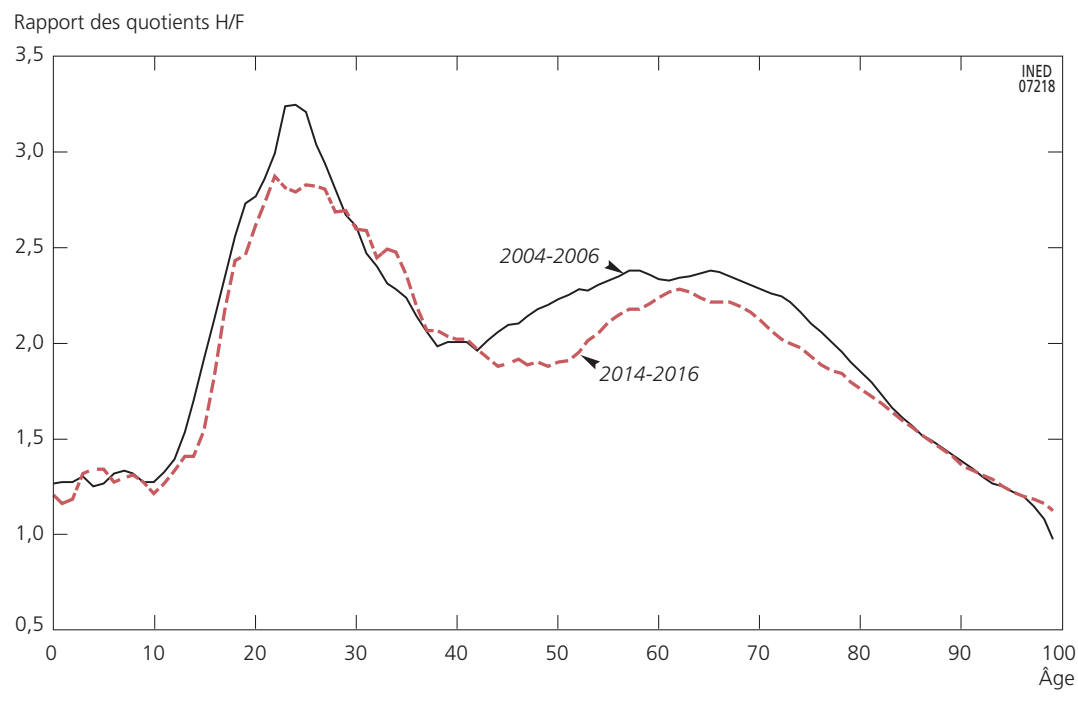

Champ : France métropolitaine.

Source: Insee, tables de mortalité 2004-2006 et 2014-2016.

Tableau 15. Contribution (\%) des groupes d'âges aux gains d'espérance de vie, gain total au cours de chaque décennie et espérance de vie en fin de période,

par sexe

\begin{tabular}{|c|c|c|c|c|c|c|}
\hline \multirow{2}{*}{$\begin{array}{l}\text { Groupe } \\
\text { d'âges }\end{array}$} & \multicolumn{3}{|c|}{ Hommes } & \multicolumn{3}{|c|}{ Femmes } \\
\hline & $\begin{array}{l}\text { De } 1984-1986 \\
\text { à } 1994-1996\end{array}$ & $\begin{array}{l}\text { De 1994-1996 } \\
\text { à 2004-2006 }\end{array}$ & $\begin{array}{l}\text { De 2004-2006 } \\
\text { à 2014-2016 }\end{array}$ & $\begin{array}{l}\text { De 1984-1986 } \\
\text { à 1994-1996 }\end{array}$ & $\begin{array}{l}\text { De 1994-1996 } \\
\text { à 2004-2006 }\end{array}$ & $\begin{array}{l}\text { De 2004-2006 } \\
\text { à 2014-2016 }\end{array}$ \\
\hline $0-14$ ans & 14,4 & 6,9 & 2,6 & 12,2 & 8,3 & 2,3 \\
\hline $15-24$ ans & 5,8 & 5,9 & 5,6 & 2,9 & 3,9 & 3,8 \\
\hline $25-44$ ans & $-1,2$ & 21,8 & 12,6 & 2,0 & 11,2 & 10,8 \\
\hline $45-64$ ans & 34,6 & 21,5 & 26,0 & 15,9 & 9,3 & 14,6 \\
\hline $65-84$ ans & 40,5 & 37,6 & 45,5 & 49,4 & 48,3 & 46,9 \\
\hline $\begin{array}{l}85 \text { ans et } \\
\text { plus }\end{array}$ & 5,8 & 5,9 & 7,8 & 17,6 & 19,0 & 21,5 \\
\hline $\begin{array}{l}\text { Gain total } \\
\text { en années }\end{array}$ & 2,57 & 3,03 & 2,31 & 2,45 & 2,05 & 1,30 \\
\hline $\begin{array}{l}\text { Espérance } \\
\text { de vie en fin } \\
\text { de période }\end{array}$ & 73,88 & 76,91 & 79,22 & 81,94 & 83,99 & 85,29 \\
\hline
\end{tabular}

Le tableau 15 présente la contribution en années de chaque groupe d'âges aux gains d'espérance de vie obtenus au cours des trois dernières décennies pour chacun des deux sexes. Seul un cinquième des gains obtenus entre 20042006 et 2014-2016, soit $21 \%$ chez les hommes et $17 \%$ chez les femmes, sont 
attribuables à la baisse de la mortalité avant 45 ans. Par rapport à la décennie antérieure (de 1994-1996 à 2004-2006), lorsqu'elles atteignaient respectivement $35 \%$ et $23 \%$, ces proportions sont faibles. Elles s'inscrivent toutefois dans une tendance de long terme : les quotients qui prévalent à ces âges n'ont en effet cessé de se réduire tout au long du vingtième siècle pour atteindre des niveaux très faibles. Les baisses de mortalité obtenues chez les jeunes pèsent donc de moins en moins dans l'évolution de l'espérance de vie à la naissance. Plus de la moitié des années de vie gagnées par les hommes et presque $70 \%$ de celles gagnées par les femmes au cours de la décennie 2004-2006 à 2014-2016 sont dues aux progrès réalisés au-delà de 65 ans. Chez les femmes, presqu'un quart du gain total est attribuable à la baisse de la mortalité à 85 ans et plus. L'examen de la mortalité par cause médicale de décès permet de mieux comprendre les évolutions différentielles de mortalité selon l'âge.

\section{L'évolution de la mortalité par cause}

La répartition par cause médicale des décès peut être analysée grâce aux statistiques établies par l'Institut national de la santé et de la recherche médicale (Inserm) jusqu'en 2015, année la plus récente pour laquelle les données sont disponibles.

La hausse de la mortalité de 2015 a affecté toutes les causes de décès, au-delà de la grippe et des autres maladies respiratoires, les plus concernées. Elle a en outre essentiellement touché les personnes âgées, tout particulièrement à 85 ans et plus. En dehors de cet épisode exceptionnel, si l'on compare la mortalité pour les six grands groupes de causes médicales de décès (tumeurs, maladies cardiovasculaires, maladies infectieuses, maladies respiratoires, autres maladies, causes mal définies, et morts violentes) au cours de la décennie 2005-2015, on observe que la baisse a concerné tous les groupes. Toutefois, des variations importantes apparaissent lorsque l'on examine la situation par sexe, par groupe d'âges et avec une classification fine des causes de décès.

\section{La mortalité cardiovasculaire continue à se réduire à un rythme soutenu}

Parmi tous les grands groupes de causes médicales de décès, la mortalité par maladie cardiovasculaire est celle qui a diminué le plus rapidement au cours de la décennie 2005-2015. Le taux comparatif a baissé de presque $30 \%$ entre 2005 et 2015, et de $50 \%$ depuis 1995. Cette baisse importante est attribuable aux progrès de la lutte contre les cardiopathies ischémiques (avec une baisse de $35 \%$ de la mortalité au cours des dix dernières années) et contre les maladies cérébro-vasculaires (30\% de baisse). La mortalité due aux autres maladies du cœur a diminué de $20 \%$ au cours de la même période et celle attribuable aux autres maladies de l'appareil circulatoire, de $40 \%$. Ces grandes tendances s'inscrivent parfaitement dans l'évolution de la mortalité cardiovasculaire depuis 1980 environ. 
Lévolution a été globalement similaire pour les hommes et pour les femmes. La seule différence significative a été une diminution plus rapide de la mortalité par cardiopathie ischémique pour les femmes (- $40 \%$ pour celles-ci contre - $30 \%$ pour les hommes entre 2005 et 2015). Le niveau de départ était déjà beaucoup plus faible pour les femmes et le taux comparatif de mortalité par maladie cardiovasculaire s'établit aujourd'hui à 74 pour 100000 pour les femmes et 131 pour les hommes (tableau annexe A.14), contre 104 et 187 pour 100000 dix ans plus tôt. Cependant, comme la mortalité générale des femmes est également plus faible que celle des hommes, la part de la mortalité par maladie cardiovasculaire dans la mortalité générale est identique pour les deux sexes ( $23 \%$ du taux comparatif tous âges et toutes causes en 2015, tableau 16).

Tableau 16. Taux comparatif de mortalité par grand groupe d'âges en 2015* (pour 100 000) et répartition par cause de décès (\%)

\begin{tabular}{|c|c|c|c|c|c|c|c|}
\hline \multirow{2}{*}{ Causes de décès } & \multicolumn{7}{|c|}{ Groupe d'âges } \\
\hline & $0-14$ ans & $15-24$ ans & $25-44$ ans & $45-64$ ans & $65-84$ ans & 85 ans et + & Tous âges \\
\hline & \multicolumn{7}{|c|}{ Hommes } \\
\hline $\begin{array}{l}\text { Taux comparatif toutes } \\
\text { causes (pour } 100000)\end{array}$ & 4 & 4 & 11 & 61 & 248 & 1501 & 595 \\
\hline Maladies infectieuses & 2,0 & 0,8 & 1,2 & 1,5 & 1,6 & 2,4 & 1,7 \\
\hline Cancers & 7,3 & 10,5 & 19,9 & 46,7 & 44,8 & 21,8 & 37,4 \\
\hline $\begin{array}{l}\text { Maladies } \\
\text { cardiovasculaires }\end{array}$ & 2,7 & 4,5 & 11,1 & 16,9 & 22,6 & 33,0 & 22,8 \\
\hline Maladies respiratoires & 1,4 & 1,3 & 1,8 & 3,4 & 7,3 & 11,7 & 7,0 \\
\hline $\begin{array}{l}\text { Maladies de l'appareil } \\
\text { digestif }\end{array}$ & 1,1 & 0,8 & 4,6 & 7,9 & 4,7 & 3,7 & 5,1 \\
\hline Autres maladies & 75,3 & 11,0 & 13,1 & 10,8 & 13,5 & 21,4 & 15,7 \\
\hline Morts violentes & 10,2 & 71,1 & 48,4 & 12,9 & 5,4 & 6,1 & 10,2 \\
\hline \multirow[t]{2}{*}{ Total } & 100,0 & 100,0 & 100,0 & 100,0 & 100,0 & 100,0 & 100,0 \\
\hline & \multicolumn{7}{|c|}{ Femmes } \\
\hline $\begin{array}{l}\text { Taux comparatifs toutes } \\
\text { causes (pour 100 000) }\end{array}$ & 3 & 2 & 5 & 29 & 127 & 1098 & 332 \\
\hline Maladies infectieuses & 2,0 & 2,2 & 1,7 & 1,3 & 1,8 & 2,3 & 1,9 \\
\hline Cancers & 7,8 & 20,2 & 45,3 & 59,2 & 43,7 & 15,6 & 37,2 \\
\hline $\begin{array}{l}\text { Maladies } \\
\text { cardiovasculaires }\end{array}$ & 3,2 & 6,0 & 9,3 & 10,9 & 21,0 & 36,0 & 22,7 \\
\hline Maladies respiratoires & 1,9 & 3,8 & 2,3 & 3,6 & 5,9 & 9,8 & 6,4 \\
\hline $\begin{array}{l}\text { Maladies de l'appareil } \\
\text { digestif }\end{array}$ & 1,3 & 0,7 & 4,1 & 5,7 & 4,6 & 3,9 & 4,5 \\
\hline Autres maladies & 75,8 & 16,8 & 14,0 & 11,1 & 17,9 & 26,8 & 20,3 \\
\hline Morts violentes & 8,0 & 50,4 & 23,4 & 8,3 & 5,0 & 5,6 & 7,0 \\
\hline Total & 100,0 & 100,0 & 100,0 & 100,0 & 100,0 & 100,0 & 100,0 \\
\hline \multicolumn{8}{|c|}{$\begin{array}{l}\text { * Ces taux sont différents de ceux du tableau annexe A.14 à cause du mode de calcul. Les causes mal définies } \\
\text { ont ici été réparties. Pour une définition des grands groupes de causes et de la méthode de répartition des causes } \\
\text { mal définies, on pourra se reporter à Meslé (2005). } \\
\text { Champ : France métropolitaine. } \\
\text { Source : Calculs des auteur.e.s à partir des données Inserm (CépiDc). }\end{array}$} \\
\hline
\end{tabular}




\section{Des inquiétudes pour les femmes dans la lutte contre le cancer}

La mortalité par cancer a décliné régulièrement pour les hommes, mais son recul est plus lent (de moitié) que celui des maladies cardiovasculaires. La baisse du taux comparatif a en effet seulement atteint $15 \%$ entre 2005 et 2015, soit un rythme comparable à celui observé au cours de la décennie précédente (1995-2005). Chez les femmes, la diminution, déjà très faible entre 1995 et 2005 (- 7 \%), a été négligeable au cours de la dernière décennie : en 2015 le taux comparatif de mortalité par cancer n'est inférieur que de $3 \%$ à son niveau de 2005. C'est la seule grande cause de décès pour laquelle la baisse a été sensiblement plus faible pour les femmes que pour les hommes, même si le taux comparatif de mortalité par cancer demeure très inférieur à celui des hommes, soit 116 pour 100000 contre 211 pour 100000 en 2015 (tableau annexe A.14). En 2015, ces maladies représentent $37 \%$ du taux comparatif de mortalité tant pour les hommes que pour les femmes (tableau 16). C'est la première cause de décès en France depuis les années 1980 pour les hommes, depuis 1999 pour les femmes.

La principale raison de l'évolution différentielle selon le sexe tient à des divergences en matière de comportements tabagiques. Tandis que la proportion de fumeurs réguliers parmi les hommes âgés de 15 ans et plus a diminué jusqu'en 2010, de 70 \% au milieu des années 1950 à un peu plus de $30 \%$ en 2010, elle a augmenté régulièrement pour les femmes, de moins de $10 \%$ à plus de $25 \%$ pendant la même période (Guignard et al., 2015; Hill et Laplanche, 2005). Depuis 2010, le tabagisme masculin est toutefois resté stable, avec $32 \%$ de fumeurs réguliers en 2010 comme en 2014, tandis que le tabagisme féminin diminuait (de $26 \%$ à $24 \%$ ). La baisse de la consommation de tabac chez les femmes est toutefois trop récente pour se traduire par une baisse concomitante de la mortalité par cancer. De fait, la mortalité par tumeur du larynx, du poumon ou des bronches, principale cause de décès dus au tabac, a augmenté de 37 \% chez les femmes au cours des dix dernières années, exactement autant qu'au cours de la décennie précédente (1995-2005). Ceci représente un doublement du taux comparatif de mortalité pour cette cause, d'à peine plus de 100 pour 100000 en 1995 à presque 200 pour 100000 en 2015. Pour les hommes, ce taux a au contraire diminué d'un quart, passant de plus de 800 à moins de 600 pour 100000 au cours des deux dernières décennies. La proportion de fumeurs ou d'anciens fumeurs parmi les hommes continue toutefois à dépasser largement celle des femmes, ce qui explique que le taux comparatif de mortalité masculin pour ce type de cancer est encore trois fois plus élevé que le taux féminin.

Les cancers des voies aérodigestives supérieures (VADS) et de l'œesophage, également fortement liés au tabagisme, connaissent aussi une nette hausse pour les femmes (augmentation depuis 2005 des taux comparatifs de $4 \%$ pour les VADS et de $12 \%$ pour l'œsophage), ce qui n'est pas le cas pour les hommes (baisse de $25 \%$ environ pour chacun de ces taux). Enfin, le ralentissement de 
la baisse de la mortalité par cancer du sein (qui n’a atteint que $10 \%$ entre 2005 et 2015 contre $12 \%$ entre 1995 et 2005) et l'absence de progrès concernant la mortalité par cancer de l'utérus (après une baisse de $15 \%$ du taux comparatif entre 1995 et 2005) pourraient être au moins en partie attribuables à l'augmentation continue du tabagisme féminin pour les générations aujourd'hui âgées de 45 ans et plus (Guignard et al., 2015). L'Organisation mondiale de la santé (OMS) considère que le décalage entre le pic du tabagisme dans une population et ses effets épidémiologiques les plus marqués est d'environ trente ans. Les femmes qui décèdent donc aujourd'hui de cancers liés à leur consommation de tabac antérieure appartiennent aux générations nées avant 1970. Une quinzaine de localisations (au premier rang desquelles figurent pour les femmes le sein, puis le côlon-rectum, le poumon et, plus loin derrière le corps de l'utérus) sont directement concernées (Marant-Micallef et al., 2018).

D’autres cancers ont toutefois évolué très favorablement, en particulier le cancer de l'estomac, dont le taux comparatif de mortalité a diminué de $21 \%$ depuis 2005 pour les hommes comme les femmes, et pour les hommes, le cancer de la prostate a reculé de $27 \%$ au cours de la même décennie. Le cancer de la prostate est le seul cancer pour lequel on observe une accélération des progrès depuis vingt ans. Cette baisse tient aux progrès du dépistage, du diagnostic et des traitements ainsi qu'à l'évolution favorable des comportements tabagiques masculins (Grosclaude et al., 2016).

\section{Une accélération de la baisse de la mortalité par accident de la circulation, par suicide et par homicide}

La mortalité due aux accidents de la circulation, qui touche essentiellement les jeunes adultes, a fortement diminué depuis vingt ans : la baisse a été de presque $70 \%$ et elle s'est accélérée entre les deux décennies passées (- $37 \%$ entre 1995 et 2005 et - 47 \% entre 2005 et 2015). Cette accélération de la baisse est également observée en ce qui concerne la mortalité par suicide $(-15 \%$ et $-22 \%$ ) et pour les homicides ( $-31 \%$ et $-35 \%$ ). Toutefois, la baisse de la mortalité pour les autres causes violentes (par chute accidentelle notamment) s'est fortement ralentie, sans que l'on sache s'il s'agit d'une évolution réelle ou d'un effet de la révision de la Classification internationale des maladies mise en ouvre en France en 2000. Le taux comparatif pour l'ensemble des causes violentes n'a finalement baissé que de $18 \%$ entre 2005 et 2015, contre $26 \%$ au cours de la décennie précédente.

\section{Les autres maladies : une évolution préoccupante}

La situation la plus préoccupante - outre celle liée à l'évolution de la mortalité féminine par cancer-concerne la mortalité par troubles mentaux et maladies du système nerveux, en augmentation rapide depuis vingt ans. Ces maladies sévissent tout particulièrement aux âges élevés. Après une forte croissance de la mortalité par maladie d'Alzheimer, la tendance paraît s'être 
inversée : le taux comparatif, qui avait doublé en quinze ans, pour atteindre un maximum en 2012 (134 pour 100000) diminue régulièrement depuis et atteint 120 pour 100000 en 2015. Dans la mesure où cette maladie n'est entrée dans les statistiques qu'à partir de 1979, l'augmentation initiale pourrait avoir au moins en partie résulté des progrès dans le diagnostic ainsi que des pratiques d'enregistrement et de certification, concernant un groupe d'âges pour lequel l'existence fréquente de pathologies multiples rend difficile l'identification de la cause initiale du décès.

La tendance est plus favorable pour les maladies infectieuses, pour les maladies de l'appareil respiratoire et pour les maladies de l'appareil digestif, mais la baisse observée entre 2005 et 2015 a été plus faible que pendant la décennie précédente, surtout pour ces deux premiers groupes de maladies (21\% de baisse entre 1995 et 2005 contre $51 \%$ entre 2005 et 2015 pour les maladies infectieuses, $13 \%$ contre $31 \%$ pour les maladies respiratoires, mais $19 \%$ contre $22 \%$ pour les maladies de l'appareil digestif). Toutefois, le poids de ces trois causes de décès dans la mortalité totale est devenu très faible. Ces pathologies ne représentent plus, respectivement, que $2 \%, 6 \%$ et $5 \%$ du taux comparatif toutes causes, avec très peu de différences selon le sexe (tableau 16).

\section{Fluctuations annuelles de la mortalité : une pointe en hiver, un creux en été}

Nous avons examiné les variations saisonnières au cours des dix dernières années $(2006-2015)^{(29)}$ en calculant des coefficients mensuels et saisonniers ajustés pour la durée variable des mois et des années ${ }^{(30)}$. Ces coefficients ont été établis à partir des données de l'Inserm sur les décès par cause de manière à mesurer les variations saisonnières pour la mortalité générale et par groupe d'âges ainsi que pour les principales causes de décès. Les coefficients des variations mensuelles sur la période 2006-2015 ont été calculés en rapportant le nombre quotidien moyen de décès pour chaque mois, de janvier à décembre, au nombre quotidien moyen de décès annuel.

Lanalyse montre d'abord une évolution systématique du nombre de décès d'un mois à l'autre qui se répète au cours des années : le nombre quotidien de décès évolue très régulièrement au cours de l'année, pour atteindre un maximum en hiver et un minimum en été (figure 23). Ce résultat est identique à celui d'autres travaux menés ailleurs en Europe (Rau, 2007). Cette périodicité est relativement récente dans la mesure où, en France comme dans les autres pays européens ayant fait l'objet de ce type d'études, l'évolution de la mortalité était marquée, au moins jusqu'à la fin du XIX ${ }^{e}$ siècle, par deux maximums de mortalité : l'un en hiver, l'autre en été, avec des causes très différentes, présentées par la suite. Tandis que le premier a perduré jusqu'à aujourd'hui, bien que

(29) Cette analyse a été menée en collaboration avec Robert Chung (Département de démographie, Université de Californie, Berkeley).

(30) Nous avons exclu les départements d'outre-mer. 
Figure 23. Nombre quotidien de décès, 2006-2015

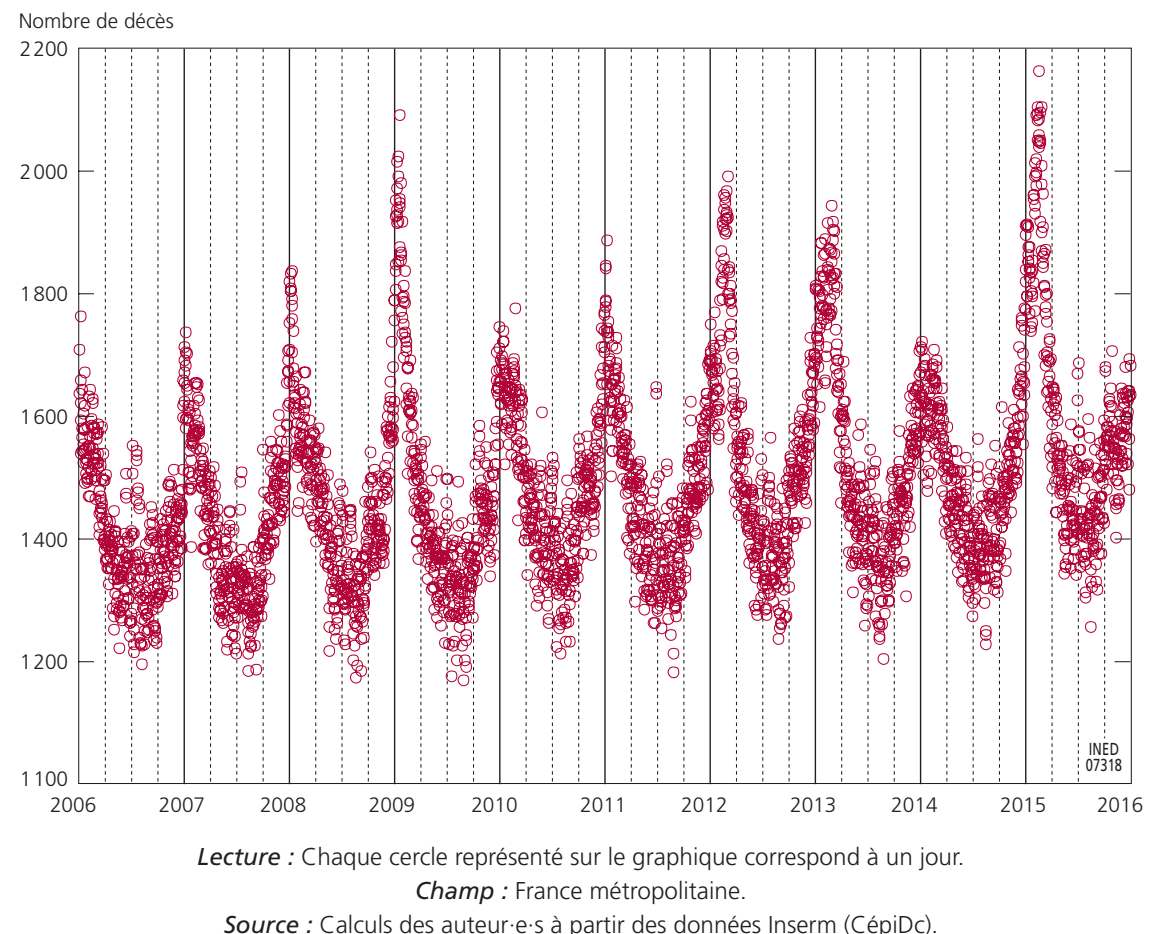

de manière moins marquée (Aubenque et al., 1979), le deuxième a complètement disparu. De fait, à l'exception des années de canicule comme celles de 2003 et de 2006, lorsque le nombre de décès quotidien peut atteindre un maximum bien supérieur à celui observé pendant les jours les plus meurtriers de l'hiver, l'été et tout particulièrement le mois d'août, correspond aujourd'hui à un minimum de mortalité (figure 24) (Corso et al., 2017; Fouillet et al., 2006; Rey et al., 2007; Toulemon et Barbieri, 2008).

Si les conditions de mortalité du mois d'août prévalaient pendant toute l'année, le nombre moyen annuel de décès au cours de la période 2006-2015 aurait été de 501000 au lieu de 553000.

La diminution des variations saisonnières au cours du temps concerne tout particulièrement les jeunes. Comme le montre la figure 25, l'amplitude entre les mois de mortalité maximum et minimum est aujourd'hui faible pour les enfants et jeunes adultes par rapport aux autres groupes d'âges, ce qui n'était pas le cas jusqu'au début du vingtième siècle (Aubenque et al., 1979). Le calendrier est aussi très différent, avec des maxima actuels en juillet et février et un minimum en septembre. Les fluctuations mensuelles de la mortalité sont de plus en plus marquées avec l'âge à partir de 45 ans environ suivant le schéma général (surmortalité hivernale et sous-mortalité estivale) et elles sont particulièrement importantes après 65 ans. 
Figure 24. Nombre quotidien de décès par mois rapporté à la moyenne journalière des décès de chaque année, 2006-2015

Nombre quotidien de décès (moyenne $=100$ )

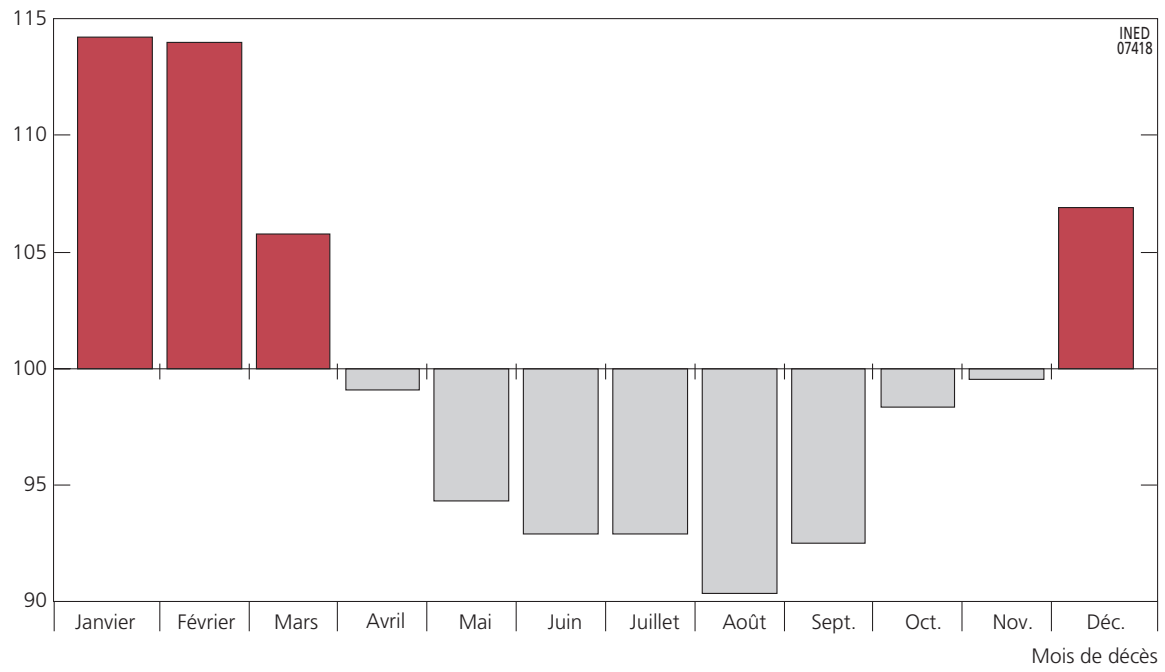

Champ : France métropolitaine.

Source : Calculs des auteur·e·s à partir des données Inserm (CépiDc).

Figure 25. Nombre quotidien de décès par mois rapporté à la moyenne journalière des décès de chaque année selon le groupe d'âges, 2006-2015

Nombre quotidient de décès (moyenne $=100$ )

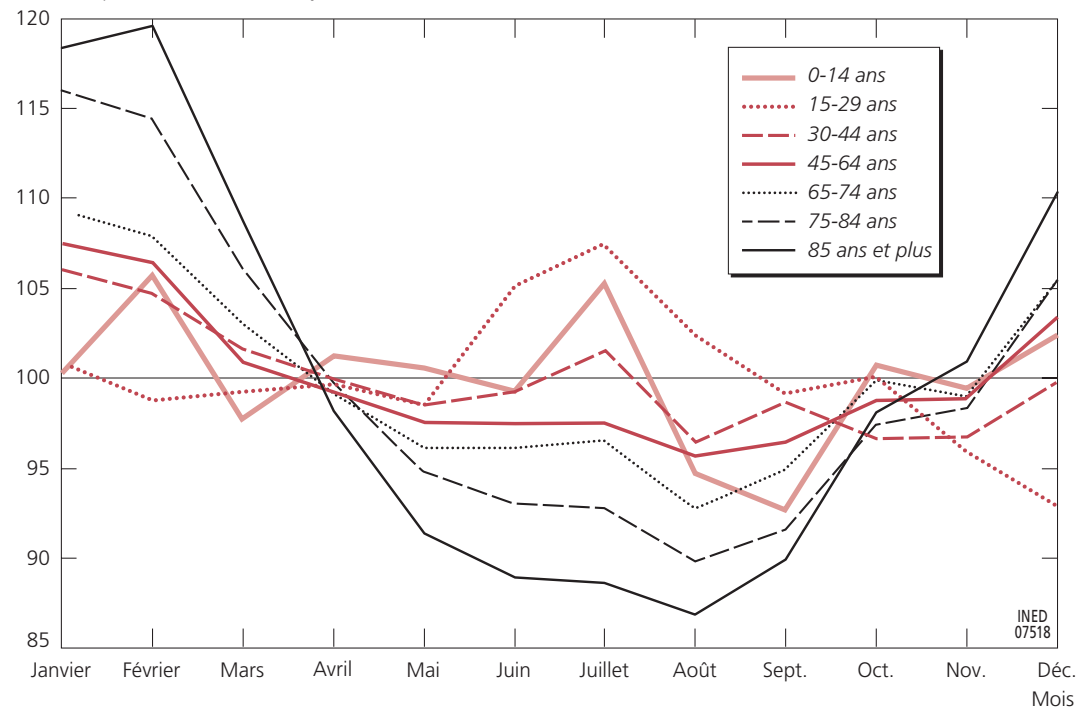

Champ : France métropolitaine.

Source : Calculs des auteur.e.s à partir des données Inserm (CépiDc). 
Tandis que la différence des nombres de décès par jour entre les mois extrêmes représente $23 \%$ de la moyenne sur l'année pour l'ensemble de la population, cette proportion atteint seulement $11 \%$ pour les moins de 30 ans. $\mathrm{Au}$ contraire, les variations sont particulièrement marquées pour les personnes âgées de 65 ans et plus avec une amplitude entre les mois extrêmes représentant $26 \%$ de la moyenne annuelle. Comme pour les enfants, les variations saisonnières de la mortalité ont toutefois diminué au cours du vingtième siècle pour les plus âgés (Aubenque et al., 1979).

Les différences d'intensité et de calendrier entre les groupes d'âges sont étroitement liées aux causes de décès concernées par les fluctuations saisonnières. Historiquement et encore aujourd'hui, les maladies cardiovasculaires et les maladies respiratoires (notamment la grippe et la pneumonie) sont principalement associées au pic hivernal de la mortalité, tandis que l'ancien pic estival était attribuable à la mortalité pour certaines maladies infectieuses (maladies gastro-intestinales, rougeole et coqueluche notamment) (Aubenque et al., 1979; Rau, 2007). Au contraire, la mortalité par cancer est très uniforme et ne présente pratiquement aucun rythme saisonnier. Les morts violentes sont les seules associées à un pic de mortalité estivale (mois de juillet) du fait de la surmortalité due aux accidents.

La baisse séculaire de la mortalité par maladies infectieuses, y compris celles qui frappent essentiellement l'été, a principalement bénéficié aux jeunes enfants, ce qui explique la disparition de l'ancien pic de mortalité estival, très prononcé pour ce groupe d'âges. Au contraire, les personnes âgées sont particulièrement sujettes aux maladies cardiovasculaires et respiratoires qui sévissent de manière plus marquée en hiver. La surmortalité hivernale des personnes âgées demeure importante, bien qu'elle ait diminué grâce à l'introduction et à l'expansion de la vaccination antigrippale qui s'est rapidement répandue en France à partir de l'épidémie de 1967-1968 (Meslé, 2010). Jusqu'à cette date, la grippe était directement responsable de 10000 à 20000 décès chaque année contre 1000 à 2000 décès actuellement. Notons que malgré la saisonnalité plus marquée de la mortalité par maladies respiratoires, la majorité des décès du pic hivernal est attribuable aux maladies cardiovasculaires dont le poids dans la mortalité générale est beaucoup plus lourd (figure 26).

Les facteurs à l'origine de la surmortalité hivernale due aux maladies respiratoires, aux autres maladies infectieuses et aux maladies cardiovasculaires sont nombreux et directement associés aux températures. Lorsque celles-ci sont faibles et que l'humidité est importante, les infections sont plus fréquentes du fait d'un confinement accru de la population; les bactéries sont aussi plus résistantes : elles survivent plus longtemps et se transmettent plus facilement; le système immunitaire est affaibli, non seulement à cause de la température mais aussi de la moindre consommation de fruits et de légumes, ce qui limite l'apport des vitamines et minéraux essentiels à son bon fonctionnement; les vaisseaux sanguins se contractent mécaniquement pour éviter la perte de 
Figure 26. Nombre quotidien de décès par mois rapporté à la moyenne journalière des décès de chaque année selon les grands groupes de causes médicales de décès, 2006-2015

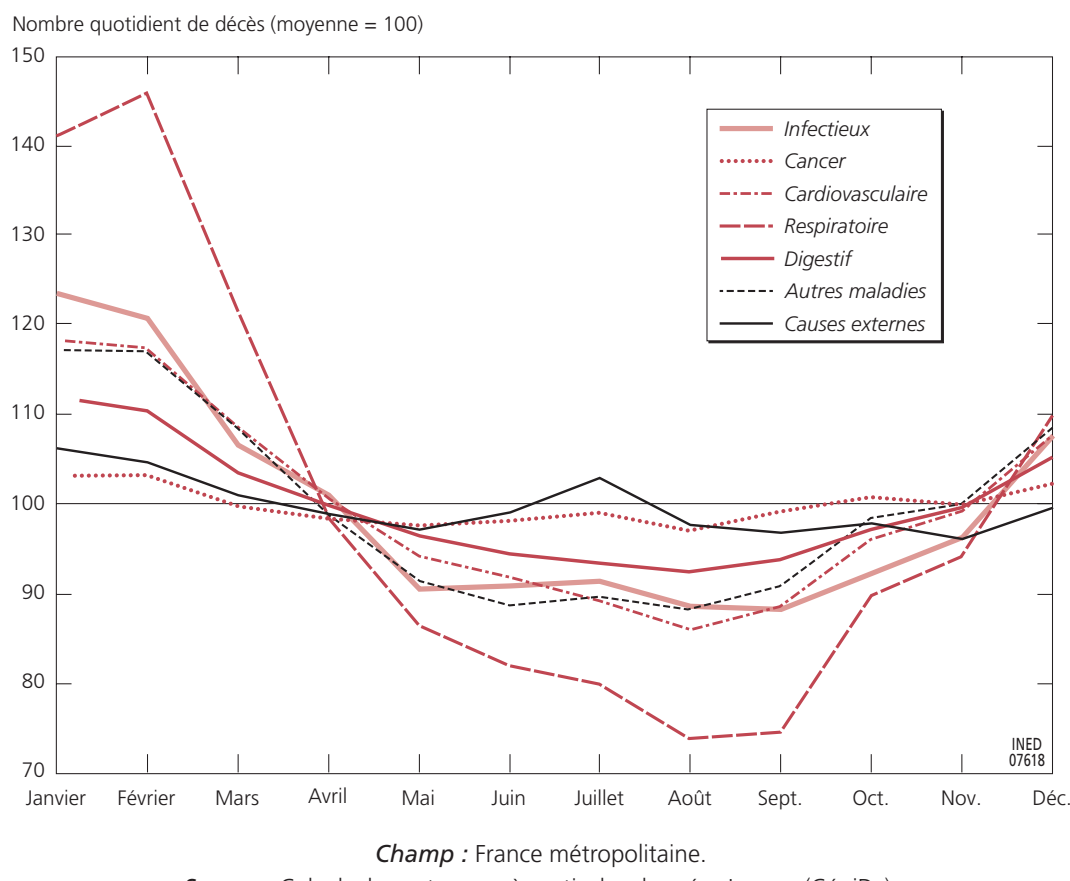

Source : Calculs des auteur.e.s à partir des données Inserm (CépiDc).

chaleur, ce qui accroît la viscosité du sang et fatigue le cour (Huyen et al., 2001 ; Keatinge et Donaldson, 1997; Rau, 2007). Par ailleurs, certains polluants dont l'émission est maximale en hiver, comme ceux résultant du chauffage au fuel (dioxyde de sulfure et monoxyde de carbone) qui favorise la diffusion de particules fines dans l'atmosphère, accroissent les risques de maladies respiratoires et cardiovasculaires. Enfin, les effets du froid sur l'organisme persistent pendant trois semaines après l'exposition aux faibles températures, ce qui participe à leur effet prolongé sur la mortalité, même lorsque ces températures ne sont pas exceptionnelles (Corso et al., 2017).

\section{Vue d'ensemble}

Le $1^{\text {er }}$ janvier 2018, la France comptait 66,9 millions d'habitants. Son accroissement n'a jamais été aussi faible depuis 20 ans, du fait notamment d'un solde naturel qui atteint un minimum historique depuis 40 ans. Sa structure par âge est parmi les plus jeunes des pays européens.

Le flux d'entrées de ressortissants étrangers en France a représenté plus de 300000 personnes en 2016. Ce flux recouvre deux populations distinctes. 
D'une part, les ressortissants étrangers soumis à l'obligation de détention d'un titre de séjour, évalués à l'Ined à partir d'une extraction de la base AGDREF, ont représenté 218354 personnes. Ce flux est principalement composé de familles (49\%) et d'étudiants ( $26 \%$ ). Le flux de demandeurs d'asile admis au séjour en France augmente continument depuis 2011 et a atteint 35262 personnes en 2016. D'autre part, les ressortissants étrangers non soumis à l'obligation de détention d'un titre de séjour selon Eurostat, ont représenté 82732 personnes. Ce flux est en baisse depuis 2013.

Pour la troisième année consécutive, le nombre annuel de naissances enregistrées en 2017 (769500) est en baisse, du fait de la diminution de la population en âge de procréer et de la fécondité. C'est la fécondité des jeunes (entre 25 et 29 ans notamment) qui a le plus baissé (en proportion); elle est concentrée dans le groupe d'âges des 25-35 ans (pour près des deux tiers).

Le nombre de naissances a fluctué selon la période de l'année : moins de naissances à la fin de l'hiver et au printemps, plus naissances en été et en automne. Le nombre journalier de naissances en 2017 a quant à lui oscillé entre un peu moins de 1700 et un peu plus de 2300. Les naissances sont plus nombreuses en semaine, moins nombreuses les week-end et jours fériés, sans doute du fait de la programmation des accouchements. Les naissances suite au recours à l'assistance médicale à la procréation représentent $3 \%$ de l'ensemble (environ 26000 naissances).

Le nombre d'IVG en 2017 a très légèrement augmenté : 216700 ont été enregistrés au cours de l'année. L'augmentation est observée principalement parmi des femmes trentenaires. Le nombre d'IVG est plus faible en avril ainsi qu'en juillet et août. L'accès aux services dédiés, plus difficile pendant la période estivale, a été pointé et reste encore un problème.

Petit à petit, le nombre de pacs rattrape celui de mariages. C'est maintenant le cas si on ne tient pas compte des mariages prolongeant un pacs. Les unions hétérosexuelles contractualisées atteignent en 2016 un nouveau minimum historique, tout comme celui des unions entre personnes de même sexe. En 2016, 3,3 \% des unions officialisées par un pacs ou un mariage, le sont entre deux personnes de même sexe. Cette baisse ne signifie toutefois pas que les mises en couples diminuent : chaque année, le nombre d'unions libres est nettement plus important que celui des mariages et pacs réunis. La saisonnalité des mariages et des pacs diffèrent : les premiers sont célébrés avant tout entre juin et septembre (au gré du nombre de samedis ces mois-là) alors que les pacs sont de plus en plus concentrés en fin d'année civile.

Les années 2015 et 2016 mettent fin à 3 années de diminution (2012 à 2014) du nombre de divorces et de la propension à divorcer, et ce quelle que soit la durée de mariage.

En 2017, l'espérance de vie à la naissance, estimée à 79,4 ans pour les hommes et 85,2 ans pour les femmes selon les chiffres provisoires de l'Insee (France entière), soit une augmentation de 0,1 an pour les hommes et un recul 
de 0,1 an pour les femmes par rapport à l'année précédente. L'espérance de vie des femmes françaises est l'une des plus élevées d'Europe, alors que celle des hommes se situe dans la moyenne. Au cours des dix dernières années, trois groupes d'âges concentrent les progrès les plus importants : autour de 20 ans, 50 ans et 80 ans. Ils ont toutefois été un peu plus marqués pour les hommes que pour les femmes, bien que la surmortalité masculine, notamment chez les jeunes adultes, demeure forte.

Tous les grands groupes de causes médicales de décès ont contribué à la progression de la durée de vie, à l'exception notable des troubles mentaux et maladies du système nerveux et, pour les femmes uniquement, des cancers. Cette évolution défavorable de la mortalité féminine par cancer est due à l'augmentation rapide du nombre de décès par cancer du poumon, contrairement à ce qui est observé chez les hommes, et à l'absence de progrès dans la lutte contre le cancer de l'utérus. La divergence concernant le cancer du poumon résulte de comportements tabagiques différenciés, les hommes ayant réduit leur consommation plus tôt que les femmes. La diminution récente du tabagisme féminin devrait toutefois entraîner une baisse de la mortalité par cancer dans le futur.

La mortalité n'est pas uniforme au cours de l'année. Elle est maximale en hiver, notamment pendant les mois de janvier et février, et minimale en été, particulièrement au mois d'août, à l'exception des années de canicule (2003 en particulier). La saisonnalité des décès augmente avec l'âge : presque négligeable pour les enfants et les jeunes adultes, elle est particulièrement marquée à partir de 75 ans. Les personnes âgées sont en effet sujettes aux maladies cardiovasculaires et respiratoires qui sévissent de manière plus marquée en hiver pour des raisons à la fois biologiques (les bactéries sont plus résistantes lorsque les températures sont basses) et comportementales (confinement).

Remerciements : Les auteur.e.s remercient Elodie Baril et Arnaud Bringé du service Méthodes statistiques de l'Ined pour leur contribution à la préparation des bases de données et des premières analyses, ainsi qu'à Ekrame Boubtane, Maître de ConférencesHDR en sciences économiques au Cerdi (École d'économie, Université Clermont Auvergne) pour son aide dans le traitement de la partie consacrée à l'immigration, Floriane Varieras, ingénieure d'études à la plateforme universitaire de Strasbourg, pour son aide dans l'étude de la saisonnalité des unions, et enfin Robert Chung du Département de démographie, Université de Californie, Berkeley, qui a contribué à l'analyse de la mortalité saisonnière. 
ANNEXES 


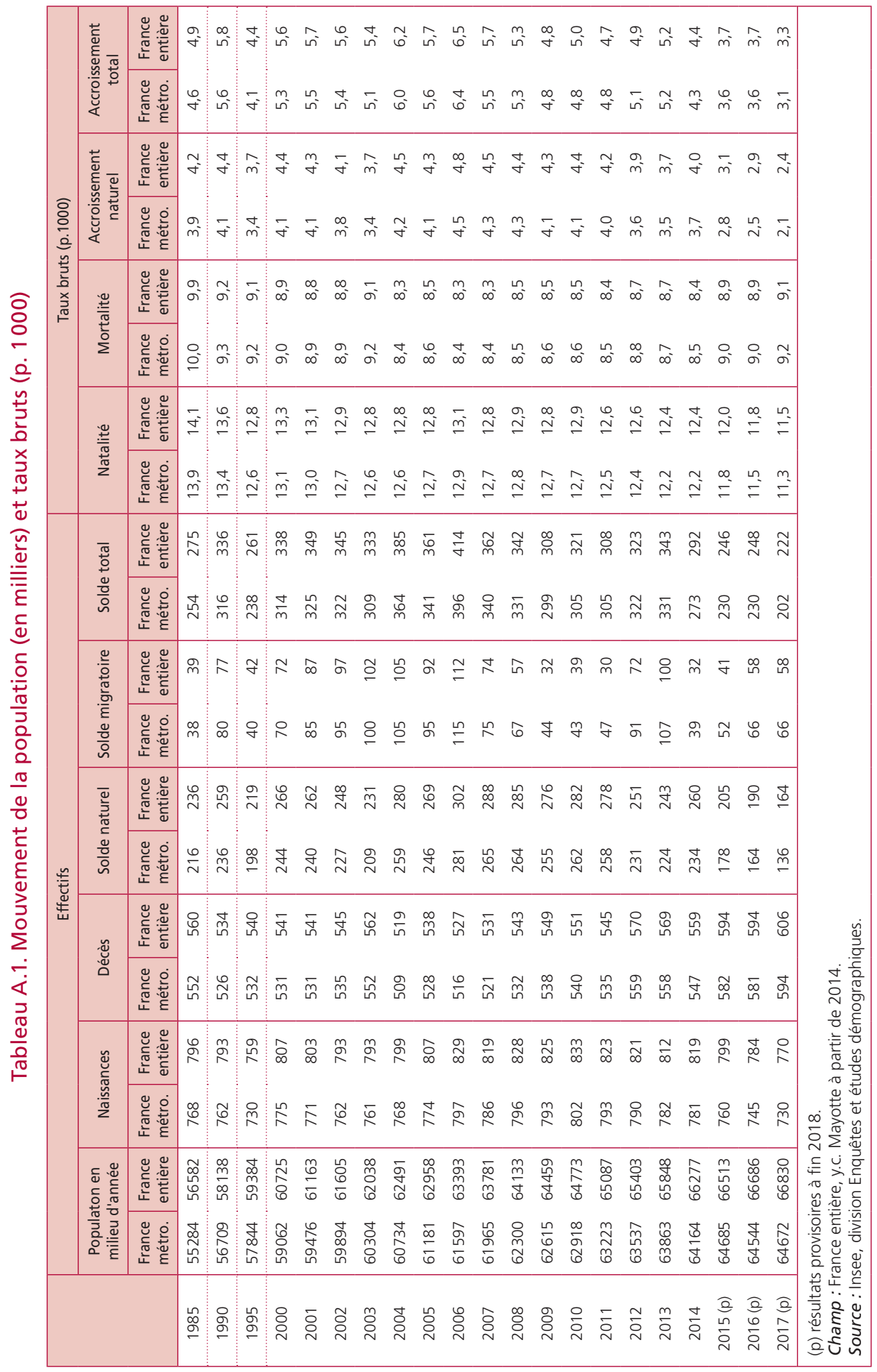


Tableau A.2. Répartition par groupe d'âges de la population au $1^{\text {er }}$ janvier (\%)

\begin{tabular}{|c|c|c|c|c|c|c|c|c|c|c|}
\hline \multicolumn{11}{|c|}{ France métropolitaine } \\
\hline Groupe d'âges & 1985 & 1990 & 1995 & 2000 & 2005 & 2010 & $\begin{array}{c}2015 \\
(p)\end{array}$ & $\begin{array}{c}2016 \\
(p)\end{array}$ & $\begin{array}{c}2017 \\
(p)\end{array}$ & $\begin{array}{c}2018 \\
(p)\end{array}$ \\
\hline $0-19$ ans & 29,2 & 27,8 & 26,1 & 25,6 & 25,0 & 24,5 & 24,3 & 24,3 & 24,1 & 24,0 \\
\hline $20-59$ ans & 52,7 & 53,2 & 53,8 & 53,8 & 54,1 & 52,7 & 50,9 & 50,5 & 50,3 & 50,0 \\
\hline 60 ans ou plus & 18,1 & 19,0 & 20,1 & 20,6 & 20,9 & 22,8 & 24,8 & 25,2 & 25,6 & 26,0 \\
\hline \multicolumn{11}{|l|}{ Dont : } \\
\hline 65 ans ou plus & 12,8 & 13,9 & 15,0 & 16,0 & 16,5 & 16,8 & 18,6 & 19,1 & 19,5 & 19,9 \\
\hline 75 ans ou plus & 6,3 & 6,8 & 6,1 & 7,2 & 8,1 & 8,9 & 9,3 & 9,3 & 9,3 & 9,3 \\
\hline Ensemble & 100,0 & 100,0 & 100,0 & 100,0 & 100,0 & 100,0 & 100,0 & 100,0 & 100,0 & 100,0 \\
\hline
\end{tabular}

\begin{tabular}{|c|c|c|c|c|c|c|c|c|c|c|}
\hline \multicolumn{11}{|c|}{ France entière } \\
\hline Groupe d'âges & 1985 & 1990 & 1995 & 2000 & 2005 & 2010 & $\begin{array}{c}2015 \\
(p)\end{array}$ & $\begin{array}{c}2016 \\
(p)\end{array}$ & $\begin{array}{c}2017 \\
\text { (p) }\end{array}$ & $\begin{array}{c}2018 \\
(p)\end{array}$ \\
\hline $0-19$ ans & nd & nd & 26,4 & 25,8 & 25,3 & 24,8 & 24,6 & 24,6 & 24,4 & 24,3 \\
\hline $20-59$ ans & nd & nd & 53,8 & 53,8 & 54,0 & 52,6 & 50,9 & 50,4 & 50,2 & 49,9 \\
\hline 60 ans ou plus & nd & nd & 19,9 & 20,4 & 20,7 & 22,6 & 24,5 & 25,0 & 25,4 & 25,8 \\
\hline Dont : & & & & & & & & & & \\
\hline 65 ans ou plus & nd & nd & 14,9 & 15,8 & 16,3 & 16,6 & 18,4 & 18,9 & 19,3 & 19,7 \\
\hline 75 ans ou plus & nd & nd & 6,0 & 7,1 & 8,0 & 8,8 & 9,1 & 9,2 & 9,1 & 9,2 \\
\hline Ensemble & & & 100,0 & 100,0 & 100,0 & 100,0 & 100,0 & 100,0 & 100,0 & 100,0 \\
\hline \multicolumn{11}{|c|}{$\begin{array}{l}\text { (p) Résultats provisoires fin } 2018 . \\
\text { nd: Non disponible. } \\
\text { Source : Insee, division Enquêtes et études démographiques, série révisée après le recense- } \\
\text { ment de } 2011 \text {. }\end{array}$} \\
\hline
\end{tabular}


Tableau A.3. Flux d'entrées de ressortissants de pays tiers (périmètre constant), selon l'année de début de validité du premier titre de séjour d'un an ou plus

\begin{tabular}{|c|c|c|}
\hline \multicolumn{1}{|c|}{ Flux d'entrées } & Total & Dont mineurs \\
\hline 2000 & 136865 & 16230 \\
2001 & 164676 & 22126 \\
2002 & 187077 & 24153 \\
2003 & 200531 & 24597 \\
2004 & 201380 & 29131 \\
2005 & 199780 & 31128 \\
2006 & 194936 & 27205 \\
2007 & 177304 & 24766 \\
2008 & 184201 & 20561 \\
2009 & 189428 & 18524 \\
2010 & 184429 & 17980 \\
2011 & 177671 & 17594 \\
2012 & 180011 & 17500 \\
2013 & 192396 & 18246 \\
2014 & 199887 & 20688 \\
2015 & 210040 & 21493 \\
2016 & 218354 & 22406 \\
\hline \multicolumn{2}{|c|}{ Champ : titres délivrés en France et à l'étranger aux ressortissants des pays étrangers, } \\
à I'exception des pays membres de l'Espace économique européen et de la Suisse. \\
Titres délivrés l'année N et enregistrés dans l'extraction de la base AGDREF réalisée en \\
juillet de l'année N+2, sauf pour l'année 2009 où l'extraction a été réalisée en juillet \\
$\begin{array}{l}\text { 2012. } \\
\text { Source : calculs des auteurs à partir des extractions de la base AGDREF transmises à } \\
\text { I'Ined. }\end{array}$ & \\
\hline
\end{tabular}


Tableau A.4. Évolution de la fécondité depuis 1970

\begin{tabular}{|c|c|c|c|c|c|c|c|c|}
\hline \multirow[b]{2}{*}{ Année } & \multicolumn{4}{|c|}{$\begin{array}{l}\text { Somme des taux par âge } \\
\text { (p. } 100 \text { femmes) }\end{array}$} & \multicolumn{2}{|c|}{$\begin{array}{l}\text { Âge moyen à la } \\
\text { maternité (années) }\end{array}$} & \multicolumn{2}{|c|}{ Fécondité hors mariage } \\
\hline & $\begin{array}{l}15-24 \\
\text { ans }\end{array}$ & $\begin{array}{l}25-34 \\
\text { ans }\end{array}$ & $\begin{array}{c}35 \text { ans } \\
\text { et }+\end{array}$ & $\begin{array}{l}\text { Total } \\
\text { (ICF) }\end{array}$ & Ensemble & $\begin{array}{c}\text { Premières } \\
\text { naissances }^{(1)}\end{array}$ & $\begin{array}{c}\text { Somme } \\
\text { des taux par âge } \\
\text { (p. } 1000 \text { femmes) }\end{array}$ & $\begin{array}{l}\text { Part dans } \\
\text { la fécondité } \\
\text { totale (\%) }\end{array}$ \\
\hline 1970 & 93 & 125 & 30 & 247 & 27,2 & 23,9 & 16 & 6,4 \\
\hline 1975 & 76 & 97 & 19 & 193 & 26,7 & 24,1 & 16 & 8,5 \\
\hline 1980 & 70 & 109 & 16 & 194 & 26,8 & 24,5 & 22 & 11,4 \\
\hline 1985 & 54 & 110 & 17 & 181 & 27,5 & 25,2 & 36 & 19,6 \\
\hline 1990 & 42 & 114 & 22 & 178 & 28,3 & 26,0 & 53 & 30,1 \\
\hline 1995 & 31 & 116 & 24 & 171 & 29,0 & 26,8 & 65 & 37,9 \\
\hline 2000 & 32 & 125 & 31 & 187 & 29,4 & 27,4 & 81 & 43,2 \\
\hline 2005 & 31 & 126 & 35 & 192 & 29,7 & 27,7 & 92 & 47,9 \\
\hline 2006 & 32 & 130 & 37 & 198 & 29,8 & 27,8 & 98 & 49,7 \\
\hline 2007 & 31 & 128 & 37 & 196 & 29,8 & 27,9 & 100 & 50,9 \\
\hline 2008 & 31 & 129 & 38 & 199 & 29,9 & 27,9 & 103 & 51,6 \\
\hline 2009 & 31 & 129 & 39 & 199 & 29,9 & 28,0 & 104 & 52,9 \\
\hline 2010 & 31 & 131 & 40 & 202 & 30,0 & 28,1 & 109 & 54,2 \\
\hline 2011 & 30 & 129 & 41 & 200 & 30,1 & & 110 & 55,2 \\
\hline 2012 & 29 & 128 & 42 & 199 & 30,1 & & 112 & 56,0 \\
\hline 2013 & 28 & 127 & 42 & 197 & 30,2 & & 112 & 56,6 \\
\hline 2014 & 27 & 127 & 44 & 197 & 30,3 & & 114 & 57,7 \\
\hline $2015(p)$ & 25 & 124 & 43 & 192 & 30,4 & & - & - \\
\hline 2016 (p) & 24 & 121 & 44 & 189 & 30,6 & & - & - \\
\hline $2017(p)$ & 22 & 120 & 44 & 186 & 30,7 & & - & - \\
\hline
\end{tabular}


Tableau A.5. Fécondité des générations : descendance atteinte, descendance finale observée ou estimée (nombre moyen d'enfants pour 100 femmes) et âge moyen à la maternité (en années)

\begin{tabular}{|c|c|c|c|c|c|c|}
\hline \multirow{2}{*}{ Génération } & \multicolumn{4}{|c|}{$\begin{array}{l}\text { Descendance atteinte pour } 100 \text { femmes } \\
\text { (âge révolu) }\end{array}$} & \multicolumn{2}{|c|}{ Projection avec gel des taux* } \\
\hline & 24 ans & 29 ans & 34 ans & 39 ans & $\begin{array}{l}\text { Descendance } \\
\text { finale }\end{array}$ & $\begin{array}{l}\text { Âge moyen } \\
\text { à la maternité }\end{array}$ \\
\hline 1930 & 90 & 177 & 231 & 256 & 263 & 27,5 \\
\hline 1935 & 89 & 181 & 233 & 254 & 258 & 27,1 \\
\hline 1940 & 96 & 181 & 225 & 238 & 241 & 26,4 \\
\hline 1945 & 99 & 174 & 206 & 219 & 222 & 26,0 \\
\hline 1950 & 89 & 154 & 192 & 207 & 211 & 26,5 \\
\hline 1955 & 77 & 148 & 190 & 209 & 213 & 27,0 \\
\hline 1960 & 66 & 139 & 184 & 206 & 212 & 27,7 \\
\hline 1961 & 63 & 135 & 181 & 203 & 209 & 27,9 \\
\hline 1962 & 60 & 131 & 179 & 202 & 208 & 28,1 \\
\hline 1963 & 56 & 127 & 176 & 200 & 207 & 28,3 \\
\hline 1964 & 53 & 122 & 173 & 198 & 205 & 28,5 \\
\hline 1965 & 49 & 118 & 170 & 196 & 204 & 28,7 \\
\hline 1966 & 46 & 114 & 168 & 195 & 202 & 28,9 \\
\hline 1967 & 44 & 111 & 167 & 194 & 201 & 29,1 \\
\hline 1968 & 42 & 109 & 166 & 193 & 201 & 29,2 \\
\hline 1969 & 39 & 105 & 163 & 192 & 200 & 29,4 \\
\hline 1970 & 37 & 103 & 162 & 192 & 200 & 29,5 \\
\hline 1971 & 35 & 100 & 160 & 191 & 199 & 29,7 \\
\hline 1972 & 33 & 98 & 159 & 191 & 199 & 29,8 \\
\hline 1973 & 32 & 97 & 159 & 191 & 200 & 29,9 \\
\hline 1974 & 31 & 96 & 160 & 192 & 202 & 30,0 \\
\hline 1975 & 30 & 96 & 161 & 194 & 203 & 30,0 \\
\hline 1976 & 30 & 95 & 160 & 194 & 203 & 30,1 \\
\hline 1977 & 31 & 96 & 161 & 196 & 205 & 30,1 \\
\hline 1978 & 31 & 95 & 162 & 196 & 205 & 30,1 \\
\hline 1979 & 31 & 96 & 163 & & 207 & 30,1 \\
\hline 1980 & 31 & 95 & 161 & & 205 & 30,1 \\
\hline 1981 & 32 & 96 & 162 & & 205 & 30,1 \\
\hline 1982 & 32 & 96 & 162 & & 205 & 30,1 \\
\hline 1983 & 31 & 95 & 160 & & & \\
\hline 1984 & 32 & 95 & & & & \\
\hline 1985 & 31 & 94 & & & & \\
\hline 1986 & 31 & 94 & & & & \\
\hline 1987 & 31 & 92 & & & & \\
\hline 1988 & 30 & 89 & & & & \\
\hline 1989 & 30 & & & & & \\
\hline 1990 & 29 & & & & & \\
\hline 1991 & 28 & & & & & \\
\hline 1992 & 27 & & & & & \\
\hline 1993 & 26 & & & & & \\
\hline \multicolumn{7}{|c|}{$\begin{array}{l}\text { * Pour les générations } 1930 \text { à 1967, il s'agit de la descendance finale et de l'âge moyen à la maternité observés ; } \\
\text { pour les générations suivantes, les taux non observés sont supposés égaux à ceux observés au même âge en } 2017 . \\
\text { Champ : France métropolitaine. } \\
\text { Source : Calculs et estimations à partir de données Insee, Division des enquêtes et études démographiques. }\end{array}$} \\
\hline
\end{tabular}


Tableau A.6. Évolution de l'indicateur conjoncturel de fécondité en Europe (nombre moyen d'enfants par femme)

\begin{tabular}{|c|c|c|c|c|c|c|c|c|c|}
\hline & \multicolumn{9}{|c|}{ Année } \\
\hline & 1980 & 1985 & 1990 & 1995 & 2000 & 2005 & 2010 & 2015 & 2016 \\
\hline Allemagne & 1,56 & 1,37 & 1,45 & 1,25 & 1,38 & 1,34 & 1,39 & 1,50 & 1,6 \\
\hline Autriche & 1,65 & 1,47 & 1,46 & 1,41 & 1,36 & 1,41 & 1,44 & 1,49 & 1,53 \\
\hline Belgique & 1,68 & 1,51 & 1,62 & 1,56 & 1,67 & 1,76 & 1,86 & 1,70 & 1,68 \\
\hline Bulgarie & 2,05 & 1,97 & 1,82 & 1,23 & 1,26 & 1,37 & 1,57 & 1,53 & 1,54 \\
\hline Chypre & - & 2,43 & 2,41 & 2,03 & 1,64 & 1,48 & 1,44 & 1,32 & 1,37 \\
\hline Croatie & 1,50 & 1,55 & 1,48 & 1,51 & 1,46 & 1,50 & 1,55 & 1,40 & 1,42 \\
\hline Danemark & 1,55 & 1,45 & 1,67 & 1,80 & 1,78 & 1,80 & 1,87 & 1,71 & 1,79 \\
\hline Espagne & 2,20 & 1,64 & 1,36 & 1,17 & 1,23 & 1,33 & 1,37 & 1,33 & 1,34 \\
\hline Estonie & 2,02 & 2,13 & 2,05 & 1,38 & 1,36 & 1,52 & 1,72 & 1,58 & 1,60 \\
\hline Finlande & 1,63 & 1,64 & 1,78 & 1,81 & 1,73 & 1,80 & 1,87 & 1,65 & 1,57 \\
\hline France & - & - & - & - & 1,89 & 1,94 & 2,03 & 1,96 & 1,92 \\
\hline France métropolitaine & 1,95 & 1,81 & 1,78 & 1,71 & 1,87 & 1,92 & 2,01 & 1,92 & 1,89 \\
\hline Grèce & 2,23 & 1,67 & 1,39 & 1,28 & 1,25 & 1,34 & 1,48 & 1,33 & 1,38 \\
\hline Hongrie & 1,91 & 1,85 & 1,87 & 1,57 & 1,32 & 1,31 & 1,25 & 1,45 & 1,53 \\
\hline Irlande & 3,21 & 2,48 & 2,11 & 1,84 & 1,89 & 1,86 & 2,05 & 1,92 & 1,81 \\
\hline Italie & 1,64 & 1,42 & 1,33 & 1,19 & 1,26 & 1,34 & 1,46 & 1,35 & 1,34 \\
\hline Lettonie & - & - & - & - & 1,25 & 1,38 & 1,36 & 1,70 & 1,74 \\
\hline Lituanie & 1,99 & 2,08 & 2,03 & 1,55 & 1,39 & 1,29 & 1,50 & 1,70 & 1,69 \\
\hline Luxembourg & 1,50 & 1,38 & 1,60 & 1,70 & 1,76 & 1,63 & 1,63 & 1,47 & 1,41 \\
\hline Malte & 1,99 & 1,95 & 2,04 & 1,77 & 1,68 & 1,38 & 1,36 & 1,45 & 1,37 \\
\hline Pays-Bas & 1,60 & 1,51 & 1,62 & 1,53 & 1,72 & 1,71 & 1,79 & 1,66 & 1,66 \\
\hline Pologne & - & - & 2,06 & 1,62 & 1,37 & 1,24 & 1,41 & 1,32 & 1,39 \\
\hline Portugal & 2,25 & 1,72 & 1,56 & 1,41 & 1,55 & 1,41 & 1,39 & 1,31 & 1,36 \\
\hline Rép. tchèque & 2,08 & 1,95 & 1,90 & 1,28 & 1,15 & 1,29 & 1,51 & 1,57 & 1,63 \\
\hline Roumanie & 2,43 & 2,31 & 1,83 & 1,33 & 1,31 & 1,40 & 1,59 & 1,58 & 1,64 \\
\hline Royaume-Uni & 1,90 & 1,79 & 1,83 & 1,71 & 1,64 & 1,76 & 1,92 & 1,80 & 1,79 \\
\hline Slovaquie & 2,32 & 2,26 & 2,09 & 1,52 & 1,30 & 1,27 & 1,43 & 1,40 & 1,48 \\
\hline Slovénie & - & 1,71 & 1,46 & 1,29 & 1,26 & 1,26 & 1,57 & 1,57 & 1,58 \\
\hline Suède & 1,68 & 1,74 & 2,13 & 1,73 & 1,54 & 1,77 & 1,98 & 1,85 & 1,85 \\
\hline Islande & 2,48 & 1,93 & 2,30 & 2,08 & 2,08 & 2,05 & 2,20 & 1,80 & 1,74 \\
\hline Norvège & 1,72 & 1,68 & 1,93 & 1,87 & 1,85 & 1,84 & 1,95 & 1,72 & 1,71 \\
\hline Suisse & 1,55 & 1,52 & 1,58 & 1,48 & 1,50 & 1,42 & 1,52 & 1,54 & 1,54 \\
\hline
\end{tabular}


Tableau A.7. Fécondité des générations en Europe

\begin{tabular}{|c|c|c|c|c|c|c|c|c|c|c|c|}
\hline \multirow[b]{2}{*}{ Génération } & \multicolumn{5}{|c|}{ Descendance finale (par femme) } & \multicolumn{5}{|c|}{ Âge moyen à la maternité (années) } & \multirow{2}{*}{$\begin{array}{l}\text { Dernière } \\
\text { année } \\
\text { disponible }\end{array}$} \\
\hline & $\begin{array}{c}1954- \\
1955\end{array}$ & $\begin{array}{c}1959- \\
1960\end{array}$ & $\begin{array}{c}1964- \\
1965\end{array}$ & $\begin{array}{c}1969- \\
1970\end{array}$ & $\begin{array}{c}1974- \\
1975^{(1)}\end{array}$ & $\begin{array}{c}1954- \\
1955\end{array}$ & $\begin{array}{c}1959- \\
1960\end{array}$ & $\begin{array}{c}1964- \\
1965\end{array}$ & $\begin{array}{c}1969- \\
1970\end{array}$ & $\begin{array}{c}1974- \\
1975^{(1)}\end{array}$ & \\
\hline Allemagne & 1,66 & 1,66 & 1,56 & 1,50 & $1,54-1,56$ & 26,4 & 27,1 & 28,1 & 29,0 & $29,5-29,6$ & 2010 \\
\hline Autriche & 1,77 & 1,71 & 1,66 & 1,61 & $1,63-1,64$ & 25,8 & 26,5 & 27,3 & 28,2 & $28,8-28,9$ & 2010 \\
\hline Belgique & 1,83 & 1,87 & 1,84 & 1,84 & $1,83-1,87$ & 26,7 & 27,4 & 28,3 & 29,2 & $29,6-29,8$ & 2009 \\
\hline Bulgarie & 2,04 & 1,96 & 1,84 & 1,66 & 1,56 & 24,0 & 23,7 & 23,6 & 24,3 & 26,0 & 2010 \\
\hline Danemark & 1,84 & 1,88 & 1,93 & 1,98 & $1,96-1,98$ & 27,2 & 28,4 & 29,2 & 29,7 & $30,2-30,3$ & 2010 \\
\hline Espagne & 1,93 & 1,80 & 1,65 & 1,50 & $1,37-1,41$ & 27,2 & 27,8 & 29,2 & 30,6 & $31,6-31,8$ & 2010 \\
\hline Estonie & & & & 1,91 & $1,83-1,86$ & & & & 26,4 & $27,7-27,9$ & 2010 \\
\hline Finlande & 1,88 & 1,95 & 1,92 & 1,89 & $1,89-1,90$ & 27,9 & 28,6 & 29,2 & 29,6 & $30,0-30,1$ & 2010 \\
\hline France métro. & 2,13 & 2,12 & 2,04 & 1,99 & $2,01-2,04$ & 27,0 & 27,6 & 28,6 & 29,5 & $29,9-30,1$ & 2010 \\
\hline Grèce & 2,02 & 1,97 & 1,79 & 1,64 & $1,55-1,58$ & 25,9 & 26,0 & 27,0 & 28,7 & $29,9-30,0$ & 2010 \\
\hline Hongrie & 1,96 & 2,02 & 1,98 & 1,88 & $1,70-1,71$ & 24,9 & 25,0 & 25,5 & 26,4 & $27,7-27,8$ & 2010 \\
\hline Irlande & & & 2,21 & 2,12 & $2,06-2,12$ & & & 30,2 & 31,0 & $31,3-31,6$ & 2010 \\
\hline Italie & 1,80 & 1,69 & 1,55 & 1,47 & $1,42-1,45$ & 27,1 & 27,9 & 29,3 & 30,6 & $31,2-31,4$ & 2010 \\
\hline Lettonie $^{(2)}$ & - & - & - & - & - & - & - & - & - & - & - \\
\hline Lituanie & 1,97 & 1,92 & 1,72 & 1,77 & $1,72-1,73$ & 26,3 & 26,0 & 26,1 & 26,0 & 26,8 & \\
\hline Luxembourg & 1,67 & 1,75 & 1,83 & 1,85 & $1,80-1,82$ & 27,6 & 28,6 & 29,2 & 29,7 & $29,9-30,0$ & 2010 \\
\hline Pays-Bas & 1,88 & 1,86 & 1,79 & 1,77 & $1,78-1,80$ & 28,1 & 29,2 & 30,0 & 30,6 & $30,7-30,8$ & 2010 \\
\hline Pologne & & & & 1,85 & $1,61-1,62$ & & & & 26,1 & $27,3-27,4$ & 2010 \\
\hline Portugal & 2,03 & 1,90 & 1,83 & 1,69 & $1,57-1,58$ & 26,2 & 26,4 & 27,4 & 28,3 & $29,0-29,1$ & 2010 \\
\hline Rép. tchèque & 2,08 & 2,03 & 1,95 & 1,87 & $1,77-1,78$ & 24,5 & 24,5 & 24,9 & 25,7 & $27,7-27,9$ & 2010 \\
\hline Roumanie & 2,33 & 2,16 & 1,94 & 1,63 & 1,55 & 25,0 & 24,5 & 24,2 & 25,2 & $26,2-26,3$ & 2010 \\
\hline Royaume-Uni & 2,01 & 1,97 & 1,92 & 1,88 & $1,90-1,93$ & 27,1 & 27,8 & 28,4 & 28,9 & $29,4-29,5$ & 2010 \\
\hline Slovaquie & 2,23 & 2,17 & 2,05 & 1,92 & 1,73 & 25,2 & 25,0 & 25,0 & 25,4 & 26,8 & 2010 \\
\hline Slovénie & & & 1,79 & 1,71 & $1,66-1,67$ & & & 25,9 & 27,3 & $28,9-29,0$ & 2010 \\
\hline Suède & 2,02 & 2,05 & 2,03 & 1,98 & $1,96-1,99$ & 27,9 & 28,6 & 28,9 & 29,6 & $30,6-30,7$ & 2010 \\
\hline Islande & 2,55 & 2,46 & 2,39 & 2,32 & $2,26-2,27$ & 26,6 & 27,4 & 28,0 & 28,4 & $29,3-29,4$ & 2010 \\
\hline Norvège & 2,05 & 2,09 & 2,07 & 2,05 & $2,00-2,01$ & 27,0 & 28,0 & 28,6 & 29,1 & $29,7-29,8$ & 2010 \\
\hline Suisse & 1,75 & 1,78 & 1,69 & 1,65 & $1,63-1,65$ & 28,0 & 28,7 & 29,5 & 30,2 & $30,7-30,8$ & 2010 \\
\hline \multicolumn{12}{|c|}{$\begin{array}{l}\text { (1) Cette estimation une repose sur le gel des taux de la dernière année d'observation. } \\
\text { (2) La série des taux publiés (2002-2010) ne permet pas le calcul et l'estimation des descendances finales. } \\
\text { Sources: Calculs et estimations d'après les taux de fécondité par âge révolu publiés sur le site internet d'Eurostat } \\
\text { (non disponibles depuis l'année 2012). }\end{array}$} \\
\hline
\end{tabular}


Tableau A.8. Évolution du nombre d'avortements et des indices annuels depuis 1976

\begin{tabular}{|c|c|c|c|c|c|c|}
\hline Année & $\begin{array}{c}\text { Nombre d'IVG } \\
+ \\
\text { IMG déclarées } \\
\text { dans les } \\
\text { bulletins }^{(1)}\end{array}$ & $\begin{array}{l}\text { Nombre d'IVG } \\
\text { Statistiques } \\
\text { médicales }^{(2)}\end{array}$ & $\begin{array}{c}\text { Nombre } \\
\text { d'IVG estimé } \\
\text { par l'Ined }^{(3)}\end{array}$ & $\begin{array}{c}\text { Nombre d'IVG } \\
\text { pour } \\
100 \text { naissances } \\
\text { vivantes }^{(4)}\end{array}$ & $\begin{array}{c}\text { Taux annuel } \\
\text { d'IVG pour } \\
1000 \text { femmes } \\
\text { de } \\
15 \text { à } 49 \text { ans }^{(4)}\end{array}$ & $\begin{array}{c}\text { Nombre } \\
\text { moyen d'IVG } \\
\text { par femme }^{(4)}\end{array}$ \\
\hline 1976 & \multicolumn{2}{|l|}{134173} & 246000 & \multicolumn{2}{|l|}{34,1} & 0,66 \\
\hline 1981 & \multicolumn{2}{|l|}{180695} & 245000 & \multicolumn{2}{|l|}{30,4} & 0,62 \\
\hline 1986 & \multicolumn{2}{|l|}{166797} & 221000 & \multicolumn{2}{|l|}{28,4} & 0,53 \\
\hline 1991 & \multicolumn{2}{|l|}{172152} & 206000 & \multicolumn{2}{|l|}{27,1} & 0,48 \\
\hline 1996 & 162792 & 187114 & 207000 & \multicolumn{2}{|l|}{28,2} & 0,50 \\
\hline 2001 & & 202180 & 206000 & \multicolumn{2}{|l|}{26,7} & 0,51 \\
\hline 2006 & 174561 & 215390 & & \multicolumn{2}{|l|}{27,0} & 0,53 \\
\hline 2007 & 185498 & 213382 & & 27,1 & 14,7 & 0,53 \\
\hline 2008 & 180108 & 209245 & & 26,3 & 14,5 & 0,52 \\
\hline 2009 & 171152 & 209987 & & 26,5 & 14,6 & 0,53 \\
\hline 2010 & 172505 & 213317 & & 26,4 & 14,8 & 0,53 \\
\hline 2011 & 170081 & 209291 & & 26,4 & 14,7 & 0,53 \\
\hline 2012 & 156824 & 207120 & & 26,2 & 14,5 & 0,53 \\
\hline 2013 & 149579 & 216697 & & 26,7 & 15,3 & 0,55 \\
\hline 2014 & 126464 & 211764 & & 27,1 & 15,0 & 0,55 \\
\hline 2015 & nd & 203463 & & 26,7 & 14,5 & 0,52 \\
\hline 2016 & nd & 201410 & & 27,0 & 14,3 & 0,52 \\
\hline $2017(p)$ & nd & 202919 & & 27,8 & 14,4 & 0,52 \\
\hline \multicolumn{7}{|c|}{$\begin{array}{l}\text { (p) Données provisoires. } \\
\text { nd: Non disponible. } \\
\text { (1) Statistiques des bulletins : interruptions volontaires de grossesse (IVG) et interruptions médicales (IMG). } \\
\text { (2) Statistiques administratives des actes médicaux. Les données à partir de } 2010 \text { intègrent les données de la } \\
\text { CNAM-TS, donc des IVG associées à des régimes particuliers (MSA et RSI). Source : DREES et CNAM-TS à partir } \\
\text { de } 2010 \text {. } \\
\text { (3) Estimation de l'Ined (IVG). À partir de 2002, les statistiques hospitalières sont considérées comme exhaustives. } \\
\text { Source : C. Rossier et C. Pirus (2007). } \\
\text { (4) Sur la base des estimations Ined jusqu'en 2001, sur la base des statistiques médicales depuis } 2002 . \\
\text { Champ : France métropolitaine. }\end{array}$} \\
\hline
\end{tabular}




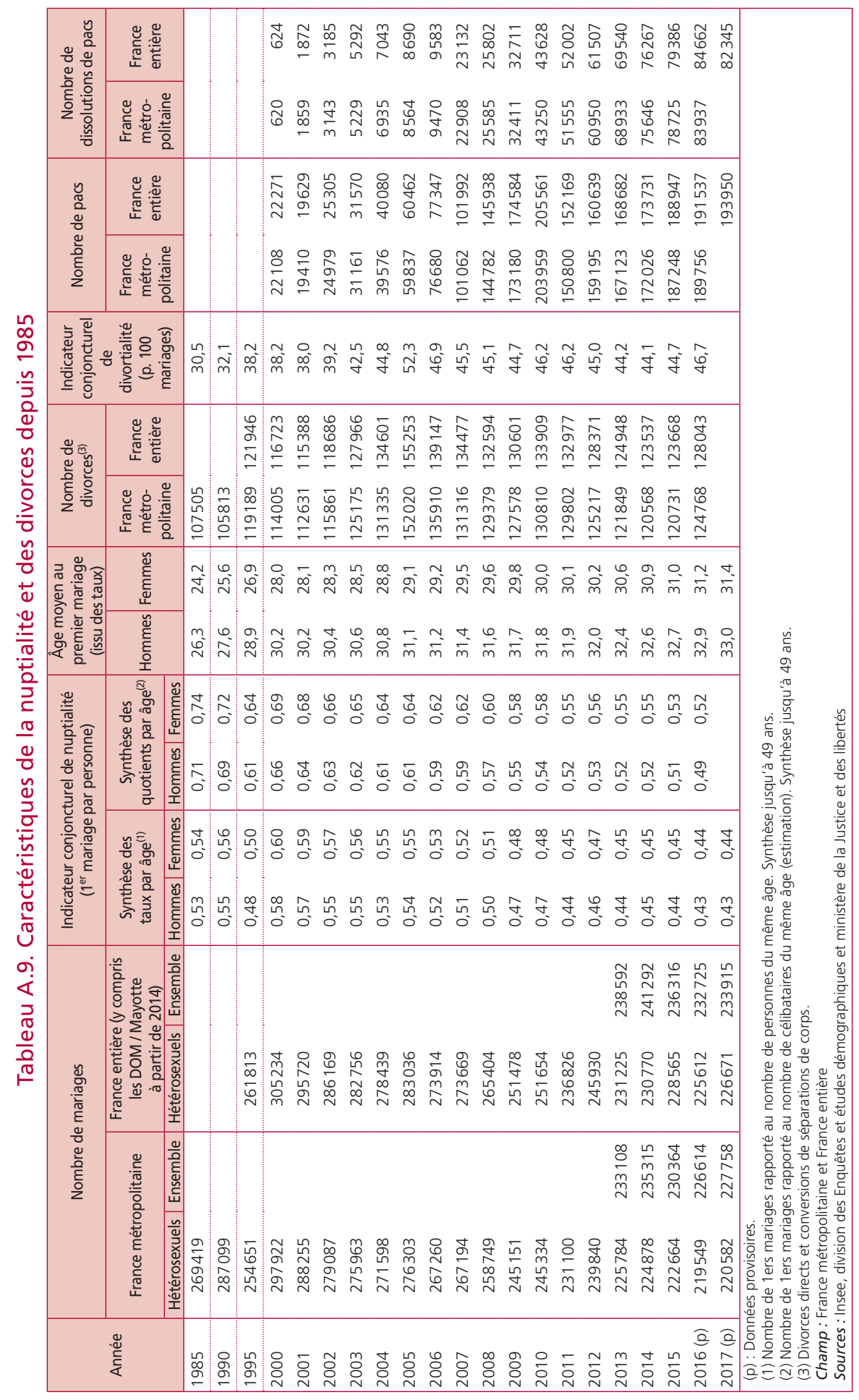


Tableau A.10. Caractéristiques de la nuptialité des générations

Hommes

\begin{tabular}{|l|c|c|c|c|}
\hline \multirow{3}{*}{ Générations } & \multirow{2}{*}{$\begin{array}{c}\text { Proportion de } \\
\text { non-célibataires } \\
\text { à 49 ans* }\end{array}$} & $\begin{array}{c}\text { Âge moyen } \\
\text { au 1 }\end{array}$ & \multicolumn{2}{|c|}{ Proportion de non-célibataires } \\
\cline { 4 - 5 } & (années) & À 25 ans & À 30 ans \\
\cline { 4 - 5 } 1955 & 0,83 & 26,40 & 0,55 & 0,72 \\
1960 & 0,77 & 27,10 & 0,39 & 0,60 \\
1965 & 0,71 & 28,90 & 0,25 & 0,48 \\
1970 & 0,66 & 30,20 & 0,15 & 0,40 \\
1975 & 0,61 & 31,00 & 0,10 & 0,35 \\
1980 & & & 0,08 & 0,28 \\
1985 & & & 0,06 & 0,23 \\
1990 & & & 0,05 & 0,20 \\
\hline
\end{tabular}

Femmes

\begin{tabular}{|c|c|c|c|c|}
\hline \multirow{2}{*}{ Génération } & \multirow{2}{*}{$\begin{array}{l}\text { Proportion de } \\
\text { non-célibataires } \\
\text { à } 49 \text { ans* }\end{array}$} & \multirow{2}{*}{$\begin{array}{l}\text { Âge moyen } \\
\text { au } 1^{\text {er }} \text { mariage* } \\
\text { (années) }\end{array}$} & \multicolumn{2}{|c|}{ Proportion de non-célibataires } \\
\hline & & & À 25 ans & À 30 ans \\
\hline 1955 & 0,88 & 22,90 & 0,71 & 0,81 \\
\hline 1960 & 0,82 & 24,20 & 0,59 & 0,72 \\
\hline 1965 & 0,76 & 26,30 & 0,43 & 0,60 \\
\hline 1970 & 0,71 & 27,80 & 0,30 & 0,52 \\
\hline 1975 & 0,66 & 28,90 & 0,23 & 0,46 \\
\hline 1980 & & & 0,18 & 0,39 \\
\hline 1985 & & & 0,14 & 0,32 \\
\hline 1990 & & & 0,10 & 0,27 \\
\hline \multicolumn{5}{|c|}{$\begin{array}{l}\text { * Les quotients de nuptialité non observés ont été prolongés en faisant la moyenne des trois année } \\
\text { précédentes. } \\
\text { Champ : France métropolitaine. } \\
\text { Source : Calculs et estimations à partir de données Insee. }\end{array}$} \\
\hline
\end{tabular}


Tableau A.11. Caractéristiques de la mortalité générale de 1946 à 2017

\begin{tabular}{|c|c|c|c|c|c|c|c|c|}
\hline \multirow{3}{*}{ Année } & \multicolumn{4}{|c|}{ Espérance de vie (en années) } & \multicolumn{2}{|c|}{$\begin{array}{l}\text { Taux de mortalité } \\
\text { (p. } 1000 \text { nés vivants) }\end{array}$} & \multicolumn{2}{|c|}{$\begin{array}{l}\text { Survivants à } 65 \text { ans } \\
\text { (p. } 1000 \text { naissances) }\end{array}$} \\
\hline & \multicolumn{2}{|c|}{ À la naissance } & \multicolumn{2}{|c|}{ À 65 ans } & \multirow{2}{*}{ Infantile ${ }^{(1)}$} & \multirow{2}{*}{$\begin{array}{l}\text { Néo- } \\
\text { natale }^{(2)}\end{array}$} & \multirow{2}{*}{ Hommes } & \multirow{2}{*}{ Femmes } \\
\hline & Hommes & Femmes & Hommes & Femmes & & & & \\
\hline 1946 & 59,9 & 65,2 & 12,2 & 14,3 & 77,8 & nd & 574 & 681 \\
\hline 1947 & 61,2 & 66,7 & 12,3 & 14,5 & 71,1 & nd & 589 & 703 \\
\hline 1948 & 62,7 & 68,8 & 12,5 & 15,0 & 55,9 & nd & 599 & 727 \\
\hline 1949 & 62,2 & 67,6 & 11,8 & 14,0 & 60,3 & nd & 595 & 716 \\
\hline 1950 & 63,4 & 69,2 & 12,2 & 14,6 & 52,0 & 26,0 & 609 & 736 \\
\hline 1951 & 63,1 & 68,9 & 11,8 & 14,2 & 50,8 & 24,0 & 602 & 732 \\
\hline 1952 & 64,4 & 70,2 & 12,3 & 14,8 & 45,2 & 22,4 & 623 & 752 \\
\hline 1953 & 64,3 & 70,3 & 11,8 & 14,4 & 41,9 & 22,0 & 617 & 753 \\
\hline 1954 & 65,0 & 71,2 & 12,4 & 15,1 & 40,7 & 21,6 & 629 & 765 \\
\hline 1955 & 65,2 & 71,5 & 12,3 & 15,1 & 38,6 & 20,8 & 631 & 772 \\
\hline 1956 & 65,2 & 71,7 & 12,1 & 14,9 & 36,2 & 20,5 & 626 & 776 \\
\hline 1957 & 65,5 & 72,2 & 12,2 & 15,2 & 33,8 & 19,5 & 631 & 783 \\
\hline 1958 & 66,8 & 73,2 & 12,8 & 15,6 & 31,4 & 18,9 & 660 & 801 \\
\hline 1959 & 66,8 & 73,4 & 12,8 & 15,7 & 29,6 & 18,1 & 657 & 801 \\
\hline 1960 & 67,0 & 73,6 & 12,6 & 15,6 & 27,4 & 17,6 & 658 & 806 \\
\hline 1961 & 67,5 & 74,4 & 13,0 & 16,1 & 25,7 & 16,7 & 664 & 815 \\
\hline 1962 & 67,0 & 73,9 & 12,6 & 15,7 & 25,7 & 16,7 & 656 & 811 \\
\hline 1963 & 66,8 & 73,9 & 12,4 & 15,6 & 25,6 & 16,6 & 652 & 810 \\
\hline 1964 & 67,7 & 74,8 & 12,9 & 16,4 & 23,4 & 15,9 & 667 & 820 \\
\hline 1965 & 67,5 & 74,7 & 12,6 & 16,2 & 21,9 & 15,2 & 661 & 820 \\
\hline 1966 & 67,8 & 75,2 & 12,9 & 16,5 & 21,7 & 14,9 & 669 & 824 \\
\hline 1967 & 67,8 & 75,2 & 12,8 & 16,5 & 20,7 & 14,5 & 668 & 826 \\
\hline 1968 & 67,8 & 75,2 & 12,7 & 16,4 & 20,4 & 14,2 & 669 & 827 \\
\hline 1969 & 67,4 & 75,1 & 12,5 & 16,3 & 19,6 & 13,7 & 661 & 824 \\
\hline 1970 & 68,4 & 75,9 & 13,0 & 16,8 & 18,2 & 12,6 & 682 & 834 \\
\hline 1971 & 68,3 & 75,9 & 13,0 & 16,8 & 17,2 & 12,0 & 680 & 836 \\
\hline 1972 & 68,5 & 76,2 & 13,1 & 17,0 & 16,0 & 11,2 & 683 & 838 \\
\hline 1973 & 68,7 & 76,3 & 13,1 & 17,0 & 15,4 & 10,6 & 688 & 842 \\
\hline 1974 & 68,9 & 76,7 & 13,3 & 17,2 & 14,6 & 9,9 & 690 & 847 \\
\hline 1975 & 69,0 & 76,9 & 13,2 & 17,2 & 13,8 & 9,2 & 691 & 849 \\
\hline 1976 & 69,2 & 77,2 & 13,3 & 17,4 & 12,5 & 8,1 & 693 & 853 \\
\hline 1977 & 69,7 & 77,8 & 13,7 & 17,9 & 11,4 & 7,4 & 702 & 860 \\
\hline 1978 & 69,8 & 78,0 & 13,7 & 17,9 & 10,7 & 6,7 & 704 & 861 \\
\hline 1979 & 70,1 & 78,3 & 13,9 & 18,1 & 10,0 & 6,0 & 707 & 864 \\
\hline 1980 & 70,2 & 78,4 & 14,0 & 18,2 & 10,0 & 5,8 & 710 & 866 \\
\hline 1981 & 70,4 & 78,5 & 14,0 & 18,2 & 9,7 & 5,5 & 714 & 869 \\
\hline 1982 & 70,7 & 78,9 & 14,3 & 18,5 & 9,5 & 5,3 & 718 & 872 \\
\hline 1983 & 70,7 & 78,8 & 14,2 & 18,4 & 9,1 & 5,0 & 719 & 872 \\
\hline 1984 & 71,2 & 79,3 & 14,5 & 18,8 & 8,3 & 4,7 & 724 & 878 \\
\hline 1985 & 71,3 & 79,4 & 14,5 & 18,8 & 8,3 & 4,6 & 727 & 880 \\
\hline
\end{tabular}


Tableau A.11 (suite). Caractéristiques de la mortalité générale de 1946 à 2017

\begin{tabular}{|c|c|c|c|c|c|c|c|c|}
\hline \multirow{3}{*}{ Année } & \multicolumn{4}{|c|}{ Espérance de vie (en années) } & \multicolumn{2}{|c|}{$\begin{array}{l}\text { Taux de mortalité } \\
\text { (p. } 1000 \text { nés vivants) }\end{array}$} & \multicolumn{2}{|c|}{$\begin{array}{l}\text { Survivants à } 65 \text { ans } \\
\text { (p. } 1000 \text { naissances) }\end{array}$} \\
\hline & \multicolumn{2}{|c|}{ À la naissance } & \multicolumn{2}{|c|}{ À 65 ans } & \multirow{2}{*}{ Infantile ${ }^{(1)}$} & \multirow{2}{*}{$\begin{array}{l}\text { Néo- } \\
\text { natale }\end{array}$} & \multirow{2}{*}{ Hommes } & \multirow{2}{*}{ Femmes } \\
\hline & Hommes & Femmes & Hommes & Femmes & & & & \\
\hline 1986 & 71,5 & 79,7 & 14,7 & 19,0 & 8,0 & 4,3 & 731 & 882 \\
\hline 1987 & 72,0 & 80,3 & 15,0 & 19,4 & 7,8 & 4,1 & 740 & 886 \\
\hline 1988 & 72,3 & 80,5 & 15,3 & 19,6 & 7,8 & 4,1 & 744 & 888 \\
\hline 1989 & 72,5 & 80,6 & 15,4 & 19,7 & 7,5 & 3,8 & 746 & 889 \\
\hline 1990 & 72,7 & 81,0 & 15,6 & 19,9 & 7,3 & 3,6 & 752 & 893 \\
\hline 1991 & 72,9 & 81,2 & 15,7 & 20,1 & 7,3 & 3,5 & 754 & 894 \\
\hline 1992 & 73,2 & 81,5 & 15,9 & 20,4 & 6,8 & 3,3 & 758 & 896 \\
\hline 1993 & 73,3 & 81,5 & 15,9 & 20,4 & 6,5 & 3,1 & 760 & 895 \\
\hline 1994 & 73,7 & 81,9 & 16,2 & 20,7 & 5,9 & 3,2 & 766 & 898 \\
\hline 1995 & 73,9 & 81,9 & 16,1 & 20,6 & 4,9 & 2,9 & 771 & 900 \\
\hline 1996 & 74,1 & 82,1 & 16,1 & 20,7 & 4,8 & 3,0 & 776 & 901 \\
\hline 1997 & 74,6 & 82,3 & 16,3 & 20,9 & 4,7 & 3,0 & 784 & 904 \\
\hline 1998 & 74,8 & 82,4 & 16,4 & 20,9 & 4,6 & 2,9 & 789 & 905 \\
\hline 1999 & 75,0 & 82,5 & 16,5 & 21,0 & 4,3 & 2,7 & 793 & 906 \\
\hline 2000 & 75,3 & 82,8 & 16,7 & 21,2 & 4,4 & 2,8 & 797 & 908 \\
\hline 2001 & 75,5 & 82,9 & 16,9 & 21,4 & 4,5 & 2,9 & 799 & 908 \\
\hline 2002 & 75,8 & 83,1 & 17,1 & 21,4 & 4,1 & 2,7 & 802 & 909 \\
\hline 2003 & 75,9 & 83,0 & 17,1 & 21,3 & 4,0 & 2,6 & 804 & 910 \\
\hline 2004 & 76,7 & 83,9 & 17,7 & 22,2 & 3,9 & 2,6 & 815 & 913 \\
\hline 2005 & 76,8 & 83,9 & 17,7 & 22,0 & 3,6 & 2,3 & 816 & 914 \\
\hline 2006 & 77,2 & 84,2 & 18,0 & 22,4 & 3,6 & 2,3 & 820 & 915 \\
\hline 2007 & 77,4 & 84,4 & 18,2 & 22,5 & 3,6 & 2,4 & 823 & 917 \\
\hline 2008 & 77,6 & 84,4 & 18,3 & 22,5 & 3,6 & 2,4 & 825 & 917 \\
\hline 2009 & 77,8 & 84,5 & 18,4 & 22,6 & 3,7 & 2,4 & 826 & 917 \\
\hline 2010 & 78,0 & 84,7 & 18,6 & 22,7 & 3,5 & 2,3 & 829 & 918 \\
\hline 2011 & 78,4 & 85,0 & 18,9 & 23,0 & 3,3 & 2,2 & 834 & 920 \\
\hline 2012 & 78,5 & 84,8 & 18,8 & 22,8 & 3,3 & 2,3 & 836 & 921 \\
\hline 2013 & 78,8 & 85,0 & 19,0 & 23,0 & 3,5 & 2,4 & 840 & 922 \\
\hline 2014 & 79,3 & 85,4 & 19,4 & 23,3 & 3,3 & 2,3 & 846 & 923 \\
\hline $2015(p)$ & 79,0 & 85,1 & 19,1 & 23,0 & 3,5 & 2,5 & 844 & 923 \\
\hline $2016(p)$ & 79,3 & 85,3 & 19,3 & 23,2 & 3,5 & 2,5 & 847 & 924 \\
\hline $2017(p)$ & 79,4 & 85,3 & 19,4 & 23,2 & 3,6 & nd & nd & nd \\
\hline \multicolumn{9}{|c|}{$\begin{array}{l}\text { (p) Données provisoires fin } 2017 . \\
\text { nd: Non disponible. } \\
\text { (1) Décès avant un an pour } 1000 \text { enfants nés vivants. } \\
\text { (2) Décès avant } 28 \text { jours pour } 1000 \text { enfants nés vivants. } \\
\text { Champ : France métropolitaine. } \\
\text { Source : Insee, division Enquêtes et études démographiqu }\end{array}$} \\
\hline
\end{tabular}


Tableau A.12. Espérance de vie à la naissance en Europe en 2016

\begin{tabular}{|l|c|c|c|}
\hline \multirow{2}{*}{\multicolumn{1}{|c|}{ Pays }} & \multicolumn{3}{|c|}{ Espérance de vie à la naissance (années) } \\
\cline { 2 - 4 } & Hommes & Femmes & Écart (F-H) \\
\hline Allemagne & 78,6 & 83,5 & 4,9 \\
Autriche & 79,3 & 84,1 & 4,8 \\
Belgique & 79,0 & 84,0 & 5,0 \\
Bulgarie & 71,3 & 78,5 & 7,2 \\
Croatie & 75,0 & 81,3 & 6,3 \\
Danemark & 79,0 & 82,8 & 3,8 \\
Espagne & 80,5 & 86,3 & 5,8 \\
Estonie & 73,3 & 82,2 & 8,9 \\
Finlande & 78,6 & 84,4 & 5,8 \\
France entière & 79,3 & 85,3 & 6,0 \\
(y compris Mayotte) & 78,9 & 84,0 & 5,1 \\
Grèce & 72,6 & 79,7 & 7,1 \\
Hongrie & 79,9 & 83,6 & 3,7 \\
Irlande & 80,4 & 84,1 & 3,7 \\
Islande & 81,0 & 85,6 & 4,6 \\
Italie & 69,8 & 79,6 & 9,8 \\
Lettonie & 69,5 & 80,1 & 10,6 \\
Lituanie & 80,1 & 85,4 & 5,3 \\
Luxembourg & 80,7 & 84,2 & 3,5 \\
Norvège & 80,0 & 83,2 & 3,2 \\
Pays-Bas & 73,9 & 82,0 & 8,1 \\
Pologne & 78,1 & 84,3 & 6,2 \\
Portugal & 76,1 & 82,1 & 6,0 \\
République tchèque & 71,7 & 79,1 & 7,4 \\
Roumanie & 79,4 & 83,0 & 3,6 \\
Royaume-Uni (p) & 73,8 & 80,7 & 6,9 \\
Slovaquie & 78,2 & 84,3 & 6,1 \\
Slovénie & 80,6 & 84,1 & 3,5 \\
Suède & 81,7 & 85,6 & 3,9 \\
Suisse & & & \\
\hline (p) Données provisoires pour & 2016. & \\
Source: Eurostat (http://epp.eurostat.ec.europa.eu/portal/page/portal/statistics/ \\
search_database, consulteee le 27 juin 2018), sauf France (Insee). \\
\hline
\end{tabular}


Tableau A.13. Mortalité infantile en Europe, 1980-2016 (taux p. 1000 nés vivants)

\begin{tabular}{|c|c|c|c|c|c|c|c|c|c|c|c|c|c|}
\hline Pays & 1980 & 1985 & 1990 & 1995 & 2000 & 2005 & 2010 & 2011 & 2012 & 2013 & 2014 & 2015 & 2016 \\
\hline Allemagne & 12,4 & 9,1 & 7,0 & 5,3 & 4,4 & 3,9 & 3,4 & 3,6 & 3,3 & 3,3 & 3,2 & 3,3 & 3,4 \\
\hline Autriche & 14,3 & 11,2 & 7,8 & 5,4 & 4,8 & 4,2 & 3,9 & 3,6 & 3,2 & 3,1 & 3,0 & 3,1 & 3,1 \\
\hline Belgique & 12,1 & 9,8 & 8,0 & 6,0 & 4,8 & 3,7 & 3,6 & 3,3 & 3,8 & 3,5 & 3,4 & 3,3 & 3,2 \\
\hline Bulgarie & 20,2 & 15,4 & 14,8 & 13,3 & 13,3 & 10,4 & 9,4 & 8,5 & 7,8 & 7,3 & 7,6 & 6,6 & 6,5 \\
\hline Croatie & nd & nd & nd & nd & 7,4 & 5,7 & 4,4 & 4,7 & 3,6 & 4,1 & 5,0 & 4,1 & 4,3 \\
\hline Danemark & 8,4 & 7,9 & 7,5 & 5,1 & 5,3 & 4,4 & 3,4 & 3,5 & 3,4 & 3,5 & 4,0 & 3,7 & 3,1 \\
\hline Espagne & 12,3 & 8,9 & 7,6 & 5,5 & 4,4 & 3,8 & 3,2 & 3,1 & 3,1 & 2,7 & 2,8 & 2,7 & 2,7 \\
\hline Estonie & 17,1 & 14,1 & 12,3 & 14,9 & 8,4 & 5,4 & 3,3 & 2,5 & 3,6 & 2,1 & 2,7 & 2,5 & 2,3 \\
\hline Finlande & 7,6 & 6,3 & 5,6 & 3,9 & 3,8 & 3,0 & 2,3 & 2,4 & 2,4 & 1,8 & 2,2 & 1,7 & 1,9 \\
\hline $\begin{array}{l}\text { France } \\
\text { entière }{ }^{(1)^{*}}\end{array}$ & nd & nd & nd & 5,0 & 4,5 & 3,8 & 3,6 & 3,5 & 3,5 & 3,6 & 3,6 & 3,7 & 3,7 \\
\hline $\begin{array}{l}\text { France } \\
\text { métropolitaine }{ }^{(1)^{*}}\end{array}$ & 10,0 & 8,3 & 7,3 & 4,9 & 4,4 & 3,6 & 3,5 & 3,3 & 3,3 & 3,5 & 3,3 & 3,5 & 3,5 \\
\hline Grèce & 17,9 & 14,1 & 9,7 & 8,1 & 5,9 & 3,8 & 3,8 & 3,4 & 2,9 & 3,7 & 3,7 & 4,0 & 4,2 \\
\hline Hongrie & 23,2 & 20,4 & 14,8 & 10,7 & 9,2 & 6,2 & 5,3 & 4,9 & 4,9 & 5,0 & 4,5 & 4,2 & 3,9 \\
\hline Irlande & 11,1 & 8,8 & 8,2 & 6,4 & 6,2 & 4,0 & 3,8 & 3,5 & 3,5 & 3,5 & 3,3 & 3,4 & 3,0 \\
\hline Islande & 7,7 & 5,7 & 5,9 & 6,1 & 3,0 & 2,3 & 2,2 & 0,9 & 1,1 & 1,8 & 2,1 & 2,2 & 0,7 \\
\hline Italie & 14,6 & 10,5 & 8,2 & 6,2 & 4,5 & 3,8 & 3,2 & 3,2 & 2,9 & 2,9 & 2,8 & 2,9 & 2,8 \\
\hline Lettonie & 15,3 & 13,0 & 13,7 & 18,8 & 10,4 & 7,8 & 5,7 & 6,6 & 6,3 & 4,4 & 3,8 & 4,1 & 3,7 \\
\hline Lituanie & 14,5 & 14,2 & 10,2 & 12,5 & 8,6 & 6,8 & 4,3 & 4,2 & 3,9 & 3,7 & 3,9 & 4,2 & 4,5 \\
\hline Luxembourg & 11,5 & 9,0 & 7,3 & 5,5 & 5,1 & 2,6 & 3,4 & 4,3 & 2,5 & 3,9 & 2,8 & 2,8 & 3,8 \\
\hline Norvège & 8,1 & 8,5 & 6,9 & 4,0 & 3,8 & 3,1 & 2,8 & 2,4 & 2,5 & 2,4 & 2,4 & 2,3 & 2,2 \\
\hline Pays-Bas & 8,6 & 8,0 & 7,1 & 5,5 & 5,1 & 4,9 & 3,8 & 3,6 & 3,7 & 3,8 & 3,6 & 3,3 & 3,5 \\
\hline Pologne & 25,4 & 22,1 & 19,4 & 13,6 & 8,1 & 6,4 & 5,0 & 4,7 & 4,6 & 4,6 & 4,2 & 4,0 & 4,0 \\
\hline Portugal & 24,2 & 17,8 & 11,0 & 7,5 & 5,5 & 3,5 & 2,5 & 3,1 & 3,4 & 2,9 & 2,9 & 2,9 & 3,2 \\
\hline $\begin{array}{l}\text { République } \\
\text { tchèque }\end{array}$ & 16,9 & 12,5 & 10,8 & 7,7 & 4,1 & 3,4 & 2,7 & 2,7 & 2,6 & 2,5 & 2,4 & 2,5 & 2,8 \\
\hline Roumanie & 29,3 & 25,6 & 26,9 & 21,2 & 18,6 & 15,0 & 9,8 & 9,4 & 9,0 & 9,2 & 8,4 & 7,6 & 7,0 \\
\hline Royaume-Uni & 13,9 & 11,1 & 7,9 & 6,2 & 5,6 & 5,1 & 4,2 & 4,2 & 4,0 & 3,9 & 3,9 & 3,9 & 3,8 \\
\hline Slovaquie & 20,9 & 16,3 & 12,0 & 11,0 & 8,6 & 7,2 & 5,7 & 4,9 & 5,8 & 5,5 & 5,8 & 5,1 & 5,4 \\
\hline Slovénie & 15,3 & 13,0 & 8,4 & 5,5 & 4,9 & 4,1 & 2,5 & 2,9 & 1,6 & 2,9 & 1,8 & 1,6 & 2,0 \\
\hline Suède & 6,9 & 6,8 & 6,0 & 4,1 & 3,4 & 2,4 & 2,5 & 2,1 & 2,6 & 2,7 & 2,2 & 2,5 & 2,5 \\
\hline Suisse & 9,0 & 6,7 & 6,7 & 5,0 & 5,3 & 4,2 & 3,8 & 3,8 & 3,6 & 3,9 & 3,9 & 3,9 & 3,6 \\
\hline \multicolumn{14}{|c|}{$\begin{array}{l}\text { Données provisoires } 2016 . \\
\text { nd: Non disponible. } \\
\text { (1) Insee pour la France entière, hors Mayotte, entre } 1995 \text { et } 2014 \text { et pour la France métropolitaine en } \\
2010 \text { et } 2015 . \\
\text { Source : Eurostat, Infant mortality rate (http://ec.europa.eu/eurostat/data/database, consulté le } 11 \text { juin } \\
\text { 2017), sauf (1). }\end{array}$} \\
\hline
\end{tabular}




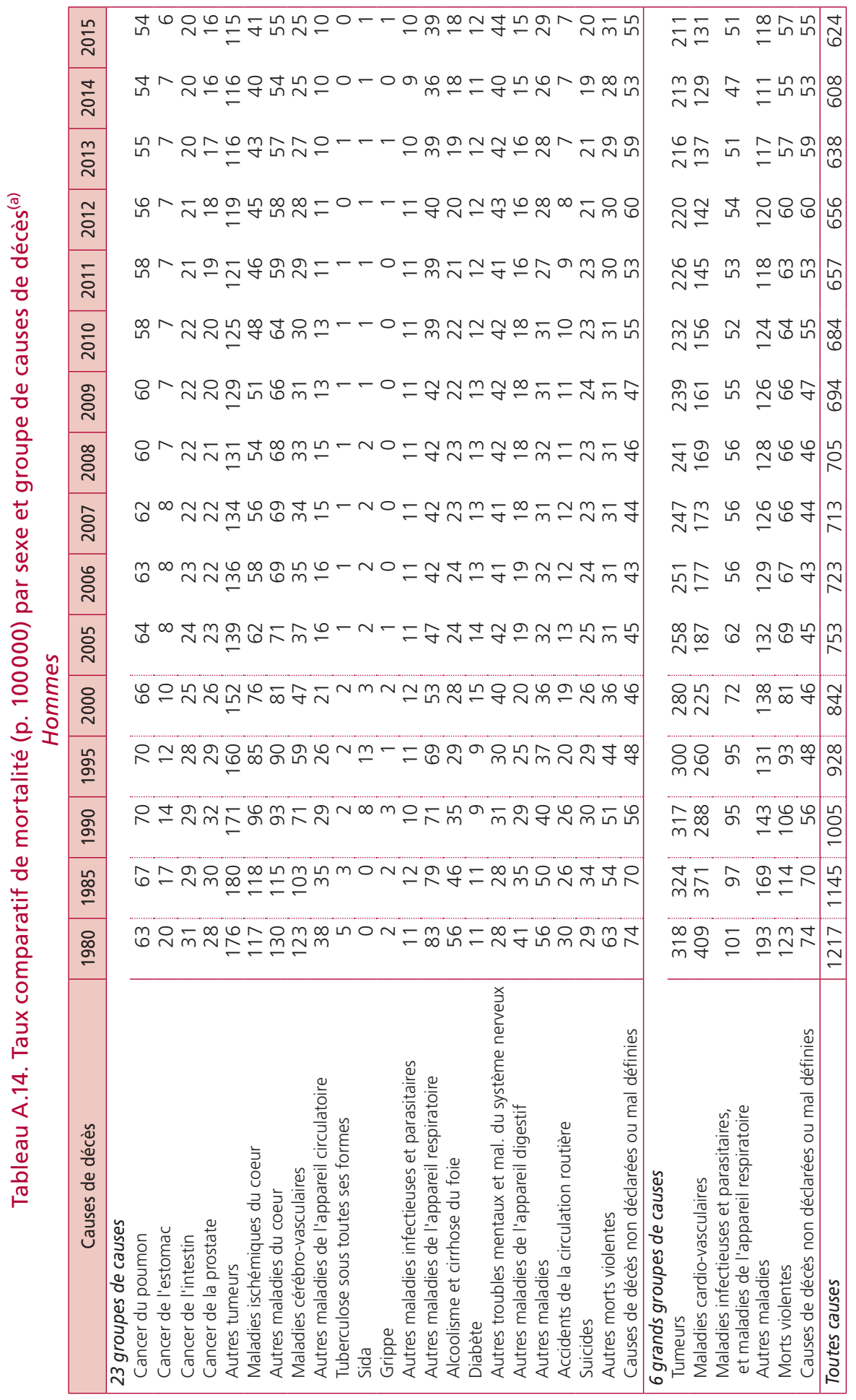




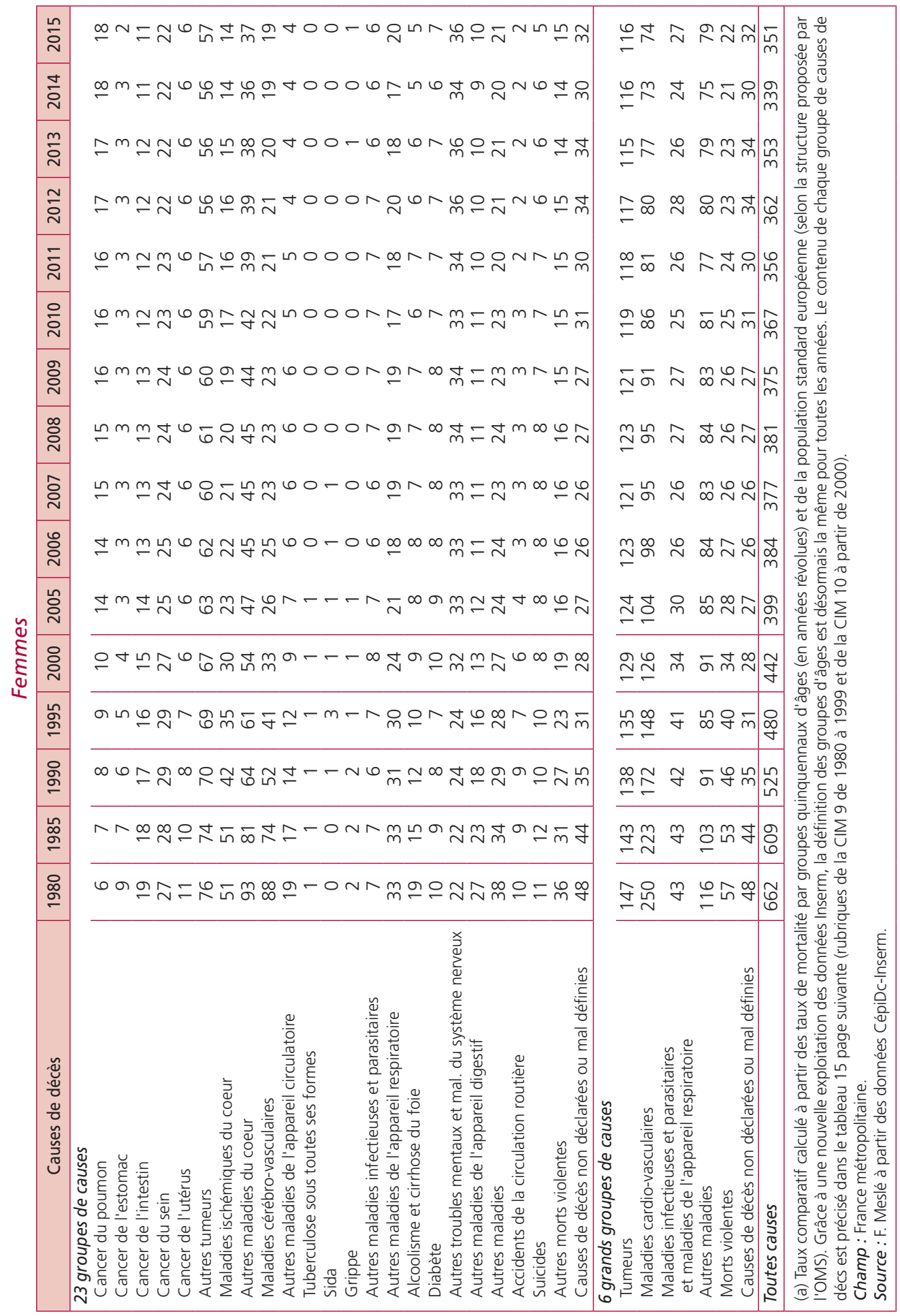




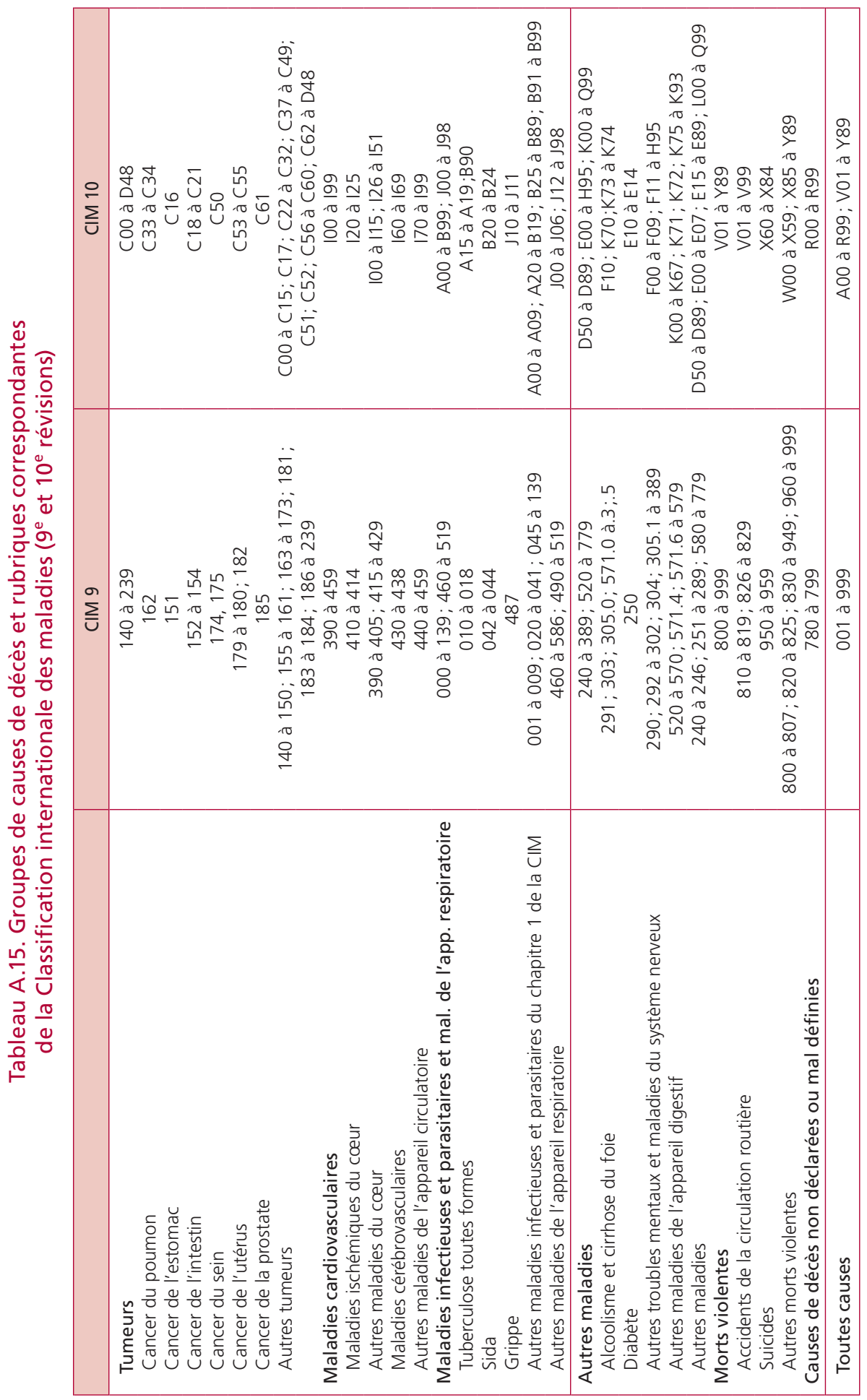




\section{RÉFÉRENCES}

AGENCE DE BIOMÉDECINE, 2018, « Rapport médical et scientifique de l'assistance médicale à la procréation et de la génétique humaines en France en 2017 » https://www.agence-biomedecine.fr/annexes/bilan2017/donnees/procreation/01-amp/ synthese.htm

Aubenque M., Damiani P., Massé H., 1979, « Variations saisonnières et séries chronologiques des causes de décès en France de 1900 à 1972 », Cahiers de sociologie et de démographie médicale, 19(1), p. 17-22.

BAILly E., RAULT W., 2013, « Les pacsés en couple hétérosexuel sont-ils différents des mariés? », Population et sociétés, n 497.

Bellamy V., BeAumel C., 2016, « Bilan démographique 2015. Le nombre de décès au plus haut depuis l'après-guerre », Insee première, $\mathrm{n}^{\circ} 1581$.

Bellamy V., BeAumel C., 2017, « Bilan démographique 2016. À nouveau en baisse, la fécondité atteint 1,93 enfant par femme en 2016 », Insee première, $\mathrm{n}^{\circ} 1630$.

BOURGEOIS-PICHAT J., 1946, « Le mariage, coutume saisonnière, contribution à une étude sociologique de la nuptialité en France », Population, 1(4), p. 623-642.

Bourgeois-Pichat J., 1950, « Où en est la natalité française », Population, 5(1), p. 15-34.

BRETON D., 2006, « Mise en couple et fécondité, aspects démographiques. À partir de l'enquête Étude de l'histoire familiale ", Informations sociales, nº132, p. 14-25.

Breton D., MAZuy M. , BARbieri M., D'Albis H., 2017, « Lévolution démographique récente de la France : de forts contrastes départementaux », Population, 72(4), p. 583-652.

BRUTEL C., 2015, « L'analyse des flux migratoires entre la France et l'étranger entre 2006 et 2013. Un accroissement des mobilités », Insee analyses, n 22.

BUISSON G., 2017, « Le recensement de la population évolue : de l'état matrimonial légal à la situation conjugale de fait ", Insee analyses, $\mathrm{n}^{\circ} 35$.

BUisson G., LAPINTE A., 2013, « Le couple dans tous ses états. Non-cohabitation, conjoints de même sexe, pacs... ", Insee première, n' 1435.

COMMISSION IVG, 2016, «IVG : état des lieux et perspectives d'évolution du système d'information », Ministère des Affaires sociales et de la santé.

CORSO M., PASCAL M., WAGNER V., 2017, « Impacts de la chaleur et du froid sur la mortalité totale en France entre 2000 et 2010 », Bulletin épidémiologique hebdomadaire, $\mathrm{n}^{\circ} 31$, p. 634-640.

COSTEMALLE V., 2017, « Formations et ruptures d'unions : quelles sont les spécificités des unions libres?» Insee, France, portrait social, p. 95-110.

DAGUET F., 2017, « Des ménages toujours plus nombreux, toujours plus petits », Insee première, $\mathrm{n}^{\circ} 1663$.

D’Albis H., BoubTAne E., 2015, « Caractérisation des flux migratoires en France à partir des statistiques de délivrance de titres de séjour (1998-2013) », Population, 70(3), p. 487-524. 
D’Albis H., BoubTANe E., 2018, « L'admission au séjour des demandeurs d'asile en France depuis $2000 »$, Population et sociétés, n552.

DUMAS-CHAMPION F., 2008, Le mariage des cultures à l'île de la Réunion, Paris, Karthala.

Fouillet A., Rey G., Jougla E., HÉmon D., 2006, « Estimation de la surmortalité observée et attendue au cours de la vague de chaleur du mois de juillet 2006 », Institut national de la santé et de la recherche médicale (Inserm), Rapport.

Grosclaude P., Remontet L., Daubisse-Marliac L., Velten M., Uhry Z. et al., 2016, « Le cancer de la prostate : incidence, survie et mortalité en France », Bulletin épidémiologique hebdomadaire, n 39-40, p. 693-699.

GROSS M., BUREAU M.-F., 2015, « L'homoparentalité et la transparentalité au prisme des sciences sociales : révolution ou pluralisation des formes de parenté? ", Enfances, familles, générations, $\mathrm{n}^{\circ} 23$, p. i-xxxvii.

Guignard R., BeCK F., Wilquin J., ANDler V., Richard J.A. et al., 2015, « La consommation de tabac en France en 2014 : caractéristiques et évolutions récentes ", Inpes, Évolutions, n 31 , p. 1-6.

Guillaume A., Rossier C., 2018, « L'avortement dans le monde. État des lieux des législations, mesures, tendances et conséquences », Population, 73(2), p. 225-322.

Hill C., LAPLANCHE A., 2005, «Évolution de la consommation de cigarettes en France par sexe, 1900-2003», Bulletin épidémiologique hebdomadaire, 22(21), p. 94-97.

Huynen M.M., Martens P., Schram D., WeijenberG M.P., Kunst A.E., 2001, " The impact of heat waves and cold spells on mortality rates in the Dutch population », Environmental Health Perspectives, 109(5), p. 463-470.

INSEE, 2019, « Rénovation du questionnaire du recensement de la population. Impact sur les évolutions annuelles de population », Note technique, janvier.

KEATINGE W.R., DONALDSON G.C., 1997, « Cold exposure and winter mortality from ishaemic heart disease cerebrovascular disease respiratory disease and all causes in warm and cold regions of Europe ", The Lancet, 349(9062), p. 1341-1346.

LA ROCHEBROCHARD (DE) E., 2018, « 1 enfant sur 30 conçu par assistance médicale à la procréation en France », Population et sociétés, n 556.

Marant-Micallef C., David Shield K., Vignat J., Hill K., Rogel A. et al., 2018, « Nombre et fractions de cancers attribuables au mode de vie et à l'environnement en France métropolitaine en 2015 : résultats principaux », Bulletin épidémiologique hebdomadaire, $\mathrm{n}^{\circ} 21$, p. 442-448.

MAZUY M., TOULEMON L., BARIL E., 2015 « Un recours moindre à l'IVG, mais plus souvent répété », Population et sociétés, n 518.

MAZuY M., BARbieri M., BReton D., D’Albis H., 2016, « L'évolution démographique récente de la France. Baisse de la fécondité, augmentation de la mortalité », Population, 71(3), p. 423-486.

Merlin P., ChoAy F., 1988, Dictionnaire de l'urbanisme et de l'aménagement, Paris, PUF.

MESLÉ F., 2010, « Recul spectaculaire de la mortalité due à la grippe : le rôle de la vaccination », Ined, Population et sociétés, $\mathrm{n}^{\circ} 470$.

MULLER M., 2017, « 728000 résidents en établissements d'hébergement pour personnes âgées en 2015. Premiers résultats de l'enquête EHPA 2015 », Études et résultats, n 1015.

PAilhÉ A., 2010, « Effet attendu de la crise économique actuelle sur les naissances : quelques hypothèses », Politiques sociales et familiales, $n^{\circ}$ 100, p. 97-103.

PAPON S., 2018, « 770000 bébés nés en France en 2017 : six sur dix sont nés hors mariage », Insee focus, $\mathrm{n}^{\circ} 124$. 
PAPON S., BEAUMEL C., 2018, « Bilan démographique 2017. Plus de 67 millions d'habitants en France au $1^{\mathrm{er}}$ janvier 2018 », Insee première, $\mathrm{n}^{\circ} 1683$.

PAPON S., BEAUMEL C., 2019, « Bilan démographique 2018. La fécondité baisse depuis quatre ans », Insee première, $\mathrm{n}^{\circ} 1730$.

Pirou D., Poullain N., Rochelle S., 2013, « La vie en communauté : 1,6 million de personnes en France », Insee première, n 1434.

RAhiB D., Lydié N. ET LE GROUPE BAROMĖTRE SANTÉ, 2016, « L'utilisation de la contraception d'urgence en France métropolitaine en 2016 : niveau et déterminants », Bulletin épidémiologique hebdomadaire, n²9, p. 590-595.

RAhib D., LE GUEN M., LydiÉ N., 2016, « Contraception. Quatre ans après la crise de la pilule, les évolutions se poursuivent ", Baromètre santé, Santé publique France.

RAU R., 2007, Seasonality in Human Mortality: A Demographic Approach, Springer Science $\&$ Business Media.

RAUlt W., RÉGNiER-LOILIER A., 2015, « La première vie en couple : évolutions récentes", Population et sociétés, n' 521.

RAult W., RÉGNiER-LOILIER A., 2016, « La saisonnalité des mariages d'hier et d'aujourd'hui », Population, 71(4), p. 719-724.

RÉGNIER-LOILIER A., 2010, «Évolution de la saisonnalité des naissances en France de 1975 à nos jours », Population, 65(1), p. 147-190.

RÉGNIER-LOILIER A., ROHRBASSER J.-M., 2011, « Y a-t-il une saison pour faire des enfants? »Population et sociétés, $\mathrm{n}^{\circ} 474$.

Rey G., Fouillet A., Jougla É., HÉMON D. 2007, « Vagues de chaleur, fluctuations ordinaires des températures et mortalité en France depuis 1971 », Population, 62(3), p. 533-564.

Rossier C., PIRUS C., 2007, «Évolution du nombre d'interruptions de grossesse en France entre 1976 et 2002 », Population, 62(1), p. 57-90.

ROZÉE GOMEZ V., LA ROCHEBROCHARD (DE) E., 2013, « Cross-border reproductive care among French patients: Experiences in Greece, Spain and Belgium », Human Reproduction, 28(11), p. 3103-3110.

TEMPORAl F., BRUTEl C., 2016, « La mesure des flux migratoires entre la France et l'étranger : et si on parlait (aussi) d'émigration? » Revue européenne des migrations internationales, 32(3-4), p. 215-229.

TOUlemon L., BARBIERI M., 2008, « The mortality impact of the August 2003 heat wave in France: Investigating the 'harvesting'effect and other long-term consequences », Population Studies, 62(1), p. 39-53.

VILAIN A., 2018, « 216700 interruptions volontaires de grossesse en 2017 », Drees, Études et résultats, n 1081. 


\section{Didier BReton, Magali BARBIERI, Hippolyte D'AlBIS, Magali MAZUY • L'ÉVOLUTION DÉMOGRAPHIQUE RÉCENTE DE LA FRANCE. NAISSANCES, DÉCÈS, UNIONS ET MIGRATIONS : À CHACUN SA SAISON}

Au premier janvier 2018, la France comptait près de 66,9 millions d'habitants, soit 122300 personnes de plus que l'année précédente, mais l'accroissement annuel moyen, et tout particulièrement l'accroissement naturel, n'ont jamais été aussi faibles depuis 20 ans, voire 40 ans. L'indice conjoncturel de fécondité poursuit sa baisse, observée notamment chez les femmes les plus jeunes. Le nombre de titres de séjour délivrés augmente en 2016 (près de 220000). La nuptialité continue de diminuer, tant pour les couples hétérosexuels que pour les couples de même sexe. En 2017, la mortalité recule de nouveau, mais le nombre de décès dépasse 600000 , chiffre lié au vieillissement de la population. Les causes de mortalité dont les évolutions sont les plus préoccupantes sont le cancer chez les femmes, les maladies par troubles mentaux et les maladies du système nerveux. Les événements démographiques ne se répartissent pas uniformément au fil de l'année : les mariages et mises en union libre sont plus souvent observés au printemps et en été, les naissances en été et à l'automne, tout comme les entrées sur le territoire; alors que l'hiver et la fin de l'année marquent une recrudescence d'enregistrements de pacs et des pics de mortalité.

Mots-clés : France, conjoncture démographique, migration, fécondité, conjugalité, mariage, pacs, union libre, divorce, couple de même sexe, vieillissement, mortalité, mortalité par cause, saisonnalité 